Der Medizinischen Fakultät der Universität Göttingen

eingereicht von apl. Prof. Dr. med. dent. Rainer F. Mausberg i. R.

\title{
Nachweis parodontalpathogener Bakterien-DNA, von Lipopolysaccharid-Binding-Protein (LBP), LBP-Rezeptor (CD14), Makrophagen (CD68) sowie von \\ Herzinsuffizienzmarkern (proBNP NT) im humanen Myokard Ergebnisse einer Pilotstudie
}

\author{
INAUGURAL-DISSERTATION \\ zur Erlangung des Doktorgrades \\ für Zahnheilkunde \\ der Medizinischen Fakultät der \\ Georg-August-Universität zu Göttingen
}

vorgelegt von

Christoph Rost

aus

Nürnberg

Göttingen 2016 
Die Dissertation entstand in der Abteilung Präventive Zahnmedizin, Parodontologie und Kariologie an der Medizinischen Fakultät der Universität Göttingen im Zeitraum von 2009 bis 2015.

Dekan:

I. Berichterstatter:

II. Berichterstatter:

III. Berichterstatterin:
Prof. Dr. rer. nat. H. K. Kroemer

Prof. Dr. med. dent. R. Mausberg

PD Dr. Bernhard Danner

Prof. Dr. Margarete Schön

Tag der mündlichen Prüfung: $\quad$ 07.12.2016 
meinen Eltern 


\section{INHALTSVERZEICHNIS}

1 EINLEITUNG ..................................................................................... 5

2 LITERATURÜBERSICHT ......................................................................... 7

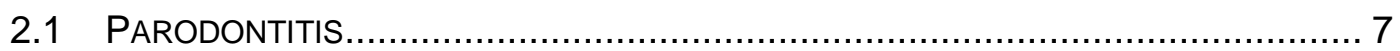

2.1.1 Definition und Klassifikation........................................................ 7

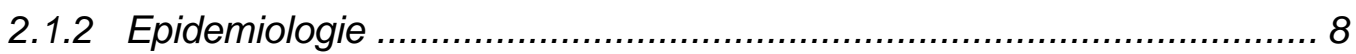

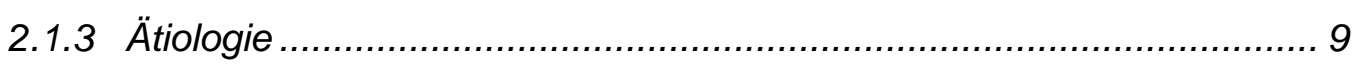

2.1.4 Pathogenese der Parodontitis ................................................. 10

2.1.4.1 Bakterien und Biofilm ........................................................ 10

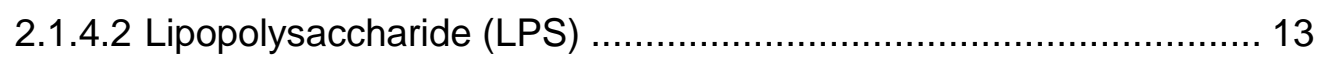

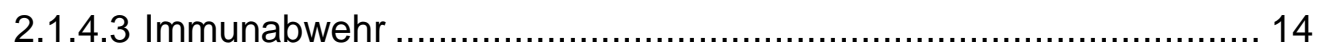

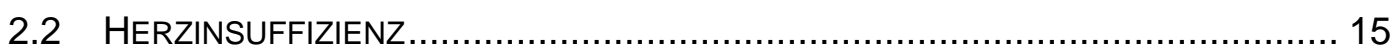

2.2.1 Definition und Klassifikation................................................. 15

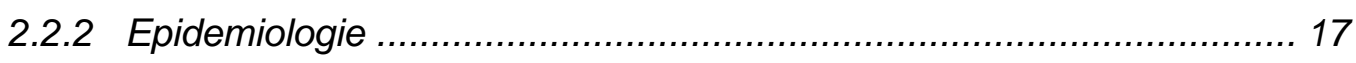

2.2.3 Pathophysiologie...................................................................... 17

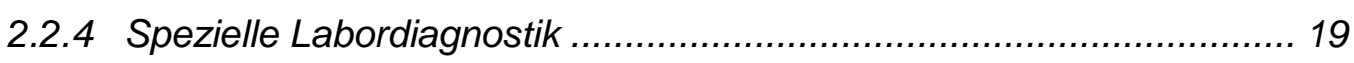

2.3 ZUSAMMENHÄNGE ZWISCHEN PARODONTITIS UND HERZERKRANKUNGEN ........ 21

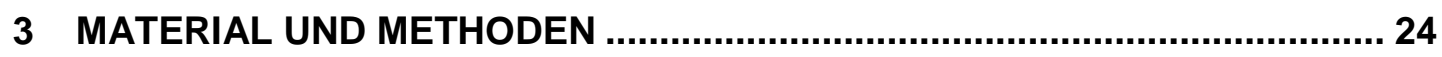

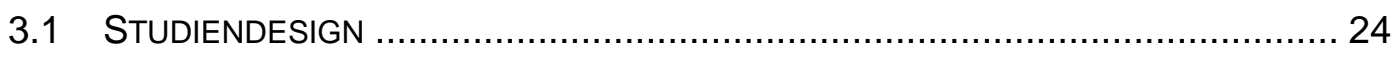

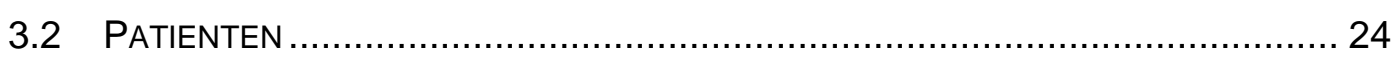

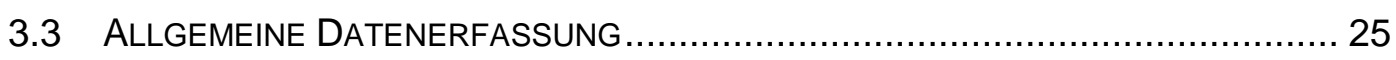

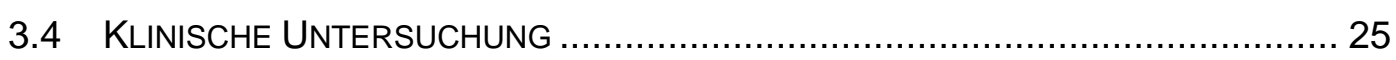

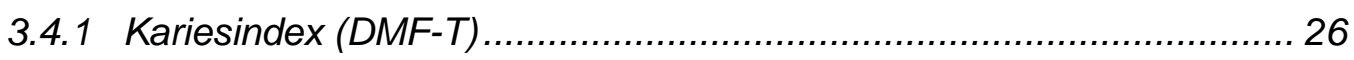

3.4.2 Parodontalstatus ................................................................ 26

3.4.3 Papillen-Blutungs-Index (PBI) ................................................ 27

3.4.4 Mikrobiologische und molekularbiologische Probenentnahme............ 27

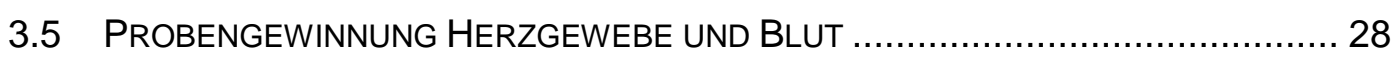

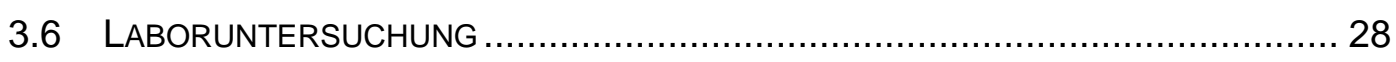

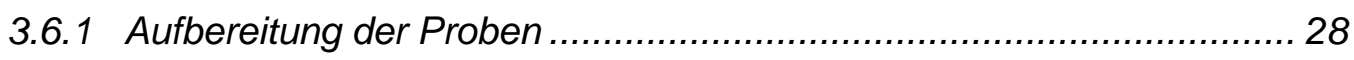

3.6.1.1 Aufbereitung der Herzgewebeproben ..................................... 28

3.6.1.2 Aufbereitung der oralen Proben ........................................... 29

3.6.1.3 Aufbereitung der Blutproben................................................. 30

3.6.2 Mikrobiologische Analyse der DNA-Proben durch Polymerase-

Kettenreaktion (PCR) ................................................................... 31

3.6.2.1 Markerkeimanalytik .............................................................. 31

3.6.2.2 Genetische Untersuchung des IL-1-Polymorphismus ................... 34

3.6.3 Proteinchemische Laboranalyse ................................................ 35

3.6.3.1 Western Blot - Nachweis von LBP und proBNP NT ................... 35 
3.6.3.2 Enzyme-linked immunosorbent assay ELISA ............................ 38

3.6.3.3 Histologie und Immunhistochemie....................................... 38

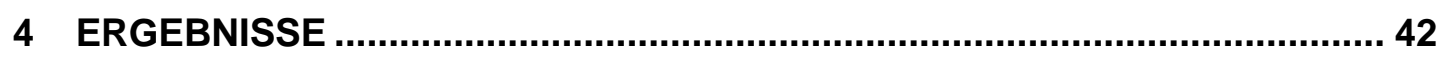

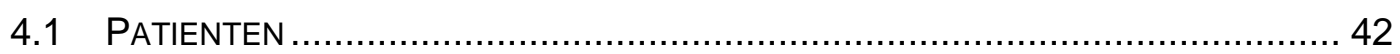

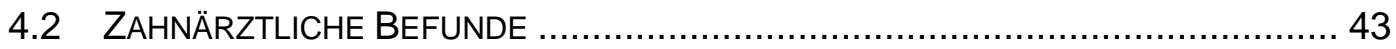

4.3 ERGEBNISSE DER MIKROBIOLOGISCHEN ANALYSE DER DNA-PROBEN ........... 44

4.3.1 Markerkeimanalytik ........................................................... 44

4.3.2 Genetische Untersuchung des IL-1-Polymorphismus..................... 47

4.4 ERGEBNISSE DER PROTEINCHEMISCHEN LABORANALYSE .......................... 48

4.4.1 Western Blot am Herzgewebe ................................................ 48

4.4.2 ELISA des Blutserums .............................................................. 51

4.4.3 Histologie und Immunhistochemie am Herzgewebe ......................... 52

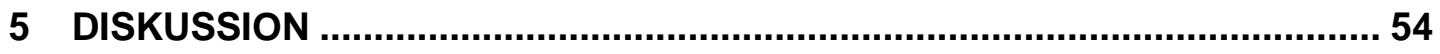

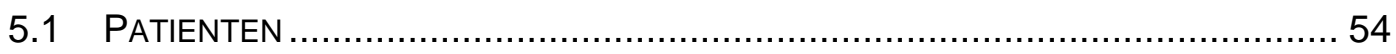

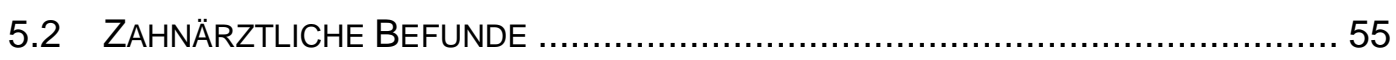

5.3 MIKROBIOLOGISCHE UNTERSUCHUNG ................................................. 56

5.3.1 Mikrobiologische Untersuchung des Mundes ................................. 56

5.3.2 Mikrobiologische Untersuchung des Herzgewebes ......................... 56

5.3.3 Vergleich der oralen und kardialen mikrobiellen Nachweise ............... 57

5.3.4 Genetische Untersuchung .................................................. 58

5.4 PROTEINNACHWEIS................................................................. 59

5.4.1 Proteinnachweis am Herzgewebe (Western Blot, Immunhistochemie und Histochemie) ........................................................................... 59

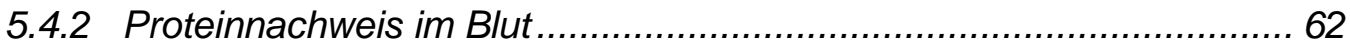

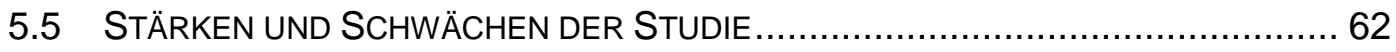

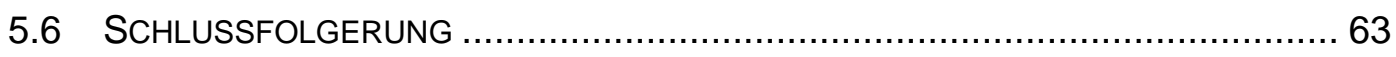

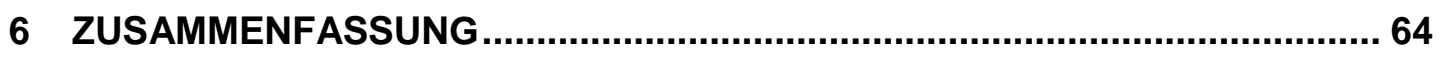

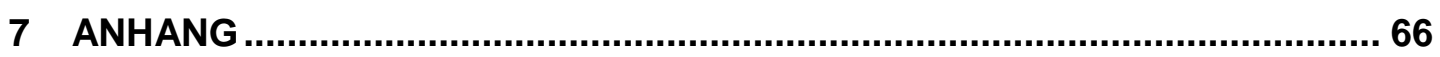

7.1 FORMULARE

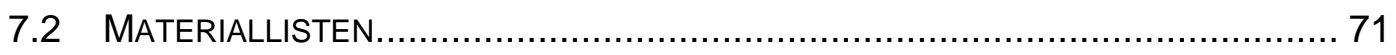

7.2.1 Molekularbiologische Untersuchung.......................................... 71

7.2.2 Proteinchemische Untersuchung............................................. 72

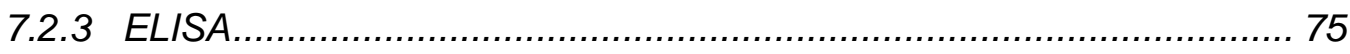

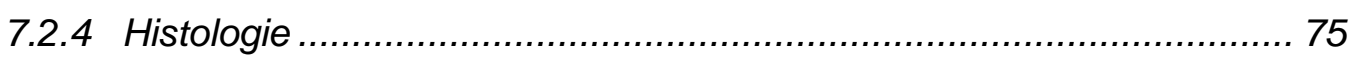

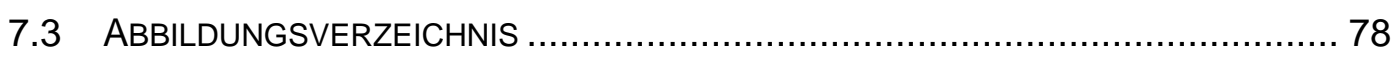

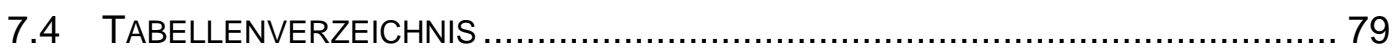

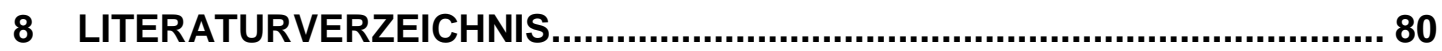




\section{Einleitung}

Parodontitis gilt als Risikofaktor für verschiedene Allgemeinerkrankungen (Slavkin und Baum 2000). Besonders trifft dies für multifaktoriell bedingte Krankheiten zu wie Atherosklerose, Apoplex, chronisch rezidivierende Bronchitis, Endokarditis, Diabetes mellitus und Pneumonie (Nishimura et al. 2007; Mealey 1999; Seymour et al. 2007; Southerland et al. 2006). Auch koronare Herzerkrankung und selbst Komplikationen in der Schwangerschaft werden mit Parodontitis assoziiert (Manau et al. 2008; Scannapieco 1998).

Parodontopathogene Bakterien nutzen die ausgeprägte Gefäßversorgung des Zahnhalteapparates als Eintrittspforte in den Organismus und verteilen sich über die Blutbahn im Organismus (Bakteriämie). Erste wissenschaftliche Nachweise für Bakteriämien, die von der Mundhöhle ausgingen, wurden ab Mitte der 30er Jahre erbracht. Dabei konnte bei zahnärztlichen Behandlungen (Okell und Elliott 1935) und selbst schon beim Zähneputzen (Cobe 1954; Rise et al. 1969; Sconyers et al. 1973; Madsen 1974) eine Bakterienverschleppung aufgezeigt werden. In der Folgezeit wurde das Augenmerk verstärkt auf die Parodontitis gelegt. So belegen Studien, dass der Schweregrad der Zahnfleischentzündung die Höhe der Bakterienlast im Blut beeinflusst (Silver et al. 1977) und eine Erhöhung von Entzündungsmediatoren wie Leukozyten, CRP, IL1 und IL6 zur Folge hat (D'Aiuto et al. 2005; Loos 2005; Tonetti et al. 2007).

Wichtiger Faktor für die schädigende Wirkung parodontopathogener Bakterien sind deren Virulenzfaktoren (Endotoxine, Exotoxine, Leukotoxine). Insbesondere gramnegative Bakterien wie Porphyromonas gingivalis $(\mathrm{Pg})$ besitzen Endotoxine, welche in der Lage sind, das Parodont anzugreifen und zu zerstören (Dahlén 1992; Schenkein 1999). Wie Kebschull et al. (2010) in einem Review beschreiben, scheint diese destruktive Wirkung analog auch an Herzkranzgefäßen möglich. Dabei steht das Endotoxin Lipopolysaccharid (LPS) im Verdacht, eine Kaskade von Reaktionen auszulösen: Der Kontakt dieses Lipoproteins mit dem CD14- und Toll-likeRezeptoren auf Monozyten oder Makrophagen führt zu einer raschen Ausschüttung von Tumor-Nekrose-Faktor-(TNF) $\alpha$, Interleukin-(IL)1, Interferon- $\gamma$, IL-6 und IL-8. Dies wiederum kann atherosklerotische Veränderungen hervorrufen (Kebschull et al. 2010).

In klinischen Studien korrelierte die Intima-Media-Dicke, die der Erfassung von atherosklerotischen Gefäßveränderungen dient, signifikant mit dem Schweregrad der Parodontitis und dem Vorliegen parodontalpathogener Bakterien (Beck et al. 2001; Desvarieux et al. 2005). Gleiches gilt für die endotheliale Dysfunktion (Amar et al. 2003). Zudem konnte die DNA von parodontalpathogenen Bakterien in athero- 
sklerotischen Plaques labortechnisch nachgewiesen und in Bezug zur klinischen parodontalen Situation gesetzt werden (Haraszthy et al. 2000; Aimetti et al. 2007); auch an Herzklappen waren mikrobiologische Befunde mit parodontalpathogenen Bakterien festzustellen (Nakano et al. 2009). In-vitro-Studien belegen, dass neben verschiedenen pathogenen Mechanismen ein prothrombotischer Effekt von parodontopathogenen Bakterien $(P g)$ möglich ist (Roth et al. 2009). Studien von Lee et al. (2005, 2006) zeigen, dass speziell Pg für die Hypertrophie des Myocards verantwortlich gemacht werden kann. Als Ursachen werden Virulenzfaktoren oder metabolische Nebenprodukte vermutet (Lee et al. 2005; Lee 2006a; Lee 2006b; Wu et al. 2008)

Diese und weitere Untersuchungen untermauern Vermutungen über eine Assoziation von Parodontitis und Endokarditis sowie koronarer Herzerkrankung (KHK) (DeStefano et al. 1993; Joshipura et al. 1996; Arbes et al. 1999; Pussinen et al. 2003; Tang et al. 2011).

Allerdings fehlt es an ausreichenden klinischen Untersuchungen, die direkte kausale Zusammenhänge aufzeigen. So wäre die Analyse von pathologisch verändertem Myokard im Hinblick auf parodontopathogene Bakterien sowie spezifische Entzündungsparameter (LPS, CD14) sinnvoll. Dieser Nachweis ist jedoch bisher im Rahmen einer klinischen Studie nicht erbracht worden. Entsprechend fehlt es an einem Studienmodell sowohl mit geeigneten klinischen, mikrobiologischen, proteinbiochemischen als auch immunhistochemischen Parametern zur Klärung möglicher (Kausal-) Zusammenhänge dieser beiden Erkrankungen.

Ziel dieser Pilotstudie war deshalb die Verifizierung eines Studienmodells sowohl mit klinischen, mikrobiologischen, proteinbiochemischen als auch immunhistochemischen Parametern zur Klärung möglicher klinischer Zusammenhängen zwischen Parodontitis und Herzinsuffizienz. 


\section{Literaturübersicht}

\subsection{Parodontitis}

\subsubsection{Definition und Klassifikation}

Die Parodontitis ist eine entzündungsbedingte Erkrankung des Zahnhalteapparates. Das Ausmaß und die Progression der Erkrankung hängen vom mikrobiellen Milieu und von der individuellen Wirtsantwort des Organismus ab (Kinane et al. 2005). Der Verlauf der Krankheit ist jedoch nicht immer gleich. So unterscheidet man heute acht verschiedene Formen von Parodontalerkrankungen. Die Klassifikation wurde von der American Acadamy of Periodontology 1999 veröffentlicht und 2002 in Deutschland von der Deutschen Gesellschaft für Parodontologie (DGP) eingeführt (Armitage 1999; DGP 2002):

I. Gingivale Erkrankungen

II. Chronische Parodontitis

III. Aggressive Parodontitis

IV. Parodontitis als Manifestation einer Systemerkrankung

V. Nekrotisierende Parodontalerkrankungen

VI. Abszesse des Parodonts

VII. Parodontitis im Zusammenhang mit endodontalen Läsionen

VIII. Entwicklungsbedingte oder erworbene Deformationen und Zustände

Gingivale Erkrankungen sind gekennzeichnet durch Rötung und Schwellung der Gingiva sowie eine erhöhte Blutungsneigung (DGParo 2013).

Geht die Entzündung tiefer und erreicht unter Beteiligung von Attachment- und Knochenverlust den Zahnhalteapparat, so spricht man von einer Parodontitis. Die am häufigsten vorkommende Form ist die chronische Parodontitis. Dieses Krankheitsbild tritt hauptsächlich bei Erwachsenen auf und steht in Zusammenhang mit lokalen Faktoren wie subgingivalen Konkrementen, überstehenden Füllungsrändern oder nicht optimaler Mundhygiene. Der weitere Krankheitsverlauf ist entscheidend determiniert durch die Virulenz der eindringenden Bakterien und die Wirtsantwort. Kennzeichen der chronischen Parodontitis ist ein langsam fortschreitender Verlauf mit vereinzelten Krankheitsschüben (Kinane et al. 2005; Newman et al. 2006; DGParo 2013). 
Eine Subklassifizierung der Erkrankung erfolgt in Abhängigkeit vom Ausmaß des Befalls (Lindhe et al. 1999):

- lokalisierte chronische Parodontitis $\rightarrow$ weniger als 30\% der gemessenen Flächen betroffen

- generalisierte chronische Parodontitis $\rightarrow$ mehr als 30\% der gemessenen Flächen betroffen

Eine weitere Einteilung erfolgt nach Schweregrad (Burgemeister und Schlagenhauf 2003):

- milde Parodontitis

- moderate Parodontitis

- schwere Parodontitis
1 - 2 mm klinischer Attachmentverlust

3 - 4 mm klinischer Attachmentverlust

$>5 \mathrm{~mm}$ klinischer Attachmentverlust

Die aggressive Parodontitis stellt eine Sonderform der Parodontitis dar. Im Gegensatz zur chronischen Parodontitis sind die von der aggressiven Form der Parodontitis betroffenen Patienten in der Regel klinisch gesund. Auch Konkremente oder andere lokale Faktoren sind meist nicht zu finden. Allerdings kann man eine deutliche familiäre Häufung der Erkrankung feststellen. Meist steht die Menge der mikrobiellen Besiedlung in keinem Verhältnis zur Schwere der parodontalen Gewebszerstörung. Als Leitkeim gilt der Aggregatibacter actinomycetemcomitans. Im Gegensatz zur chronischen kommt die aggressive Form meist bei jüngeren Patienten vor. Sie verläuft im pubertären Alter üblicherweise lokalisiert, später oft generalisiert (Brunner et al. 2002; Newman et al. 2006; Lindhe et al. 2008; DGParo 2013).

Es gibt Hinweise darauf, dass die systemische Entzündung bei der aggressiven Parodontitis stärker ausgeprägt ist als bei der chronischen Parodontitis (Wohlfeil et al. 2012). Dies wird auf überempfindlich reagierende Makrophagen zurückgeführt, welche Prostaglandin E2 (PGE2) und Interleukin 1B (IL-1B) in erhöhten Mengen produzieren (Lang et al. 1999).

\subsubsection{Epidemiologie}

Die Vierte Deutsche Gesundheitsstudie von 2006 zeigte, dass 52,7\% der Erwachsenen (35-44 Jahre) in Deutschland unter einer mittelschweren und 20,5\% unter einer schweren Form der Parodontitis leiden. Des weiteren sind 48,0\% der Senioren 
(65-74 Jahre) von einer mittelschweren und 39,8\% von einer schweren Parodontalerkrankung betroffen.

Risikofaktoren sind insbesondere das Rauchen und ein niedriger Bildungsstand. Aus der Kombination beider Faktoren ergibt sich ein um den Faktor 3,3 erhöhtes Risiko, an einer Parodontitis zu erkranken. Schwere Formen einer Parodontalerkrankung zeigten sich vermehrt bei Männern (Micheelis und Schiffner 2006).

\subsection{3 Ätiologie}

Die Entwicklung der Parodontitis beginnt mit der Bildung eines spezifischen bakteriellen Biofilms. Dies ist ein weicher, strukturierter, zäher Belag, der mit Wasserspray nicht entfernbar ist. Er setzt sich aus Bakterien zusammen, die in einer organischen Matrix aus Speichelglykoproteinen und extrazellulären Bakterienprodukten eingebunden sind (Plagmann 1998).

Wie Abb. 1 zeigt, ist die Parodontitis eine multifaktorielle Erkrankung. Entscheidend für Ausbruch und Verlauf sind jedoch die genetisch determinierte Immunabwehr des Wirts sowie äußere Faktoren wie Rauchen, schlechte Mundhygiene, Alkohol oder Stress (Abb.1). Die Parodontitis verursacht irreversible Schäden, was mit spezifischen Bakterien assoziiert werden kann. Im Gegensatz dazu verursacht die Mischflora der supragingivalen Plaque eine reversible Entzündungsreaktion (Socransky et al. 1998; Haffajee und Socransky 2005; Rateitschak et al. 2012). 


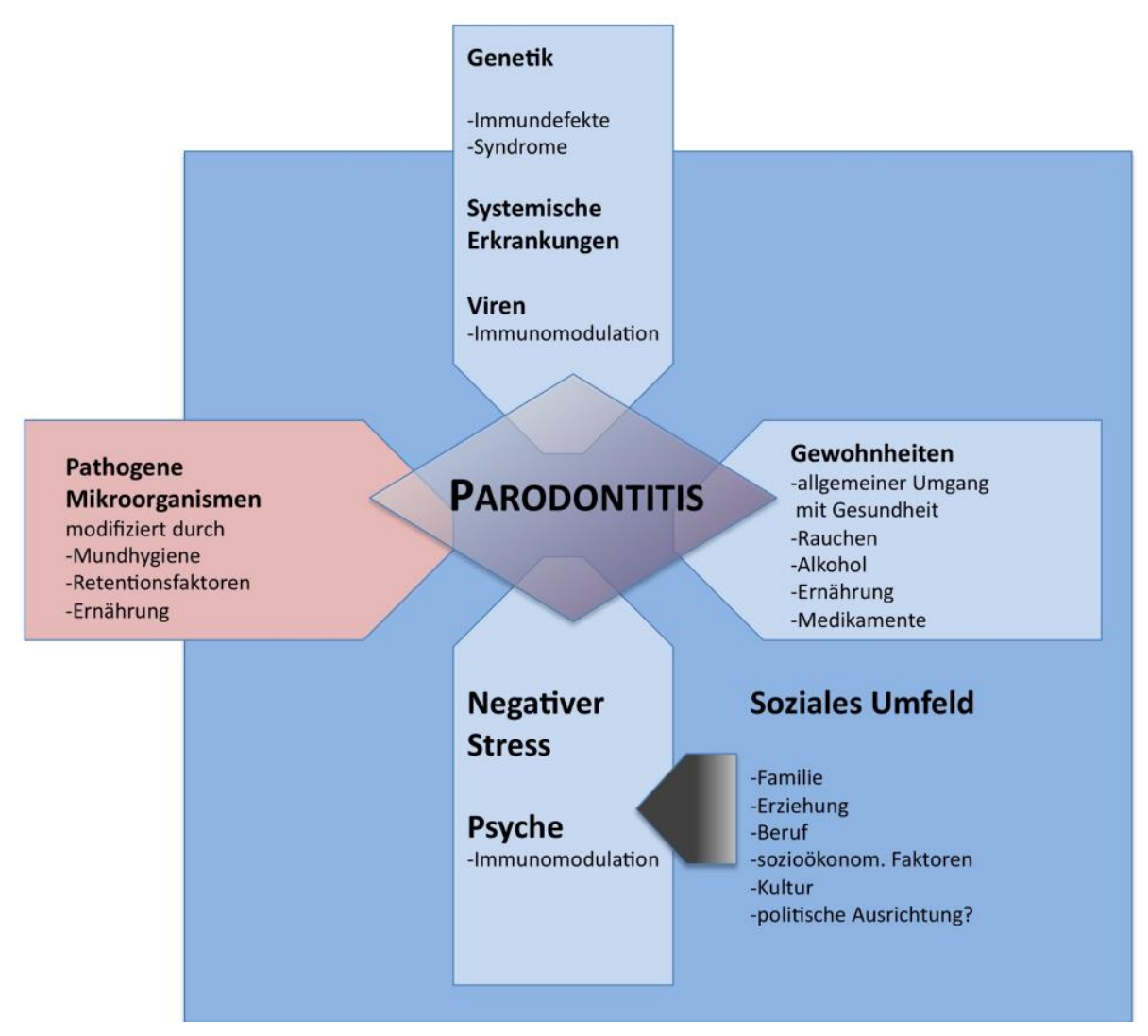

Abbildung 1 Ätiologie der Parodontitis (nach Rateitschak et al. 2012, Seite 22, Abb. 41)

\subsubsection{Pathogenese der Parodontitis}

\subsubsection{Bakterien und Biofilm}

Die Anzahl der in der Mundhöhle bekannten Bakterienspezies hat sich in den letzten Jahren drastisch erhöht. Ging man vor zehn Jahren noch von ca. 500 verschiedenen Bakterienspezies aus (Paster et al. 2000), zeigen neuere gentechnische Methoden, dass man mit mindestens 19.000 rechnen muss (Keijser et al. 2008).

Die Bakterien bilden einen Biofilm, der aus vielen Mikrokolonien besteht, die sich wiederum aus unterschiedlichen Bakterienspezies zusammensetzen. Diese kommunizieren untereinander über flüssigkeitsgefüllte Kanälchen. Nährstoffe und Stoffwechselprodukte werden so ausgetauscht; es kommt zu einem Aufbau von Nahrungsketten. Darüber hinaus werden Signalstoffe ausgesendet (Signaltransduktion), die bei Erreichen eines Schwellenwertes zu Funktionsveränderungen bei den Mikroorganismen führen können. Diese Interaktion der verschiedenen Organismen untereinander wird auch quorum sensing genannt. Sie ist von entscheidender Bedeutung für die Pathogenität des Biofilms (Miller und Bassler 2001) und der Grund für die gute Anpassungsfähigkeit, was ihn resistent gegen nahezu alle Einflüsse von außen (Desinfizienzien, Antibiotika) macht. 
Üblicherweise folgt eine bakterielle Infektion den Kriterien, die in den Kochschen Postulaten zu finden sind. Dies gilt jedoch nicht für die Parodontitis. Socransky und Haffajee (1992) haben stattdessen folgende Modifikation vorgenommen.

\section{Ein parodontopathogener Erreger}

1. lässt sich in hoher Anzahl in oder um parodontale Läsionen nachweisen,

2. ist in niedriger Anzahl auch bei parodontal Gesunden oder Personen mit anderen Formen parodontaler Erkrankungen nachweisbar,

3. induziert eine starke humorale Immunreaktion bei parodontal Erkrankten,

4. exprimiert Virulenzfaktoren, die mit der klinischen Histopathologie vereinbar sind,

5. besitzt im Tiermodell vergleichbare pathogene Fähigkeiten.

Obwohl die Bedeutung für die Mundgesundheit bei den allermeisten Spezies noch unbekannt ist, lassen sich nach heutigem Kenntnisstand einige hochpathogene Bakterien in Zusammenhang mit der Parodontitis bringen. Die am besten dokumentierten Bakterien sind gleichzeitig auch diejenigen, die nach heutigem Kenntnisstand mit einer aktiven und schweren Form der Parodontitis in Verbindung gebracht werden (Tabia et al. 1981). Zudem weisen gerade diese meist gram-negativen Bakterien eine Vielzahl von Virulenzfaktoren auf (Ximénez-Fyvie et al. 2000). Als Ursache für die Parodontitis werden vor allem folgende vier Bakterien genannt, die auch als roter Komplex bezeichnet werden (Guthmiller und Novak 2002):

- Aggregatibacter actinomycetemcomitans (Aa)

- Porphyromonas gingivalis $(P g)$

- Tannerella forsythia (Tf)

- Treponema denticola $(T d)$

Die zugehörigen Virulenzfaktoren umfassen (Newman 2006; Rateitschak et al. 2012):

- Toxine: u.a. Lipopolisaccharide (LPS) von Pg und Aa (Ximénez-Fyvie et al. 2000)

- Fähigkeit zur Invasion: $P g$ und Aa schützen sich vor unspezifischer Immunantwort durch Eindringen in Wirtszellen

- Enzyme - Proteasen: zell- und matrixauflösende Enzyme sowie "Gingipains“, welche die Immunität des Wirts hemmen 
Die Pathogenität hängt stark von dem vorherrschenden Milieu ab. So konnte man bestimmte Erstbesiedler (Actinomyces naes/undii/viscosus, Streptococcus sp. u.a.) identifizieren, die das Milieu der Tasche unter anderem durch die Bildung eines Biofilms und die Reduzierung des Sauerstoffgehalts vorbereiten. $\mathrm{Pg}$ ist strikt anaerob, und so ist die weitere Entwicklung einer Tasche von dem in ihr vorherrschenden aneaeroben Milieu abhängig. Diese vorbereitenden Bakterien treten meist in einer bestimmten Reihenfolge und in Komplexen (Abb. 2) von mehreren Bakterien auf. Der Nachweis einer dieser wenig virulenten Bakterienspezies kann also ein Hinweis auf eine sich entwickelnde Parodontitis sein (Rateitschak et al. 2012).

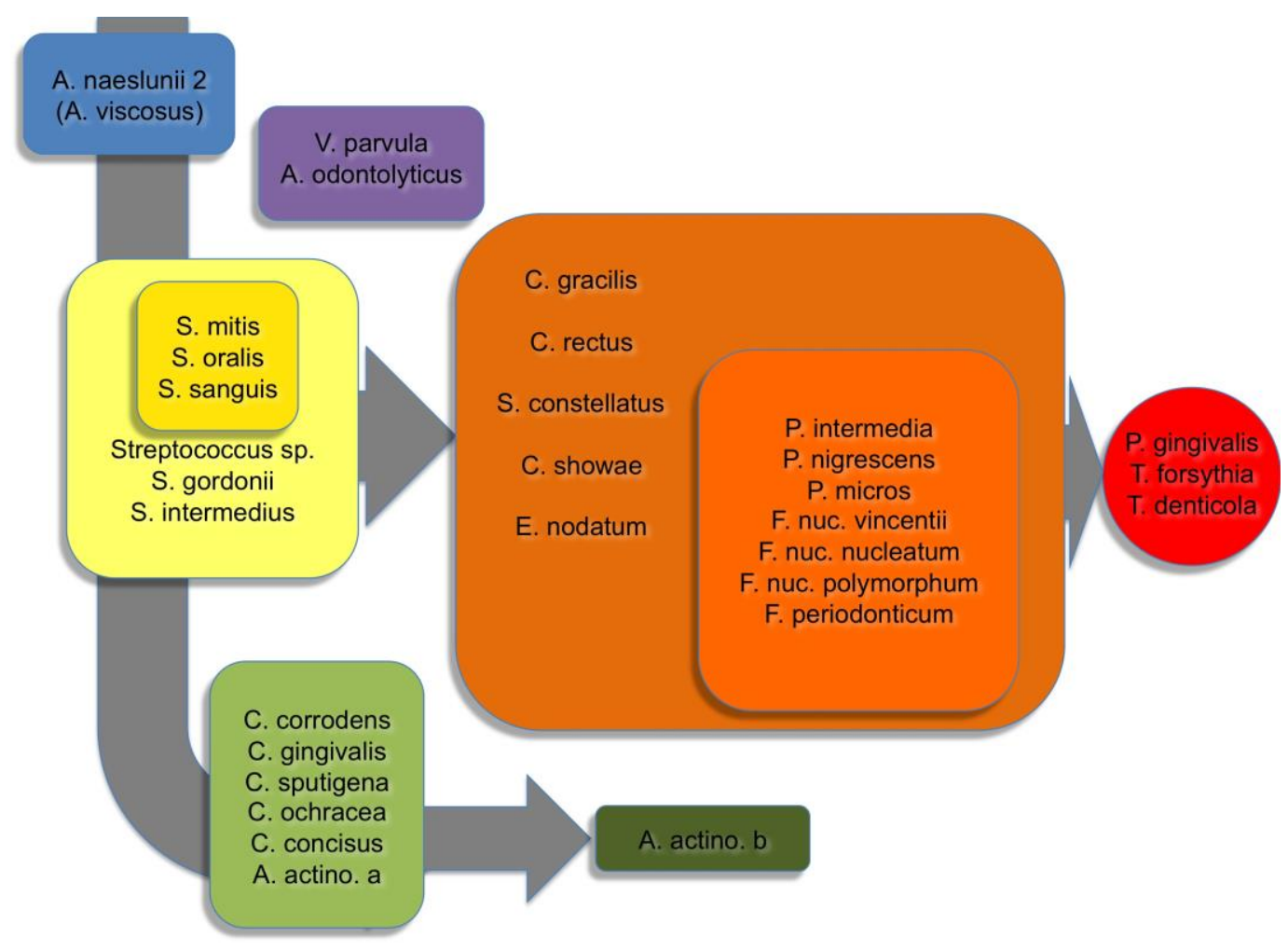

Abbildung 2 Entwickung von Komplexen (nach Rateitschak et al. 2012, Seite 37, Abb. 77)

Betrachtet man das klinische Bild einer Parodontitis, zeigt sich das typische Bild einer Entzündung mit rubor, tumor, calor und selten auch dolor. Es ist Ausdruck einer Auseinandersetzung zwischen den bakteriellen Toxinen und dem körpereigenen Immunsystem, das versucht die bakterielle Invasion zu stoppen. Das Ausmaß und die Progression sind von verhaltensbedingten und genetischen Faktoren abhängig (Abb.3) (Rateitschak et al. 2012; Page und Kornman 1997). 


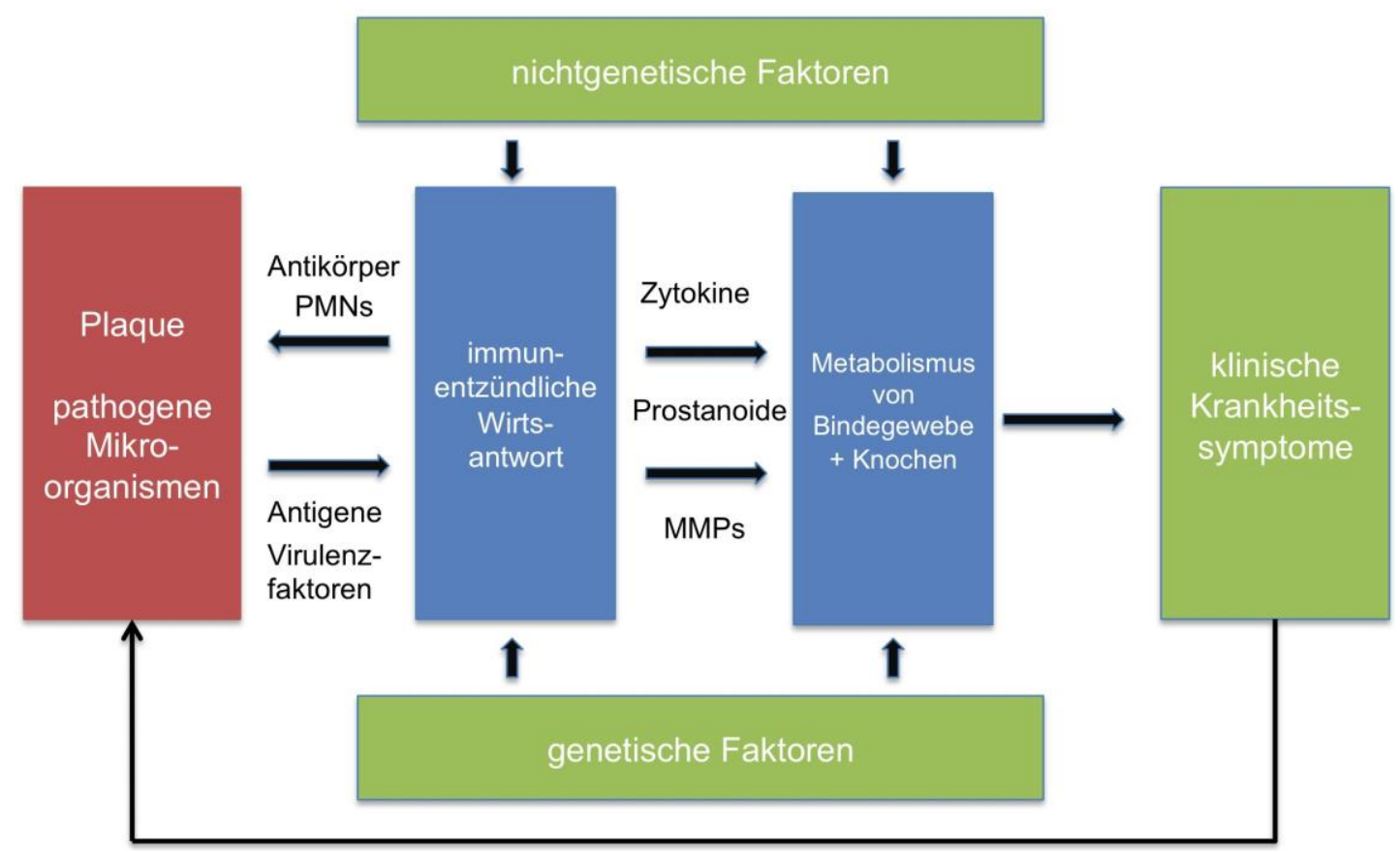

Abbildung 3 Pathogenese der menschlichen Parodontitis. (nach Page und Kornman 1997, Seite 10, Abb. 1)

(PMN: Polymorphkernige, MMPs: Matrixmetalloproteinasen)

\subsubsection{Lipopolysaccharide (LPS)}

LPS sind hochmolekulare, thermostabile Biomoleküle, die sowohl pyrogen als auch immunogen wirken (Oethringer 1997). Diese bakteriellen Endotoxine befinden sich in der äußeren Membran der Zellwand gramnegativer Bakterien. An dieser Stelle bilden sie eine für Antibiotika schwer passierbare Barriere. Das LPS wird unter bestimmten Bedingungen aus der Membran freigesetzt und kann dann seine für den Wirt toxische Wirkung entfalten. Freie LPS-Moleküle entstehen durch Vesikelbildung, Zellteilung (Vermehrung) und nach dem Tod des Bakteriums in Folge der Auflösung der Zellwand (Rateitschak et al. 2012).

Freies LPS koppelt an das Lipopoloysaccharid-Binding-Protein (LBP) und aktiviert bei Makrophagen über den LPS-Rezeptor CD14 die Produktion von Zytokinen, Sauerstoffradikalen und bioaktiven Lipiden (Ximénez-Fyvie et al. 2000). Die Menge der produzierten Zytokine unterscheidet sich bei den verschiedenen Bakterien. So ist sie bei LPS von Pg höher als bei allen anderen parodontopathogenen Bakterien. Während die Aktivierung der Makrophagen in niedrigen Konzentrationen einen positiven Effekt auf das Immunsystem hat (es wird „trainiert“), kann es bei erhöhter Konzentration zu einer überschießenden Immunreaktion kommen (Rateitschak et al. 2012). 


\subsubsection{Immunabwehr}

Das Immunsystem soll ein Eindringen bzw. eine Schädigung des Körpers durch körperfremde Keime verhindern. Die erste Barriere stellen Epithelien auf der Körperoberfläche dar. Neben ihrer Funktion als physische Barriere sondern sie auch abwehraktive Sekrete ab. Überwindet ein Keim diesen ersten Abwehrmechanismus, kommt es zu einer Entzündungsreaktion mit dem Ziel, die eingedrungenen Stoffe zu zerstören und auszuscheiden (Silbernagl und Despopoulos 2003).

Die zweite Barriere ist die angeborene unspezifische Immunabwehr. Sie reagiert sofort mit der Ausschüttung von chemotaktischen Stoffen, die neutrophile Granulozyten und Makrophagen zur Phagozytose der eindringenden Substanzen veranlassen. Diese können über Mannose- und scavenger-Rezeptoren erkannt werden. Neben dieser zellulären Komponente erkennen Monozyten und Makrophagen sogenannte Toll-like-Rezeptoren (TLR) auf der Oberfläche der Keime. Beim Menschen sind ca. 10 TLR bekannt, die auf Kontakt zu unterschiedliche Strukturen auf der Oberfläche von Mikroorganismen (z.B. LPS) reagieren. Dies führt zu einer humoralen Freisetzung proinflammatorischer Zytokine, wie Interleukinen (IL-1, IL-6, IL12, IL-18) und Tumornekrosefaktor- $\alpha$ (TNF- $\alpha$ ). IL-1, IL-6 und TNF- $\alpha$ wirken pyrogen; IL-6 aktiviert darüber hinaus auch die Freisetzung von C-Reaktives Protein (CRP) in der Leber (Löffler 2007). Ein weiterer wichtiger Teil der humoralen Reaktion ist das Komplementsystem. Es opsoniert fremde Mikroorganismen und präsentiert diese den phagozytierenden Zellen. Gleichzeitig aktiviert und beeinflusst das Komplementsystem die Leukotaxis von Leukozyten und reguliert durch Mediatoren (Freisetzung aus Mastzellen und Granulozyten) die Vasodilatation der Blutgefäße (Silbernagl und Despopoulos 2003).

Das vom Parodont abgesonderte Sekret (sulcus fluid) enthält ebenfalls Teile dieser zweiten Barriere. Neutrophile Granulozyten treten im Sulkus aus und unterhalten bei guter Mundhygiene eine „physiologische Entzündung“. Bei einem etablierten Biofilm ist die Phagozytose jedoch nicht mehr möglich (Rateitschak et al. 2012).

Die unspezifische Immunität hat keine Gedächtnisfunktion. Jedoch kommen die phagozytierten Keime in Kontakt mit Teilen der dritten Abwehrbarriere. Diese spezifische Immunabwehr erkennt bestimmte Oberflächenmerkmale (Antigene) des eingedrungenen Keims und produziert antigenspezifische T- und B-Lymphozyten (=Tund B-Zellen). Makrophagen präsentieren den zytotoxischen T-Zellen und den THelferzellen das Antigen. Zytotoxische T-Zellen sezernieren daraufhin Zytoxine (TNFB). T-Helferzellen fördern die Differenzierung der B-Zellen und weiterer Abwehrzellen (Eosinophile und Makrophagen). B-Zellen differenzieren sich dabei zu Plasmazellen, die antigenspezifische Antikörper (Immunglobuline) produzieren. Es 
gibt fünf verschiedene Klassen von Immunglobulinen: $\lg A, \lg \mathrm{D}, \lg \mathrm{E}, \lg \mathrm{G}, \lg \mathrm{M}$. Sie wirken opsonierend, toxinneutralisierend und aktivieren das Komplementsystem. Die Bildung der Antikörper dauert beim Erstkontakt mehrere Tage, allerdings verfügt das spezifische Immunsystem über eine Art Gedächtnis. Bei einem erneuten Angriff bekannter Bakterien erfolgt dann eine schnellere Immunreaktion (Silbernagl und Despopoulos 2003).

Im Falle der Parodontitis weiß man, dass es durch Funktionsstörungen neutrophiler Granulozyten, Polymorphismen im IL-1 oder Mutationen in den Genloci für IgG2 zu einer erheblichen Steigerung dieser selbstzerstörenden Wirkung kommen kann. Der Schweregrad der Destruktion kann dabei durch Außeneinwirkungen (sog. Risikofaktoren), wie Rauchen, Stress, Ernährungsgewohnheiten, Diabetes mellitus, HIV, Blutungserkrankungen und Osteoporose noch gesteigert werden. Mutationen einzelner Basenpaare sind beispielsweise bei IL-1 recht häufig zu finden. Durch Kontakt von Monozyten mit LPS wird bei dem veränderten IL-1 Genotyp die vierfache Menge IL1 ausgeschüttet. Die Verbrennungsprodukte beim Rauchen verstärken die Reaktion der Makrophagen. Zudem führt Nikotin als Sympathomimetikum zu einem reduzierten Stoffwechsel im parodontalen Gewebe. Entscheidend ist weiterhin der erniedrigte IgG2-Spiegel beim Raucher. IgG2 bindet an polysaccharidartige Antigene, womit es zu einer reduzierten Abwehrleistung gegenüber gramnegativen Bakterien kommt (Aac, Pg) (Rateitschak et al. 2012; Kornman et al. 1997).

\subsection{Herzinsuffizienz}

\subsubsection{Definition und Klassifikation}

Bei der Herzinsuffizienz ist das Herz nicht mehr in der Lage, den Organismus ausreichend mit Blut und dadurch mit genügend Sauerstoff zu versorgen, um den Stoffwechsel unter Ruhe- wie unter Belastungsbedingungen zu gewährleisten (ICD 10 150).

Die Herzinsuffizienz führt - in Ruhe oder auch erst bei Belastung - zu typischen Symptomen wie Dyspnoe, Müdigkeit oder Flüssigkeitsretention. Wenn die Symptomatik nur bei Belastung auftritt, spricht man von einer kompensierten Herzinsuffizienz. Bei einer dekompensierten Herzinsuffizienz dagegen bestehen die Symptome schon in Ruhe (Rickenbacher 2001; Classen et al. 2004; Swedberg et al. 2005).

Des weiteren kann in Abhängigkeit von dem betroffenen Ventrikel eine Rechtsherzvon einer Linksherzinsuffizienz unterschieden werden. Der dünnwandige rechte Ventrikel ist sehr viel dehnbarer und insgesamt deutlich empfindlicher auf Änderungen der Vor-/Nachlast, als es beim linken Ventrikel der Fall ist. Eine isolierte 
Rechtsherzinsuffizienz wird selten beobachtet, z.B. bei pulmonaler Hypertonie. Meistens tritt die Rechtsherzinsuffizienz konsekutiv bei der Linksherzinsuffizienz hinzu. Man spricht dann von einer Globalinsuffizienz. Die im Folgenden gemachten Angaben zur Herzinsuffizienz und deren Adaptionsmechanismen beziehen sich im Wesentlichen auf den linken Ventrikel (Classen et al. 2004).

Die Funktionsstörung des Herzens kann entweder die Systole oder die Diastole betreffen, und so unterscheidet man die systolische von der diastolischen Herzinsuffizienz. Die erstere ist gekennzeichnet durch eine Kontraktilitätsstörung des Ventrikels (Lederhuber und Lange 2010) mit Abfall der Auswurffraktion. Die Kontraktilität des Herzmuskels ist schwierig zu definieren oder gar zu messen. So bleibt nur übrig, die Kontraktiliät an Hand von volumetrischen Variablen abzuschätzen, wie der Auswurffraktion (EF-Fraktion). Diese wird echokardiographisch beschrieben als Anteil der ausgeworfenen Blutmenge in Prozent des enddiastolischen Volumens (Classen et al. 2004).

Der diastolischen Herzinsuffizienz liegt eine Füllungsstörung des (linken) Ventrikels zugrunde. Diese kann entweder durch eine geringere Dehnbarkeit (Compliance) des Muskels oder durch eine Einengung des Herzens z.B. durch das Perikard verursacht werden. Eine Compliance-Störung des Myokards kann entweder durch eine eigenständige Myokarderkrankung entstehen, wie es bei restriktiven Kardiomyopathien (z.B. Endomyokardfibrose) der Fall ist oder sekundär durch die Adaptionsmechanismen bei der chronischen Herzinsuffizienz (sog. Remodeling) (Classen et al. 2004).

In Abhängigkeit von der funktionellen klinischen Ausprägung wird die Herzinsuffizienz entsprechend der von der New York Heart Association vorgenommenen Klassifikation in 4 verschiedene Schweregrade eingeteilt (The Criteria Committee of the New York Heart Association 1994):

I. körperliche Leistungsfähigkeit nicht eingeschränkt, aber pathologische haemodynamische Indizes bei Belastung (z.B. erhöhter Füllungsdruck),

II. körperliche Leistungsfähigkeit leicht eingeschränkt; Beschwerden bei alltäglicher körperlicher Belastung,

III. körperliche Leistungsfähigkeit stark eingeschränkt; Beschwerden bereits bei geringer körperlicher Belastung; keine Beschwerden in Ruhe,

IV. Beschwerden bei allen körperlichen Aktivitäten und in Ruhe; Bettlägerigkeit. 


\subsubsection{Epidemiologie}

Die in erster Linie altersabhängige Prävalenz der Herzinsuffizienz hat in den letzten 20 Jahren drastisch zugenommen (Classen et al. 2004). Dieser Zuwachs wird auf den steigenden Anteil älterer Menschen in der Bevölkerung sowie auf die verbesserten therapeutischen Möglichkeiten von akuten Herzerkrankungen zurückgeführt. In Deutschland liegt die Prävalenz in der Altersgruppe zwischen 45-55 Jahren unter $1 \%$ der Bevölkerung; in der Altersgruppe von 65-75 Jahre beträgt sie etwa 4\% und bei den über 80 -Jährigen erreicht sie fast $10 \%$. Die Herzinsuffizienz ist derzeit die häufigste Klinikdiagnose bei Patienten über 75 Jahre (Classen et al. 2004). In der Todesursachenstatistik nimmt die Herzinsuffizienz in Deutschland bei den Frauen den zweiten und bei den Männern den vierten Platz ein (Statistisches Bundesamt 2011).

\subsubsection{Pathophysiologie}

Meistens liegt eine koronare Herzkrankheit bei (systolischen) Kontraktilitätsstörungen vor (54-70\%). Häufig (in 35-42\% der Fälle) ist diese mit einer arteriellen Hypertonie kombiniert (Hoppe et al. 2005). Durch die Ischiämie des Herzmuskels kommt es zum Verlust von funktionsfähigem Herzmuskelgewebe (McMuray und Stewart 2000). Die systolische Herzinsuffizienz mit einer EF $\leq 40 \%$ überwiegt mit etwa $60 \%$ der Fälle im Vergleich zur diastolischen Herzinsuffizienz (40\%) (Hoppe und Erdmann 2004; Senni und Redfield 2001).

Neben den genannten Ursachen für die Herzinsuffizienz gibt es noch ein weites Feld an Ursachen, die teils im Herzen selbst begründet sind (Vitien, Herzrhythmusstörungen, primäre Herzmuskelerkrankungen u.a.m.), teils auch extrakardial bedingt sein können (Hyper- u. Hypothyreose, Anaemien, immunologische Erkrankungen u.a.m.) (Classen et al. 2004).

Unabhängig von der Ursache der Herzinsuffizienz ist der Organismus in der Lage, funktionale, neurohumorale und morphologische Adapationsmechanismen in Gang zu setzen, die der Minderversorgung des Körpers mit Sauerstoff entgegen wirken (Classen et al. 2004).

Die vom gesunden Herzen her bekannten funkionalen Adapationsmechanismen wie der Frank-Starling-Mechanismus (Steigerung der Kontraktilität durch erhöhte Vorlast), das Treppenphänomen (Steigerung der Kontraktilität durch erhöhte Herzfrequenz) und die Tachykardie (Steigerung der Herzminutenvolumens) sind bei der Herzinsuffizenz weniger wirksam (Classen et al. 2004; Weil und Schunkert 2006).

Der neurohumorale Adaptionsmechanismus bewirkt bei Absinken der kardialen Pumpfunktion eine verbesserte Kontraktilität des Myokards. Dies wird über eine 
Aktivierung des sympathischen Nervensystems mit seiner positiv inotropen (kontraktilitätssteigernd), chronotropen (frequenzsteigernd) und lusitropen (relaxationssteigernd) Wirkung der Katecholamine hervorgerufen (Classen et al. 2004). Dieser Effekt verliert bei der chronischen Herzinsuffizienz allerdings an Wirkung, weil infolge der ständigen adrenergen Stimulation die $\beta 1$-Adrenorezeptoren-Dichte abnimmt (Weil und Schunkert 2006). Die Aktivierung des Renin-Angiotensin-AldosteronSystems führt durch Flüssigkeitsretention zur Steigerung der Vorlast und durch die Vasokonstriktion in der Peripherie zu einer Steigerung der Nachlast. Weiterhin werden verstärkt Vasopressin (synonym: antidiuretisches Hormon, ADH) und Endothelin ausgeschüttet, welche beide die Flüssigkeitsretention und damit Nachlasterhöhung noch verstärken (Classen et al. 2004).

Gleichzeitig werden auch gegenregulatorische Systeme aktiviert, deren Volumen eliminierende und vasodilatatorische Effekte nur von geringer Bedeutung sind. Im Einzelnen handelt es sich hierbei um die Prostaglandine, Bradykinin, Dopamin, Stickstoffmonoxid und um die direkt aus dem Myokard ausgeschütteten natriuretischen Peptide, deren Bedeutung als diagnostischer Parameter im nächsten Kapitel bearbeitet wird (Bruneau et al. 1997).

Die morphologischen Adaptionsmechanismen bei der chronischen Herzinsuffizienz werden auch als Remodeling bezeichnet (Cohn et al. 2000). Bei erhöhter Druckbelastung, z.B. infolge arterieller Hypertonie oder einer Aortenklappenstenose, kommt es zu einer Zunahme der kontraktilen Muskelmasse (konzentrisches Remodeling), wodurch zumindest vorübergehend eine Mehrbelastung ausgeglichen werden kann. Mit dieser Hypertrophie des Herzmuskels kann aber die arterielle Versorgung nicht Schritt halten. Es kommt zum fibrotischen Umbau und damit über eine verminderte Compliance zu einem weiteren Abfall der Herzleistung (Weil und Schunkert 2006). Bei erhöhter Volumenbelastung (z.B. bei Aorteninsuffizienz) wird eine Zunahme des linksventrikulären Durchmessers, also eine Dilatation der Ventrikelmuskulatur, beobachtet (exzentrisches Remodeling) (Weil und Schunkert 2006). Diese Dilatation führt über eine Zunahme des Schlagvolumens vorübergehend zu einer Verbesserung. Längerfristig bewirkt sie allerdings über eine Zunahme der Belastung der Herzmuskelfasern einen progressiven Zellverlust (Apoptose) und damit ebenfalls wieder eine weitere Verschlechterung der Herzinsuffizienz (Classen et al. 2004).

Darüber hinaus werden bei der Herzinsuffizienz auch chronisch-entzündliche Veränderungen mit systemischer und lokaler Aktivierung von proinflammatorischen Zytokinen (TNF-a, IL-1, IL-6 und CD14) beschrieben (Seta et al. 1996; Mann 2002; Staudt et al. 2002; Rauchhaus et al. 2000; Sharma et al. 2005b; Rauchhaus 2008; 
Niederbichler et al. 2011). Bekannt sind negativ inotrope Effekte und Auswirkungen auf die Kardiomyocyten (Diwan et al. 2003) im Rahmen des Remodeling.

Die genannten Adaptionsmechanismen haben gemeinsam, dass sie die Herzleistung nur vorübergehend stabilisieren, längerfristig aber in einem circulus vitiosus münden mit einem weiteren Absinken des Herzleistung (Rickenbacher 2001). Dies erklärt auch die ungünstige Prognose der Herzinsuffizienz: Bei Patienten im Stadium NYHA II liegt die jährliche Mortalität bei $15-30 \%$, bei Patienten im Stadium NYHA IV schon bei 50\% (Classen et al. 2004).

\subsubsection{Spezielle Labordiagnostik}

Die Messung des Gehalts an Brain Natriuretic Peptide (BNP) bzw. des N-terminalen BNP im Blut gilt heute bei der Diagnostik und insbesondere der Verlaufskontrolle/Monitoring der Herzinsuffizienz als Standard (Krum und Abraham 2009; Pauriah et al. 2012; Pfisterer et al. 2009; Valle et al. 2011; Luchner et al. 2003). Das BNP gehört zur Gruppe der natriuretischen Peptide, welche bei der Herzinsuffizienz vermehrt ausgeschüttet werden (Bruneau et al. 1997).

Das Herz bildet drei sogenannte natriuretische Peptide. Die Struktur des atrial natriuretic peptid (ANP) wurde erstmals 1984 identifiziert. Eine weitere Substanz, die ähnlich wie ANP natriuretisch und diuretisch wirkt, wurde 1988 isoliert. Nachdem diese Substanz aus Schweinehirn isoliert worden war, wurde es als brain (B-Typ) natriuretic peptid bezeichnet, obwohl es hauptsächlich im Herzen selbst gebildet wird. 1990 wurde dann ein drittes Mitglied der natriuretischen Peptide identifiziert und als C-Typ bezeichnet. Dieses hat eine andere Struktur als die beiden anderen und wird im Gegensatz zum ANP und BNP, die im Myokard gebildet werden, vor allem im Zentralnervensystem und im Gefäßsystem synthetisiert (de Lemos et al. 2003).

Es wurden drei Rezeptoren für die natriuretischen Peptide nachgewiesen: NPR-A, NPR-B und NPR-C. Die Peptide ANP und BNP bevorzugen den NPR-A Rezeptor, während CNP den Rezeptor NPR-B bevorzugt (Abb. 4). 


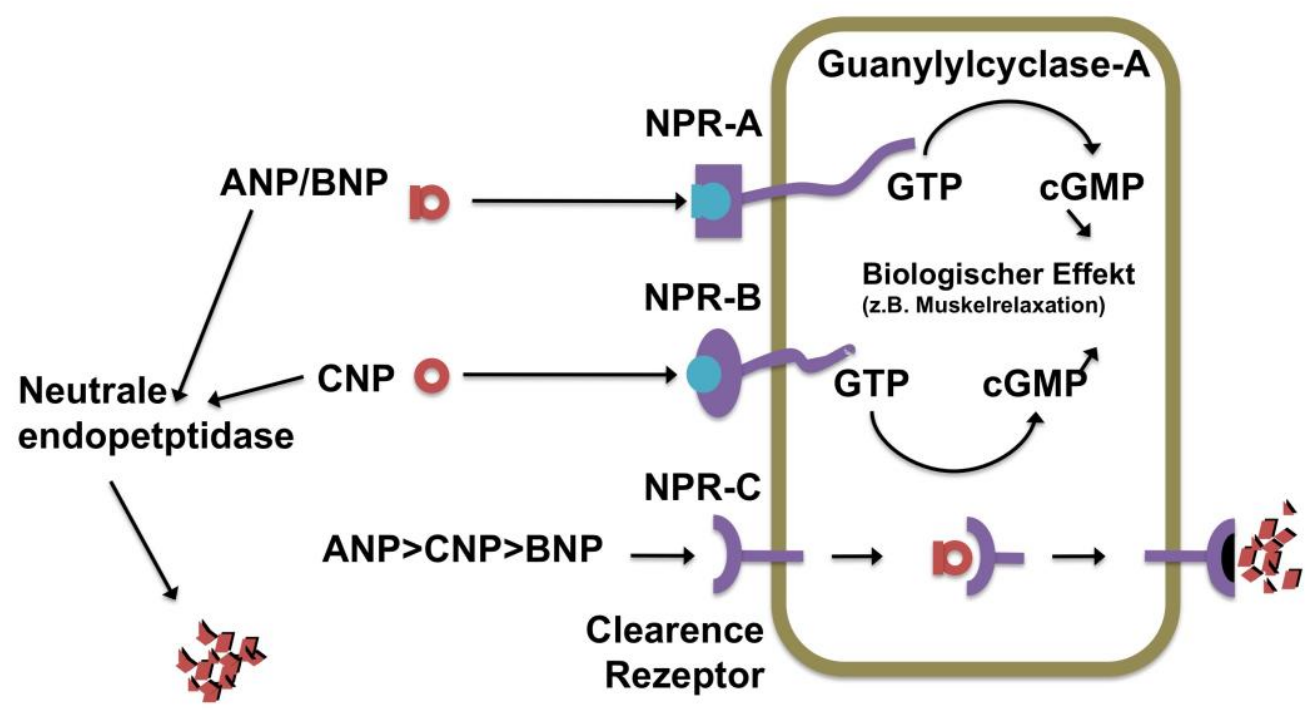

Abbildung 4 Aufnahme und Abbau von BNP (nach de Lemos et al. 2003)

ANP und BNP steigern an der Niere die glomeruläre Filtration und inhibieren die Natriumrückresorption. Damit wirken sie diuretisch und natriuretisch. An der glatten Gefäßmuskulatur führen die natriuretischen Peptide über eine Abnahme der intrazellulären Calciumkonzentration zu einer arteriellen und venösen Relaxation, womit die Vor- und Nachlast gesenkt wird. Des Weiteren fungieren ANP und BNP antagonistisch im Rahmen der gegenregulatorischen, neurohumoralen Stimulation (Noradrenalin, Angiotensin II). CNP wirkt im Gegensatz zu ANP und BNP nicht als zirkulierendes Hormon, sondern überwiegend lokal im Gefäß- und zentralen Nervensystem. Der Abbau der natriuretischen Peptide erfolgt über die neutrale Endopeptidase und über den Rezeptor NPR-C (Classen et al. 2004).

Das Hormon wird zunächst in Form einer Vorstufe (proBNP) gebildet; durch Proteolyse entstehen daraus das biologisch aktive Peptid BNP und das inaktive Nterminale pro BNP (NT-pro BNB). Im Blut liegen beide Moleküle im gleichen äquimolaren Verhältnis vor; allerdings hat das BNP mit ca. 20 Minuten eine wesentlich kürzere In-vivo Halbwertszeit als das NT-proBNP mit 120 Minuten. Die Bestimmung von NT-proBNP stellt im Vergleich zu BNP einen noch empfindlicheren Marker für die Herzinsuffizienz dar (Zhou et al. 2010).

Die Synthese von BNP wird über eine Dehnung der Herzmuskelzelle stimuliert. Die Aktivierung von proBNP im linksventrikulären Myokard erfolgt schnell und zuverlässig (Nakagawa et al. 1995). Die Plasmakonzentrationen sind bei Herzinsuffizienz schon im Stadium NYHA I erhöht und steigen mit zunehmendem Schweregrad stark an (Maisel 2001). Bei der Interpretation der Werte ist zu berücksichtigen, dass sie bei der Frau höher liegen und die Konzentration altersabhängig auch beim Gesunden ansteigt. Die NT-proBNP-Spiegel steigen proportional mit dem zunehmenden 
Schweregrad einer Herzinsuffizienz an und können deshalb zur Objektivierung des Schweregrades sowie zum Therapiemonitoring angewandt werden (Luchner et al. 2003).

Im Rahmen von Studien (Bay et al. 2003) konnte gezeigt werden, dass durch die NT-proBNP-Bestimmung im Rahmen der Primärdiagnostik das Vorliegen einer Herzinsuffizienz bei einem Wert von $<125 \mathrm{pg} / \mathrm{ml}$ nahezu ausgeschlossen werden kann (negativer prädiktiver Wert von 97\%).

\subsection{Zusammenhänge zwischen Parodontitis und Herzerkrankungen}

Weit mehr als 1000 Bakterienarten sind in der Mundhöhle zu finden. Nur rund 40 davon sind heute als pathogen anzusehen. Die anatomisch enge Beziehung zu zahlreichen Blutgefäßen legt nahe, dass eine Verbreitung von diesen Bakterien über die Blutbahn im Sinne einer Bakteriämie wahrscheinlich ist (Forner et al. 2006). Studien zeigen, dass parodontal erkrankte Patienten einen erhöhten Antikörpertiter gegen Pg haben (Yamazaki et al. 2007).

Findet im Organismus eine chronische Entzündung statt, erhöht sich das Risiko für eine kardiovaskuläre Erkrankung (Libby et al. 2002). Somit kann man davon ausgehen, dass Bakterien, die eine Infektion in der Mundhöhle auslösen können, auch an anderen Stellen des Körpers relevant sein könnten.

In den letzten Jahrzehnten gab es eine Vielzahl von Studien, die Parodontitis mit verschiedenen Allgemeinerkrankungen in Zusammenhang bringen konnten (Silver et al. 1977; Meyer und Fives-Taylor 1998; Slavkin 1999; Slavkin und Baum 2000; Grau et al. 2004; Seymour 2007; Blaizot 2009; Tonetti 2009; Kebschull et al. 2010). Dazu zählen insbesondere Diabetes mellitus und kardiovaskuläre Erkrankungen (Mealey und Oates 2006; Meyer und Fives-Taylor 1998). Ein Erklärungsmodell für die Zusammenhänge von Parodontitis und KHK wird von Dietrich et al. (2008) beschrieben. Demnach gibt es direkte Auswirkungen der Parodontitis auf die Ausprägung der koronaren Herzerkrankung als Folge von Bakteriämie und indirekte Effekte ausgelöst durch die chronische Entzündung. Hinzukommt ein nicht-kausaler Weg unter Beteiligung wirtseigener, genetischer und verhaltensbedingter Faktoren.

Pucar et al. (2007) konnten in PCR-Analysen hohe Mengen von parodontopathogenen Bakterien (darunter $\mathrm{Pg}, \mathrm{Tf}, \mathrm{Aac}$ ) an atherosklerotisch veränderten Gefäßen feststellen. Kebschull et al. (2010) haben die bislang erforschten Mechanismen des hoch parodontopathogenen Bakteriums $P g$ in Zusammenhang mit den Pathomechanismen der Atherosklerose wie folgt dargestellt (Abb. 5). 


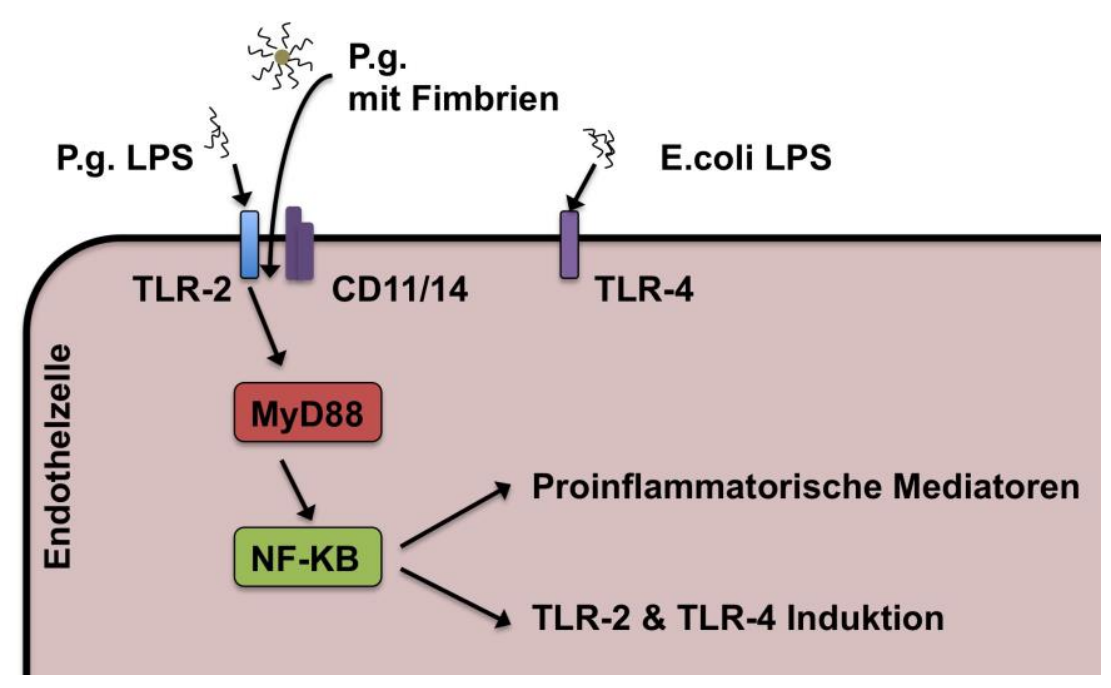

Abbildung 5 TLR-Signalweg (modifiziert nach Kebschull et al. 2010)

Die Endothelzelle wird durch Pg sowie durch dessen LPS aktiviert. Dadurch kommt es zu einer Hochregulation von Zelladhäsionsmolekülen und Sekretion von proinflammatorischen Mediatoren. Enterococcus coli (Ecoli) ist ein weiteres gramnegatives Bakterium, welches über LPS verfügt und ähnliche Effekte hervorrufen kann. Allerdings aktiviert dieses LPS den Rezeptor TLR-4.

$P g$ wiederum kann über CD14 in die Endothelzelle invadieren, wo es sich vermehrt und Monozyten über einen Gradienten an chemotaktischen Zytokinen (Chemokinen) rekrutiert. Schließlich kommt es zur Apoptose der Endothelzelle - zum einen über Antikörper, zum anderen über $P g$ direkt. Die von den Parodontalpathogenen aktivierten Monozyten folgen nun den Chemokingradienten und migrieren in den subendothelialen Raum. Dort wandeln sich diese in Makrophagen um und nehmen oxidiertes Low Density Lipoprotein (LDL) auf, wodurch sie in Schaumzellen umgewandelt werden (Kebschull et al. 2010).

Durch die zunehmende Bildung von Plaques an der Gefäßwand verlieren diese an Elastizität, und das Gefäßlumen verkleinert sich. Minderdurchblutung und Sauerstoffmangel des Herzens sind die Folge (= koronare Herzkrankheit) (Classen et al. 2004). Verschiedene Studien konnten einen Zusammenhang zwischen der IntimaMedia-Dicke und Parodontitis nachweisen (Beck et al. 2001; Amar et al. 2003; Desvarieux et al. 2005). Eine parodontale Therapie hatte zur Folge, dass es zu einer Reduktion der Intima-Media-Dicke und damit zu einer Erholung des Gefäßsystems kam (Piconi et al. 2008). Zudem konnte In-vitro die DNA von parodontalpathogenen Bakterien in atherosklerotischer Plaque nachgewiesen und mit dem Schweregrad der klinischen parodontalen Situation in Zusammenhang gesetzt werden (Haraszthy 
et al. 2000; Aimetti et al. 2007). Auch an Herzklappen waren mikrobiologische Befunde mit parodontalpathogenen Bakterien festzustellen (Nakano 2009).

Tsioufis et al. (2011) gehen davon aus, dass bei der Atherosklerose ähnliche pathophysiologische Vorgänge ablaufen wie bei der Parodontitis: die systemische Inflammation durch parodontopathogene Bakterien, die genetisch bedingte veränderte Immunabwehr und direkte mikrobielle Effekte auf das Gefäßsystem und Veränderungen der Endothelfunktion.

In-vitro-Studien zeigten, dass neben verschiedenen pathogenen Mechanismen ein prothrombotischer Effekt von parodontopathogenen Bakterien $(P g)$ möglich ist (Roth et al. 2009). Angeli et al. (2003) stellten fest, dass der Schweregrad der Parodontitis in einem signifikanten Bezug zur linken Ventrikelmasse steht. In diesem Zusammenhang zeigen verschiedene In-vitro-Studien, dass die mitogen-aktivierte Proteinkinase und Calcineurin in Anwesenheit des parodontalpathogenen Bakteriums Porphyromonas gingivalis eine Hypertrophie und Apoptose von Kardiomyocyten zur Folge haben können, ähnlich wie man es beim oben beschriebenen exzentrischen Remodeling beobachten kann (Lee et al. 2005, 2006a, 2006b; Wu et al. 2008).

Verschiedene andere Studien zeigen, dass bei erhöhtem Antikörper-Titer gegen Aac und $\mathrm{Pg}$ das Risiko für koronare Herzerkrankungen steigt (Spahr et al. 2006; Pussinen et al. 2003). Ob hier ein kausaler Zusammenhang vorliegt oder ob es sich nur um eine Begleiterscheinung handelt, ist noch nicht abschließend geklärt.

Allerdings konnten Taylor et al. (2006) und Ellis et al. (2007) nachweisen, dass die Heilung einer schweren Parodontitis eindeutig positive Effekte auf den Organismus hat. Hierfür haben sie das Blut von Patienten vor und nach einer notwendigen totalen Zahnextraktion auf Entzündungsmarker getestet. Es zeigte sich, dass alle untersuchten Entzündungswerte nach der Extraktion, insbesondere das CRP, deutlich abgesunken waren. Des Weiteren sind proinflammatorische Zytokine, wie sie bei einer Herzinsuffizienz im Blutserum zu messen sind, auch bei einer schweren Parodontitis nachweisbar (D'Aiuto et al. 2004). 


\section{Material und Methoden}

\subsection{Studiendesign}

Bei dieser Untersuchung handelt es sich um eine klinische Querschnittsstudie in Kooperation mit der Klinik für Thorax-, Herz- und Gefäßchirurgie (Direktor Prof. Dr. Dipl.-Phys. Friedrich Schöndube) und der Poliklinik für Präventive Zahnmedizin, Parodontologie und Kariologie im Zentrum Zahn-, Mund-, und Kieferheilkunde der Medizinischen Fakultät der Universität Göttingen. Die Ethikkommission der Medizinischen Fakultät der Georg-August-Universität Göttingen genehmigte die Studie unter dem Namen „Klinisch-experimentelle Studie zur möglichen Assoziation parodontaler Gesundheit und verschiedenen Herzerkrankungen" mit der Nummer 6/2/09. Die Patienten wurden mündlich und schriftlich über die Studie aufgeklärt und gaben schriftlich ihr Einverständnis zur Teilnahme. Sie wurden während ihres Aufenthaltes im Universitätsklinikum auf den Stationen der Thorax-, Herz- und GefäßChirurgie 2011, 2012 und 2013 im Bettenhaus 1, 2. Ebene im Zimmer untersucht. Dies geschah zwischen dem 10.05.2009 und dem 13.10.2009.

\subsection{Patienten}

Alle Patienten dieser Pilotstudie waren Patienten der Klinik für Thorax-, Herz- und Gefäß-Chirurgie des Universitätsklinikums Göttingen, bei denen zwischen dem 10.05.2009 und dem 13.10.2009 ein chirurgischer Eingriff an der Aortenklappe aufgrund einer Aortenklappenstenose vorgenommen wurde. Die teilnehmenden Patienten wurden in einem Zeitraum von einem bis zu sieben Tagen postoperativ auf der Station der Thorax-Herz-Gefäß-Chirurgie im Universitätsklinikum Göttingen zahnärztlich untersucht. Gemäß den Richtlinien der American Heart Association (Wilson et al. 2007) erfolgte bei allen Patienten zur Endokarditisprophylaxe eine einmalige Gabe von $2 \mathrm{~g}$ Amoxicillin oder, bei bestehender Penicillinallergie, 600mg Clindamycin eine Stunde vor Untersuchungsbeginn. In die Pilotstudie wurden zehn Patienten zwischen 38 und 80 Jahren aufgenommen.

Folgende Einschlusskriterien wurden festgelegt:

- anstehender Aortenklappenersatz aufgrund einer Aortenklappenstenose

- älter als 35 Jahre

- mindestens sechs Restzähne 
Ausschlusskriterien waren:

- Zahnlosigkeit

- Z.n. Myokardinfarkt

- Apoplex innerhalb der letzten 6 Monate

- Patient unter Immunsuppression (z.B. nach Organtransplantation)

- Niereninsuffizienz

- Anfalls- bzw. Nervenleiden

- suchtkranker Patient

- Hepatitis A, B, C, TBC oder HIV

- nicht durchführbare orale Untersuchung

- Tod vor oraler Untersuchung

- Parodontalbehandlung (Scaling-Root-Planing) innerhalb der letzten 6 Monate vor der Untersuchung

- Antibiotikatherapie innerhalb der letzten 3 Monate vor Untersuchung

\subsection{Allgemeine Datenerfassung}

Aus den Akten der behandelnden Chirurgen wurden folgende anamnestische Daten gewonnen:

- OP-Indikation

- Proben-Entnahmestelle (OP-Bericht)

- aktuelle Laborwerte (CRP)

- Art und Dauer sowie bisherige Therapie der Herzerkrankung

- Allgemeinerkrankungen

- Medikamentenstatus

- Rauchverhalten (Raucher, Nichtraucher, ehemaliger Raucher)

\subsection{Klinische Untersuchung}

Für die Untersuchung eines Patienten war ein Zeitraum von 20 Minuten vorgesehen. Den Patienten entstanden aus der Untersuchung keine Risiken oder zusätzliche Kosten. Die zahnmedizinische Untersuchung umfasste der Reihenfolge nach folgende Parameter:

- Kariesindex (DMF-T)

- Parodontalstatus

- Papillen-Blutungs-Index (PBI) als Entzündungsindex

- Mikrobielle und molekularbiologische Probenentnahme

Nachfolgend werden die einzelnen Entzündungsparameter ausführlich beschrieben. 


\subsubsection{Kariesindex (DMF-T)}

Der DMF-T-Index wird zur Messung der Kariesinzidenz und -prävalenz angewandt. Er wird an allen bleibenden Zähnen - außer den Weisheitszähnen - erhoben. Er stellt die Summe der kariösen (decayed), extrahierten/fehlenden (missing) und mit Füllungen versorgten Zähne (filled) pro Gebiss dar. Die Beurteilung bezieht sich auf den Zahn als Ganzes (tooth). Daraus ergibt sich eine maximale Zahnanzahl von 28. Der DMF-T wird zur erhöhten und differenzierten Aussagekraft in DT, MT und FT gesplittet (Gaengler et al. 1988).

\subsubsection{Parodontalstatus}

Zur Beurteilung der parodontalen Situation wurde der Parodontalstatus ausschließlich mit Hilfe klinischer Parameter erhoben. Für die Studie wurden keine Röntgenaufnahmen angefertigt. Der Parodontalstatus gibt Auskunft über den Zustand der Parodontien. Folgende Einzelbefunde wurden ermittelt (s. Anhang):

I. fehlende Zähne

II. Messung der Sondierungstiefen an sechs Messstellen (distal-bukkal, zentral-bukkal, mesial-bukkal, mesial-oral, zentral-oral, distal-oral) je Zahn (PCP 15, Hu-Friedy, Chicago, US) sowie des max. klinischen Attachmentverlustes (CAL) je Zahn

III. Sondierungsbluten (BOP = bleeding on probing):

Ja/Nein- Entscheidung zum Vorhandensein einer Blutung nach Sondierung.

Anhand dieser Untersuchungsergebnisse wurde der Schweregrad einer möglichen Parodontitis mit den von Page und Eke (2007) vorgeschlagenen Parodontitisdefinitionen ermittelt. Von besonderer Bedeutung sind dabei der Attachmentverlust (CAL) und die Sondierungstiefe (TT). Es werden drei Formen der Parodontitis unterschieden (Tab. 1). 


\begin{tabular}{|c|c|c|c|}
\hline \multirow{2}{*}{$\begin{array}{c}\text { Schweregrad } \\
\text { der } \\
\text { Parodontitis }\end{array}$} & \multicolumn{3}{|c|}{ Klinische Definition } \\
\hline & CAL & & TT \\
\hline Schwer & $\begin{array}{c}\geq 2 \text { approximale Messstellen } \\
\text { mit CAL } \geq 6 \mathrm{~mm} \\
\text { (nicht am selben } Z \text { ahn) }\end{array}$ & und & $\begin{array}{c}\geq 1 \text { approximale Messstellen mit } \\
\mathrm{TT} \geq 5 \mathrm{~mm}\end{array}$ \\
\hline Moderat & $\begin{array}{c}\geq 2 \text { approximale Messstellen } \\
\text { mit } C A L \geq 4 \mathrm{~mm} \\
\text { (nicht am selben } Z \text { ahn) }\end{array}$ & oder & $\begin{array}{c}\geq 2 \text { approximale Messstellen mit } \\
\mathrm{TT} \geq 5 \mathrm{~mm} \\
\text { (nicht am selben Zahn) }\end{array}$ \\
\hline $\begin{array}{l}\text { Keine oder } \\
\text { leichte Form }\end{array}$ & \multicolumn{3}{|c|}{ weder "moderate" noch "schwere" Parodontitis } \\
\hline
\end{tabular}

Tabelle 1 Einteilung der Parodontitis nach Schweregrad (Page und Eke 2007)

\subsubsection{Papillen-Blutungs-Index (PBI)}

Der Papillen-Blutungs-Index wird zur Beurteilung des Entzündungsgrades der Gingiva herangezogen. Der Entzündungsgrad der Gingiva korreliert neben dem Auftreten von Schwellungen und Rötungen vor allem mit der Blutungsneigung der Gingiva nach stumpfem Sondieren mit einer Parodontalsonde (PCP 15, Hu-Friedy, Chicago, US). Hierzu wurde nach vorsichtigem Ausstreichen des Sulkus im Winkel von $45^{\circ}$ mit einer stumpfen Parodontalsonde (PCP 15, Hu-Friedy, Chicago, US) die nach 20 Sekunden auftretende Blutung im Papillenbereich bewertet. Im ersten und dritten Quadranten erfolgt die Bewertung oral, im zweiten und vierten Quadranten vestibulär. Folgende Bewertungen werden unterschieden (Lange et al. 1977):

Grad 0: $\quad$ keine Blutung

Grad 1: Auftreten eines Blutungspunktes

Grad 2: $\quad$ Auftreten mehrerer Blutungspunkte oder einer Blutungslinie

Grad 3: Ausfüllen eines interdentalen Dreiecks mit Blut

Grad 4: profuse Blutung nach Sondierung, das Blut fließt über den Zahn oder die Gingiva

\subsubsection{Mikrobiologische und molekularbiologische Probenentnahme}

Pro Patient wurde eine Poolprobe der mikrobiellen Taschenflora mittels steriler Papierspitzen der Firma Hain (Hain Lifescience, Nehren, Deutschland) entnommen. Diese sind in fertigen, sterilen Blisterpackungen mit jeweils sechs Papierspitzen der 
ISO-Größe 20 erhältlich und Bestandteil des micro-IDent bzw. micro-IDent plus Tests (Hain Lifescience, Nehren, Deutschland).

Die Papierspitzen wurden mit einer sterilen Pinzette bis zum Taschenboden der tiefsten Taschen eingeführt und dort für zehn Sekunden belassen. Hochakute Taschen mit Entleerung von Pus wurden dabei gemieden. Um eine Verfälschung der mikrobiologischen Flora zu verhindern, wurde die supragingivale Plaque und vorhandene Nahrungsreste entfernt sowie der Entnahmeort mit Wattepellets trockengelegt. Des weiteren sollte der Patient 30 Minuten vor der Probenentnahme nichts gegessen haben.

Pro Patient wurden zwei bis vier Papierspitzen eingesetzt und danach in einem nummerierten E-Cup gepoolt aufbewahrt. Um einen Pilzbefall oder eine Vermehrung der Flora im feuchten Milieu zu verhindern, wurden die Papierspitzen im E-Cup 24 Stunden getrocknet. Bis zur DNA-Isolierung wurden die Proben bei Raumtemperatur kurzeitig (bis zu max. sieben Tagen) aufbewahrt.

Darüber hinaus wurden Speichelproben in Form eines Wangenabstriches mit sterilen Wattestäbchen der Firma Hain (Hain Lifescience, Nehren, Deutschland) zur Bestimmung des IL1-Gen-Polymorphismus entnommen.

\subsection{Probengewinnung Herzgewebe und Blut}

Gewebe aus Herz-Atrium, Ventrikel und Klappengewebe wurde im Rahmen einer Herzoperation bei Aortenklappenstenose gewonnen. Dem Patienten wurde dafür kein zusätzliches Herzgewebe entnommen, sondern nur das ohnehin durch den Eingriff anfallende Gewebe verwendet. Gleichzeitig konnte das standardmäßig während der Operation gewonnene und nicht benötigte Blut für die Studie gesichert werden. Sowohl die Herzproben (Atrium/Ventrikel/Klappe) als auch das Blut wurde zur molekular- und mikrobiologischen Untersuchung an die Studiengruppe weitergegeben. Die Gewebeproben wurden abhängig von der Entnahmestelle gruppenweise (Atrium, Ventrikel, Klappe) bei $-80^{\circ} \mathrm{C}$ im Gefrierschrank gelagert.

\subsection{Laboruntersuchung}

\subsubsection{Aufbereitung der Proben}

\subsubsection{Aufbereitung der Herzgewebeproben}

Die Proteine wurden mit Hilfe von Lysispuffer (Tab. 2 + Tab. 3) aus dem Gewebe herausgelöst. Die in Tab. 2 angegebenen Substanzen wurden für $100 \mathrm{ml}$ Lysispuffer angemischt und bei $4^{\circ} \mathrm{C}$ gelagert. Für jede Messung wurde die benötigte Menge 
Lysispuffer entnommen und mit der entsprechenden Menge (Zugabe zu $1 \mathrm{ml}$ Lysispuffer) der Substanzen aus Tab. 3 aktiviert.

\begin{tabular}{|l|l|l|}
\hline & & Konzentration in $100 \mathrm{ml}$ \\
\hline TRIS & $0,242 \mathrm{~g}$ & $20 \mathrm{mM}$ \\
\hline $\mathrm{NaCL}$ & $0,292 \mathrm{~g}$ & $50 \mathrm{mM}$ \\
\hline $\mathrm{NaF}$ & $0,209 \mathrm{~g}$ & $50 \mathrm{mM}$ \\
\hline $\mathrm{Na}-$ Pyrophosphat & $0,223 \mathrm{~g}$ & $5 \mathrm{mM}$ \\
\hline Sucrose & $8,557 \mathrm{~g}$ & $0,25 \mathrm{mM}$ \\
\hline ad $100 \mathrm{ml}$ Aqua Bidest - $\mathrm{pH} 7,4$ & & \\
\hline
\end{tabular}

Tabelle 2 Lysispuffer/Homogenisationspuffer - für $100 \mathrm{ml}$

\begin{tabular}{|l|l|l|}
\hline & & Konzentration in $1 \mathrm{ml}$ \\
\hline Triton X-100 (gebr.fertig) & $10 \mu \mathrm{l}$ & $1 \%$ \\
\hline DTT $(100 \mathrm{mM})$ & $10 \mu \mathrm{l}$ & $1 \mathrm{mM}$ \\
\hline Protease Inhibitor Cocktail & $1 \mu \mathrm{l}$ & $1: 1000$ \\
\hline
\end{tabular}

Tabelle 3 Zugabe zu $1 \mathrm{ml}$ Lysispuffer

Die Herzproben wurden in einen Mörser mit $\mathrm{N}_{2}$ gegeben und mit Hilfe eines Stößels homogenisiert. Das Homogenat wurde je nach Gewebemenge in E-Cups mit 500 bis $1000 \mu \mathrm{l}$ Lysispuffer überführt und anschließend für 10 Minuten bei 3000 upm zentrifugiert (Zentrifuge auf $4^{\circ} \mathrm{C}$ gekühlt). Der Überstand wurde abpipettiert und in neue E-Cups überführt. Bei sehr geringen Mengen wurden diese noch in der Vakuumzentrifuge eingeengt. Danach wurden die Proben bei $-18^{\circ} \mathrm{C}$ eingefroren und gelagert.

Zur Gewinnung der RNA- und DNA-Phase wurden die Proben mit TriFast (Peqlab, Erlangen, Deutschland) aufbereitet und mit dem RNeasy-Mini Kit und dem DNA Mini Kit (Qiagen, Hilden, Deutschland) isoliert.

\subsubsection{Aufbereitung der oralen Proben}

Zunächst musste die DNA aus den bei Raumtemperatur (RT) getrockneten Papierspitzen aufbereitet werden. Dies erfolgte in einem DNA freien Raum mit Mithilfe des Geno Type DNA Isolation Kit (Hain Lifescience, Nehren, Deutschland). Gemäß der beiliegenden Arbeitsanleitung wurde folgendermaßen vorgegangen:

1. Pro Probe $100 \mu$ l Lysispuffer und $10 \mu$ Proteinase $\mathrm{K}$ in ein Gefäß geben und vermischen; 
2. $110 \mu \mathrm{l}$ der oben gewonnenen Mischung in jedes E-Cup mit Papierspitze geben und für $10 \mathrm{~s}$ vermischen;

3. Inkubation bei $70^{\circ} \mathrm{C}$ im Thermomixer für $10 \mathrm{~min}$;

4. je Probe $100 \mu$ l Bindungspuffer B6 hinzugeben und durch mehrmaliges Auf- und Abpipettieren vermengen; die Filtersäule in ein beschriftetes 2,0 $\mathrm{ml}$ E-Cup geben und das Lysat auf den Filter pipettieren;

5. den Deckel verschließen und das Gefäß in einer Tischzentrifuge $1 \mathrm{~min}$ bei $13.000 \mathrm{G}$ zentrifugieren;

6. $300 \mu \mathrm{l}$ Waschpuffer I anschließend auf die Membran der Filtersäule geben und erneut für $30 \mathrm{~s}$ bei $13.000 \mathrm{G}$ zentrifugieren;

7. E-Cup mit dem Filtrat nun verwerfen;

8. Filtersäule in ein neues, beschriftetes $2,0 \mathrm{ml}$ E-Cup geben;

9. $750 \mu \mathrm{l}$ Waschpuffer II auf die Membran der Filtersäule geben und erneut für $30 \mathrm{~s}$ bei $13.000 \mathrm{G}$ zentrifugieren;

10. Filtrat ein weiteres Mal verwerfen;

11. Filtersäule in das E-Cup geben und 2 min bei $13.000 \mathrm{G}$ zentrifugieren;

12. E-Cup mit dem Filtrat verwerfen;

13. Filtersäule in ein neues, beschriftetes $1,5 \mathrm{ml}$ Auffanggefäß überführen; Bei 1-2 Papierspitzen $200 \mu \mathrm{l}$, bei 3-4 Papierspitzen $400 \mu$ l Elutionspuffer auf die Membran der Filtersäule geben;

14. 1 min Inkubation bei RT;

15. 1 min Zentrifugieren bei $6.000 \mathrm{G}$;

16. Filtersäule verwerfen;

17. DNA Eluat bei $-20^{\circ} \mathrm{C}$ lagern.

\subsubsection{Aufbereitung der Blutproben}

Die Isolierung der DNA aus den Blutproben erfolgte mit Hilfe des QIAamp DNA Mini Kits (Qiagen, Hilden, Deutschland) gemäß der mitgelieferten Arbeitsanleitung:

1. $20 \mu \mathrm{l}$ Proteinase $\mathrm{K}$ zu jedem Proben-Cup pipettieren und mischen;

2. $200 \mu \mathrm{l}$ AL-Puffer zugeben und $15 \mathrm{~s}$ mischen;

3. $10 \mathrm{~min}$ bei $56^{\circ} \mathrm{C}$ inkubieren;

4. $5 \mathrm{~s}$ anzentrifugieren;

5. $200 \mu \mathrm{l}$ Ethanol (100\%) zugeben, mischen und $5 \mathrm{~s}$ bei $8.000 \mathrm{upm}$ anzentrifugieren;

6. Inhalt des Cups auf eine Spinnsäule mit Collectiontube geben und Säule mit Deckel verschließen und 1 min bei 8.000 upm zentrifugieren. 
7. Filtrat wird verworfen;

8. Spinnsäule auf neues Collectiontube setzen;

9. $500 \mu \mathrm{l} \mathrm{AW} 1$ Puffer auf die Membran geben und $1 \mathrm{~min}$ bei 8.000 upm zentrifugieren;

10. Filtrat erneut verwerden;

11. Spinnsäule auf neues Collectiontube setzen;

12. $500 \mu \mathrm{l}$ AW 2 Puffer auf die Membran geben und 3 min bei 13.000 upm zentrifugieren;

13. Filtrat erneut verwerfen;

14. Spinnsäule auf neues Collectiontube setzen;

15. $50 \mu \mathrm{l}$ AE-Puffer mittig auf die Membran der Spinnsäule geben;

16. 1 min Inkubation bei RT;

17. 1 min Zentrifugieren bei 8000 upm;

18. Spinnsäule verwerfen;

19. DNA-Eluat bei $-20^{\circ} \mathrm{C}$ lagern.

\subsubsection{Mikrobiologische Analyse der DNA-Proben durch Polymerase- Kettenreaktion (PCR)}

\subsubsection{Markerkeimanalytik}

Die Markerkeimanalytik diente dem Nachweis von elf parodontophatogenen Bakterien:

- Aggregatibacter actinomycetemcomitans (Aac)

- Porphyromonas gingivalis $(\mathrm{Pg})$

- Tanerella forsythia (Tf)

- Treponema denticola $(T d)$

- Prevotella intermedia (Pi)

- Peptostreptococcus micros (Pm)

- Fusobacterium nucleatum (Fn)

- Campylobacter rectus (Cr)

- Eubacterium nodatum (En)

- Eikanella corrodens (EC)

- Capnocytophaga spec (Cs)

Hierfür kam ein molekularbiologisches Nachweisverfahren, die PolymeraseKettenreaktion (PCR), zum Einsatz, welches eine zügige und hoch sensitive Vermehrung der DNA-Moleküle und anschließende Auswertung ermöglicht. Für diese 
Studie wurde das semiquantitative Testverfahren micro-IDent plus der Fa. Hain Lifescience (Hain Lifesience, Nehren, Deutschland) verwendet. Es beruht auf der DNA-Strip-Technologie und wird mit dem dafür vorgesehenen Versuchsprotokoll durchgeführt. Folgende Arbeitsschritte wurden für alle drei Kompartimente der Herzproben (Atrium, Ventrikel, Klappe) und der gepoolten oralen Sulkusproben durchgeführt:

1. Herstellung des Amplifikationsmix aus folgenden Substanzen:

\begin{tabular}{|l|l|}
\hline Primer-/Nukleotid-Mix & $17,5 \mu \mathrm{l}$ \\
\hline Polymerase-Puffer & $2,5 \mu \mathrm{l}$ \\
\hline $\mathrm{MgCl}_{2}$-Lösung & $2,5 \mu \mathrm{l}$ \\
\hline taq-Polymerase & 1 Unit \\
\hline
\end{tabular}

2. Je 2,5 $\mu$ l DNA-Lösung des Amplifikationsmix in ein Reaktionsgefäß pipettieren und auf einem Thermocycler mit folgendem Protokoll amplifizieren:

\begin{tabular}{|c|c|c|}
\hline Zeit & Temperatur in ${ }^{\circ} \mathbf{C}$ & Zyklen \\
\hline $5 \mathrm{~min}$ & 95 & 1 \\
\hline $30 \mathrm{~s}$ & 95 & \multirow{2}{*}{10} \\
\hline $2 \min$ & 58 & \\
\hline $25 \mathrm{~s}$ & 95 & \multirow{3}{*}{$\begin{array}{l}20 \text { (für orale Proben) } \\
25 \text { (für Herzgewebe) }\end{array}$} \\
\hline $40 \mathrm{~s}$ & 53 & \\
\hline $40 \mathrm{~s}$ & 70 & \\
\hline $8 \mathrm{~min}$ & 70 & 1 \\
\hline
\end{tabular}

3. Reverse Hybridisierung mit dem Hybridisierungspuffer und der StringentWaschlösung in einem $45^{\circ} \mathrm{C}$ vorgewärmten Wasserbad;

4. Ansatz der Konjugatlösung ( $10 \mu \mathrm{l} \mathrm{CON-C}+1 \mathrm{ml} C O N-D / P r o b e)$ und Substratlösung (10 $\mu$ l SUB-C + $1 \mathrm{ml}$ SUB-D/ Probe);

5. Denaturierung: Jedes micro-IDent plus Testkit (Hain Lifesience, Nehren, Deutschland) enthält eine spezielle Probenwanne mit 12 Kavitäten; in jede Wan- 
nenkavität wird $20 \mu$ l Denaturierungsreagenz und $20 \mu \mathrm{l}$ des Amplifikats hinzugegeben, vermengt und 5 min bei RT inkubiert;

6. je Wannenkavität wird $1 \mathrm{ml}$ des vorgewärmten Hybridisierungspuffer zugegeben und ein mit Bleistift nummerierter Teststreifen eingelegt. Die Probenwanne wird nun in einem Schüttelwasserbad (TwinCubator, Hain Lifesience, 72147 Nehren, Deutschland) bei $45^{\circ} \mathrm{C}$ inkubiert und der Hybridisierungspuffer nach 30 min wieder vollständig entfernt;

7. je Wannenkaität wird $1 \mathrm{ml}$ der vorgewärmten Stringent-Waschlösung zugegeben und $15 \mathrm{~min}$ auf dem TwinCubator bei $45^{\circ} \mathrm{C}$ inkubiert;

8. die Stringent-Waschlösung wird anschließend vollständig entfernt und Flüssigkeitsreste auf saugfähigem Papier abgeklopft;

die weiteren Schritte erfolgen auf dem TwinCubator bei RT:

9. die Membranstreifen werden nun 1 min mit $1 \mathrm{ml}$ Rinse-Lösung gewaschen und danach wieder getrocknet;

10. zu jedem Teststreifen wird $1 \mathrm{ml}$ verdünntes Konjugat gegeben und $30 \mathrm{~min}$ inkubiert;

11. die Lösungen werden wieder entfernt und die Membranstreifen $2 \times 1$ min mit destilliertem Wasser gewaschen;

12. nach dem letzten Schritt werden die Membranstreifen durch vorsichtiges Abklopfen auf einem saugfähigem Papier gut getrocknet;

13. zu jedem Membranstreifen wird $1 \mathrm{ml}$ verdünntes Substrat gegeben und bei RT inkubiert;

14. um die Substratreaktion zu stoppen, wird 2 mal mit destilliertem Wasser gewaschen;

15. schließlich werden die Membranteststreifen mit einer Pinzette aus der Kavität genommen, getrocknet und anschließend auf den Auswertungsbögen fixiert.

Die Auswertung des Bandenmusters erfolgte visuell mithilfe einer Schablone. Anhand der Intensität der Farbaufnahme erfolgte der qualitative Nachweis eines Bakteriums (Färbung einer Reaktionszone = Nachweis einer Bakterienart). Eine semiquantitative Bestimmung erfolgte durch die Beurteilung des Verdunkelungsgrads (Verfärbungsgrad $=$ Konzentration). Jedem Verdunkelungsgrad ist laut Hersteller eine bestimmte Nachweisgrenze zugewiesen, mit einem Scorewert der von 0-4 reicht (Tab. 4). 


\begin{tabular}{|c|c|c|}
\hline Score & Verdunkelungsgrad & Keimkonzentration \\
\hline 0 & - & $<10^{4}\left(\right.$ Sonderfall Aac: $\left.<10^{3}\right)$ \\
\hline 1 & $(+)$ & $=10^{4} \quad\left(\right.$ Sonderfall Aac: $\left.=10^{3}\right)$ \\
\hline 2 & + & $<10^{5}$ (Sonderfall Aac: $\left.<10^{4}\right)$ \\
\hline 3 & ++ & $<10^{6}$ (Sonderfall Aac: $\left.<10^{5}\right)$ \\
\hline 4 & +++ & $>10^{7} \quad\left(\right.$ Sonderfall Aac: $\left.>10^{6}\right)$ \\
\hline
\end{tabular}

Tabelle 4 Verfärbungsgrad der Membran mit entsprechender Keimkonzetration und Score

\subsubsection{Genetische Untersuchung des IL-1-Polymorphismus}

Aus dem Wangenabstrich erfolgte mittels Genotypisierung die molekulargenetische Charakterisierung eines möglichen Interleukin-1-Polymorphismus. Hierzu wurde mit einem kommerziell erhältlichen Test (GenoType PST plus- Test; Fa. Hain Lifescience $\mathrm{GmbH}$, Nehren, Deutschland) und dessen IL1-Polymorphismusspezifischen Gensonden der Nachweis der Polymorphismen: IL-1A -889 (Allel 1 (C): -C889, Allel 2 (T): -889T), IL-1B +3953 (Allel 1 (C): +C3953, Allel 2(T): +3953T) und IL-1RN (IL-1-Rezeptorantagonist) +2018 (Allel 1 (T): +T2018, Allel 2 (C): +2018C) des menschlichen Interleukin-Genklusters vorgenommen. Daraus kann man vier verschiedene Genotypen mit unterschiedlichem Risiko für eine Entzündungsreaktion bestimmen:

- Genotyp 1 (II-1A7B negativ, II-1-RN negativ): normale Entzündungreaktion, kein erhöhtes genetisches Risiko für progressive Parodontitis

- Genotyp 2 (II-1A7B positiv, II-1-RN negativ): erhöhte Entzündungsreaktion, erhöhtes genetisches Risiko für progressive Parodontitis

- Genotyp 3 (II-1A7B positiv, II-1-RN positiv): stark erhöhte Entzündungsreaktion, stark erhöhtes genetisches Risiko für progressive Parodontitis

- Genotyp 4 (II-1A7B negativ, II-1-RN positiv): verminderte genetische Entzündungshemmung

Die labortechnische Untersuchung verlief analog zu der oben genannten Methode des micro-IDent plus Kit (Hain Lifesience, Nehren, Deutschland). Die Mengen und Zeiten für Waschung und Inkubation variieren und wurden gemäß Herstellerangaben befolgt. 


\subsubsection{Proteinchemische Laboranalyse}

Zum Nachweis der pathogenen Wirkung von parodontopathogenen Bakterien am Herzen wurde sowohl das Herzgewebe als auch das Blut der Patienten auf LBP und den Herzinsuffizienzmarker proBNP NT untersucht. Hierfür wurden zwei unterschiedliche Verfahren gewählt. Zur Auftrennung der Proteine im Herzgewebe kam das Western Blot Verfahren zum Einsatz. Die Proteine werden hierfür gelöst, auf einer Membran fixiert und per Sodiumdodecylsulfat-Polyacrylamid-Gelelektrophorese (SDS-PAGE) nach Größe getrennt. Anschließend werden die Proteine auf eine Nitrocellulosemembran geblottet und durch eine Antikörper-AntikörperChemilumineszenz-Reaktion auf einem Röntgenfilm sichtbar gemacht. Bei den Blutproben wurde der Enzym-gekoppelte Immunoadsorptionstest (ELISA) im Sandwichverfahren angewandt, bei dem es sich ebenfalls um eine Antikörper-AntikörperChemilumineszenz-Reaktion handelt, die photometrisch ausgewertet wird.

Nachfolgend werden beide Methoden ausführlich besprochen.

\subsubsection{Western Blot - Nachweis von LBP und proBNP NT}

Bestimmung der Proteinkonzentration mittels Bicinchoninsäure (BCA):

Der verwendete BCA-Proteinassay Kit (Thermo Fisher Scientific, Waltham, USA) diente dem quantitativen Nachweis von Proteinen in Lösungen. Dem Verfahren liegt die sogenannte Biuret-Reaktion zugrunde, bei der in alkalischer Lösung Kupfer-(II)Ionen durch Proteine zu Kupfer-(I)-lonen reduziert werden. Nun kann Bicinchoninsäure mit dem einwertigen Kupfer reagieren und es kommt zu einem violetten Farbkomplex, der im Photometer bei 562 nm nachgewiesen wird. Die Stärke der Absorption steht in einem linearen Verhältnis zur Proteinkonzentration im Bereich von 5 $250 \mu \mathrm{g} / \mathrm{ml}$. Durch eine Standardreihe kann der Proteingehalt der Proben über eine Ausgleichsgerade ermittelt werden.

Bei der Ausführung wurde das folgende Protokoll des BCA Protein Assay Kits (Thermo Fisher Scientific, Waltham, USA) genau befolgt:

1. Je $10 \mu \mathrm{l}$ in Lysispuffer gelöste Probe wird mit jeweils $200 \mu \mathrm{l}$ BCA Reagenz $(A+B$ im Verhältnis $50+1)$ versetzt;

2. ebenfalls werden $10 \mu \mathrm{l}$ Blank mit $200 \mu \mathrm{l} B C A$ Reagenz (A+B im Verhältnis $50+1$ ) versetzt;

3. für die Standardreihe wird BCA mit Lysispuffer auf die Konzentrationen 5, 25, 50, 125 und $250 \mu \mathrm{g} / \mathrm{ml}$ verdünnt und analog zu den anderen Proben mit $200 \mu \mathrm{l} \mathrm{BCA} \mathrm{Reagenz} \mathrm{vermengt} \mathrm{und} \mathrm{in} \mathrm{Eppendorf} \mathrm{E-Cups} \mathrm{1,5} \mathrm{ml} \mathrm{(Eppendorf}$ AG, Hamburg, Deutschland) gegeben; 
4. alle E-Cups für 30 min bei $37^{\circ} \mathrm{C}$ im Eppendorf Thermostat (Eppendorf AG, Hamburg, Deutschland) inkubieren.

Der sichtbare Farbwechsel von grün zu violett zeigte die erfolgreiche Reaktion an. Mit einem Spectrophotometer (BioMate5, Thermo Spectronic, Dreieich, Deutschland) wurde die Proteinkonzentration in Eppendorf-Uvetten (Eppendorf AG, Hamburg, Deutschland) photometrisch ermittelt und in $\mu \mathrm{g} / \mu \mathrm{l}$ notiert.

Sodiumdodecylsulfat-Polyacrylamid-Gelelektrophorese (SDS-PAGE):

Zur Auftrennung der Proteine nach ihrem Molekulargewicht wurde die SDSGelelektrophorese nach Laemmli (1970) angewendet. Das SDS denaturiert die Proteine und überdeckt die Eigenladung der Proteine. Dadurch entstehen negativ geladene Komplexe mit einem konstanten Ladungs-Masse-Verhältnis. Durch Anlegen einer Spannung wandern diese dann vom negativen zum positiven Pol. Wichtig für eine saubere Auftrennung der Proteine ist die Abstimmung der PolyacrylamidKonzentration des Gels mit dem Molekulargewicht der gesuchten Proteine. Sowohl für LBP (Molekulargewicht $58 \mathrm{kDa}$ ) als auch für proBNP NT (Molekulargewicht 30 kDa) gilt eine Konzentration von $12 \%$ für das Trenngel und $4 \%$ für das Sammelgel als optimal. Der niedrige $\mathrm{pH}$-Wert des Sammelgels sorgt dafür, dass die Proben auf eine gemeinsame Lauffront zusammengezogen werden. Pro Tasche wurden $30 \mu \mathrm{l}$ Probenauftrag pipettiert. Dieser setzt sich aus $10 \mu \mathrm{l}$ Auftragspuffer und $20 \mu \mathrm{l}$ Probe und Ampuwa zusammen. Die Probenmenge beträgt dabei jeweils $25 \mu \mathrm{g}$. Als Auftragspuffer wurde Sampel-Reducing-Puffer und Mercaptoethanol in einem Verhältnis von 190:20 verwendet. Überstieg die nötige Probenmenge $20 \mu \mathrm{l}$, wurde die Probe in der Vakuumzentrifuge der Fa. Eppendorf (Hamburg, Deutschland) eingeengt. Nach dem Ansetzen wurden Puffer und Proben bei $97^{\circ} \mathrm{C}$ für 7 Minuten denaturiert und zusammen mit einem vorgefärbten Proteinstandard in die Taschen aufgetragen. In die Elektrophoresekammer wurde nun bei Zimmertemperatur 1x Laufpuffer gegeben. Zunächst wurden 100 Volt Spannung angelegt, bis die Lanes nach ca. 15 Minuten das Trenngel erreicht hatten. Schließlich erfolgte die Elektrophorese für ca. 100 Minuten bei 160 Volt.

\section{Proteintransfer (Western Blot):}

Nach Beendigung der Elektrophorese erfolgte die Übertragung der Informationen im Gel auf eine Nitrocellulosemembran. Hierfür wurde das Gel auf besagte Membran luftblasenfrei gelegt und zwischen Filterpads und Fiberpads in die Blotkassette eingespannt und in das Elektromodul geschoben. Das Ganze wurde nun in den Buffertank gesetzt und mit $4^{\circ} \mathrm{C}$ kühlem Blotpuffer aufgefüllt. Der Blot erfolgte für drei Stunden bei 200 mA unter ständiger Kühlung. 
Als nächster Schritt folgte das Färben der Membran mit Ponceau-Lösung. Dieser diente zur Kontrolle, ob Proteine auf die Membran geblottet wurden und ob sie durch in der Färbelösung enthaltene Trichloressigsäure fixiert wurden. Die folgenden Schritte erfolgten jeweils unter Schwenken bei 30 upm. Die Membran wurde mit Aqua Bidest und 1x TBS gewaschen, mit Starting Blocking Solution geblockt und wiederum, diesmal mit TTBS, gewaschen.

Immundetektion:

Es folgte die Inkubation des ersten Antikörpers über Nacht bei $+4^{\circ} \mathrm{C}$. Für LBP wurde der Antikörper „big42 antibody to human LBP“ (Biometec GmbH, Greifswald, Deutschland) und für proBNP NT der Antikörper „Anti-BNP antibody [EPR3735]“ (abcam, Cambridge, Vereinigtes Königreich) verwendet. Als House-keeping-Gen diente GAPDH. Am ersten Antikörper koppelte der zweite Antikörper goat anti mouse HRP (Thermo Fisher Scientific, Waltham, USA), der an HRP (horse radish peroxidase) gekoppelt war. Dieser wurde in einem Verhältnis von 1:25.000 verdünnt und am nächsten Morgen nach weiteren Waschvorgängen mit 1x TTBS auf die Membran gegeben. Nach zwei Stunden Inkubationszeit bei Raumtemperatur wurde diese wiederum mit $1 \times$ TTBS gewaschen.

\section{Chemolumineszenz:}

Schließlich erfolgte die Inkubation mit der Chemolumineszenz SuperSignal West Pico bzw. Femto Chemiluminescent Substrate der Firma Thermo Scientific. Die beiden Komponenten wurden im Verhältnis 1:1 in ein dunkles Gefäß gegeben und die Membran bei Raumtemperatur darin eingelegt. Nach fünf Minuten wurden die feuchten Nitrocellulose-Membranen in Klarsichtfolie gelegt und in eine Röntgenkassette gegeben. Es folgte die Belichtung der Fuji Photo Film - Röntgenfilme und die maschinelle Entwicklung. Diese wurden schließlich densitometrisch ausgewertet (Beispiel: Abb. 6). 


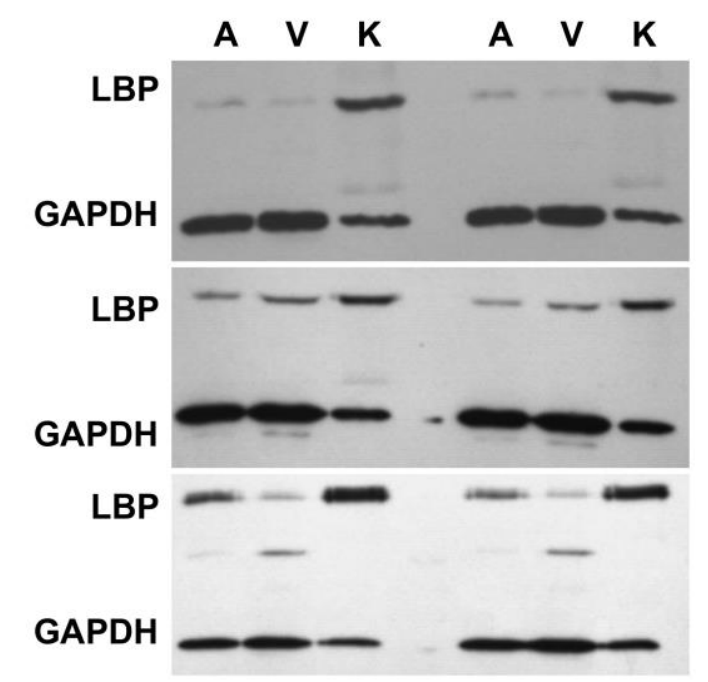

Abbildung 6 Entwickelter Röntgenfilm mit sichtbarem Bandenmuster von LBP und GAPDH (A: Atrium, V: Ventrikel, K: Klappe)

\subsubsection{Enzyme-linked immunosorbent assay ELISA}

Zusätzlich wurde das Serum mit dem enzyme-linked immunosorbent assay (ELISA) auf LBP und proBNP NT untersucht. Die Bestimmung von LBP erfolgte mit einem Test-Kit der Fa. biometec (LBP: Enzyme Immunoassay für Quantification of free human LBP, Fa. biometec, Greifswald, Germany). Das N-terminale pro BNP wurde mit Elecsys proBNP (Fa. Roche) bestimmt.

\subsubsection{Histologie und Immunhistochemie}

Anhand von histologischen Schnitten wurde ein Inflammation-Scoring (Score 0-3) mit Hilfe einer Hämatoxylin-Eosin-Färbung (HE) an den Präparaten von Atrium, Ventrikel und Klappe durchgeführt. Hierzu wurden aus den in Paraffin eingebetteten Gewebeproben Schnittserien von $1 \mu \mathrm{m}$ hergestellt.

Die immunhistochemische Analyse erfolgte nur für Atrium und Ventrikel, da eine immunhistochemische Aufbereitung für die Herzklappe aufgrund des Gewebezustandes nicht möglich war. Anhand von immunhistologischen Schnitten (1 $\mu \mathrm{m})$ erfolgte für Atrium und Ventrikel der immunhistochemische Nachweis ausgewählter Markern mit folgenden Antikörpern: Lipopolysaccharid-binding-protein (LBP:big42), LBP-Rezeptor (CD14) und Makrophagen (CD68). Hierzu wurden die PrimärAntikörper big42 (CML002, Fa. Leica Microsystems, Newcastle Upon Tyne, United Kingdom), CD14 (NCL-CD14-223, Fa. Leica Microsystems, Newcastle Upon Tyne, United Kingdom) und CD68 (M0876, Fa. DakoCytomation, Hamburg, Deutschland) bei $4^{\circ} \mathrm{C}$ inkubiert. Für CD14 erfolgte im Weiteren eine Behandlung mit Endvision und abschließende Inkubation mit Chromogen. Abschließend erfolgte eine Kernfärbung mit Hämalaun und die Dehydrierung in abgestuften Alkoholkonzentrationen $(96 \%, 100 \%)$ sowie in Xylol für alle drei Parameter. 
Die histologische und immunhistochemische Auswertung erfolgte unabhängig von zwei zuvor kalibrierten Untersuchern anhand erstellter hochauflösender Bilder der aufbereiteten Schnitte (Auflösung). Die H.-E. Färbung erfolgte wie in Tab. 5 dargestellt.

\begin{tabular}{|l|l|l|}
\hline Schritt & Arbeitsschritt & Zeit in min \\
\hline 1 & $3 \times$ Xylol & 3 \\
\hline 3 & $2 \times 100 \%$ Alkohol & 3 \\
\hline 4 & $\begin{array}{l}\text { absteigende Alkoholreihe: 96\%, 70\%, 50\%, 30\% und } \\
\text { Aqua Bidest }\end{array}$ & 3 \\
\hline 5 & $3 \times$ Hämalaun & 1,3 \\
\hline 6 & fließendes Leitungswasser & 8 \\
\hline 7 & $2 \times 1 \%$ iges Eosin & $2-3$ \\
\hline 8 & Aqua Bidest & ca. 0,5 \\
\hline 9 & $2 x 96 \%$ Alkohol & 3 \\
\hline 10 & $2 x 100 \%$ Alkohol & 3 \\
\hline 11 & $3 x$ Xylol & \\
\hline
\end{tabular}

Tabelle 5 Hämatoxilin-Eosin-Färbung

Nach der Erfassung des H.E.-Scores wurden die Objektträger mit der immunhistochemischen Färbemethodik angefärbt, die wie in Tab. 6 durchgeführt wurde.

\begin{tabular}{|c|c|c|c|}
\hline \multirow[t]{2}{*}{ Schritt } & \multicolumn{2}{|c|}{ Arbeitsschritt } & \multirow[t]{2}{*}{$\begin{array}{l}\text { Zeit } \\
\text { in } \min \end{array}$} \\
\hline & für CD68 & für CD14 & \\
\hline 1 & \multicolumn{2}{|c|}{ Entparaffinieren der OT mit 3x Xylol } & 3 \\
\hline 2 & \multicolumn{2}{|c|}{$\begin{array}{l}\text { Rehydrieren mit } 2 x \text { absteigender Alkoholreihe } 100 \%, 96 \% \text {, } \\
70 \%, 50 \% \text { und entionisiertem Wasser }\end{array}$} & 3 \\
\hline \multirow[t]{3}{*}{3} & \multicolumn{2}{|c|}{$\begin{array}{l}\text { Antigendemaskierung mit Target Retrieval Solution im Dampf- } \\
\text { garer }\end{array}$} & \\
\hline & ph9 & & 15 \\
\hline & & ph6 & 40 \\
\hline 4 & \multicolumn{2}{|c|}{ Küvette abkühlen lassen bei RT } & 20 \\
\hline 5 & \multicolumn{2}{|c|}{ OT $5 x$ waschen in $0,05 \mathrm{M} \mathrm{pH} \mathrm{7,6} \mathrm{Tris-Puffer}$} & 3 \\
\hline 6 & \multicolumn{2}{|c|}{ Blocken der endogenen Peroxidase mit 3\% Wasserstoffperoxid } & 17 \\
\hline
\end{tabular}




\begin{tabular}{|c|c|c|c|}
\hline Schritt & \multicolumn{2}{|l|}{ Arbeitsschritt } & $\begin{array}{l}\text { Zeit } \\
\text { in min }\end{array}$ \\
\hline & \multicolumn{2}{|l|}{ bei RT (feuchte Kammer) } & \\
\hline 7 & \multicolumn{2}{|c|}{ OT $5 x$ waschen in $0,05 \mathrm{M} \mathrm{pH} 7,6$ Tris-Puffer } & 3 \\
\hline 8 & \multicolumn{2}{|c|}{ OT mit AK-Diluent inkubieren bei RT (feuchte Kammer) } & 30 \\
\hline \multirow[t]{2}{*}{9} & \multicolumn{2}{|c|}{ OT mit Primä-AK im Kühlschrank inkubieren über Nacht } & \\
\hline & $\begin{array}{l}\text { CD68 (Primär-AK, M0876, } \\
\text { DakoCytomation) } \\
\text { in Verdünnung 1:200 }\end{array}$ & $\begin{array}{l}\text { CD14 (Primär-AK, NCL-CD14- } \\
\text { 223, Leica Biosystems) } \\
\text { in Verdünnung 1:100 }\end{array}$ & \\
\hline 10 & \multicolumn{2}{|c|}{ OT 7x waschen in 0,05M pH 7,6 Tris-Puffer } & 3 \\
\hline \multirow[t]{2}{*}{11} & \multicolumn{2}{|c|}{$\begin{array}{l}\text { Sekundär- AK aufgeben bei RT (feuchte Kammer) in Ver- } \\
\text { dünnung } \\
1: 100\end{array}$} & \multirow{2}{*}{30} \\
\hline & $\begin{array}{l}\text { Rabbit-anti-Mouse (Sekundär- } \\
\text { AK, P0260, DakoCytomation) }\end{array}$ & $\begin{array}{l}\text { Mouse-anti-Rabbit (Sekundär- } \\
\text { AK, M0633, DakoCytomation) }\end{array}$ & \\
\hline 12 & \multicolumn{2}{|c|}{ OT $7 x$ waschen in $0,05 \mathrm{M} \mathrm{pH} 7,6$ Tris-Puffer } & 3 \\
\hline 13 & & Envision auftropfen $100 \mu \mathrm{l}$ & 30 \\
\hline 14 & & $\begin{array}{l}\text { OT } 7 x \text { waschen in } 0,05 \mathrm{M} \mathrm{pH} \\
7,6 \text { Tris-Puffer }\end{array}$ & 3 \\
\hline 15 & \multicolumn{2}{|c|}{ Chromogen ansetzen $=1 \mathrm{Tr}$. DAB zu $1 \mathrm{ml}$ Substrat } & \\
\hline \multirow[t]{2}{*}{16} & $\begin{array}{l}\text { OT mit } 100 \mu \mathrm{l} \text { Chromogen in- } \\
\text { kubieren bei RT unter Kontrol- } \\
\text { le im LM }\end{array}$ & & 9 \\
\hline & & $\begin{array}{l}\text { OT mit } 100 \mu \mathrm{l} \text { Chromogen } \\
\text { inkubieren bei RT unter Kon- } \\
\text { trolle im LM }\end{array}$ & 1,5 \\
\hline 17 & \multicolumn{2}{|c|}{$\begin{array}{l}\text { Abbruch durch Spülen mit Aqua Bidest und Spülung ein 2. Mal } \\
\text { erneuern }\end{array}$} & 5 \\
\hline 18 & \multicolumn{2}{|l|}{ Kernfärbung mit Hämalaun } & 5 \\
\hline 19 & \multicolumn{2}{|c|}{ Differenzieren unter fließendem Wasser } & 8 \\
\hline 20 & \multicolumn{2}{|c|}{ Dehydrieren: 2x 96\%, 2x 100\% Alkohol, 3x Xylol } & 3 \\
\hline 21 & \multicolumn{2}{|c|}{ Eindecken mit Entellan und Lufttrocknung über Nacht } & \\
\hline
\end{tabular}

Tabelle 6 Immunhistochemische Färbung 
Für das HE-Inflammations-Scoring (Nachweis von Entzündungszellen) wurde ein in der Arbeitsgruppe etablierter Score verwendet (Schmitto et al. 2008). Zur immunhistochemischen Untersuchung von Atrium und Ventrikel auf die Parameter LBP, CD14 und CD68 wurde ein mit dem Inflammations-Scoring vergleichbarer Score (03) entwickelt. Abbildung 7 zeigt die entsprechenden Scores für den HEInflammations-Score sowie LBP (big42), CD14 und CD68 (Score 0-3).

Es folgte die Zählung der CD68- und CD14- exprimierenden Makrophagen pro Mikroskopie-Gesichtsfeld. Pro Schnitt wurden drei Einzelbilder in 25x Vergrößerung und pro Einzelbild wiederum dreimal in 100x Vergrößerung abgelichtet (Abb. 7). Pro Patient wurden bei insgesamt sieben Gewebeschnitten pro Färbung zwölf Aufnahmen angefertigt. Die Auswertung erfolgte mit Hilfe des Computerprogrammes Data Soft (Datasoft Software Consulting Inc., New York, USA) mit anschließender Hintergrundkorrektur und Weißabgleich. Bei jedem immunhistochemischen Färbedurchgang wurde auch eine Blindfärbung mit durchgeführt, um das Ergebnis zu verifizieren. Die Herzklappen konnten für das immunhistochemische Verfahren nicht aufbereitet werden und wurden somit nicht verwertet.

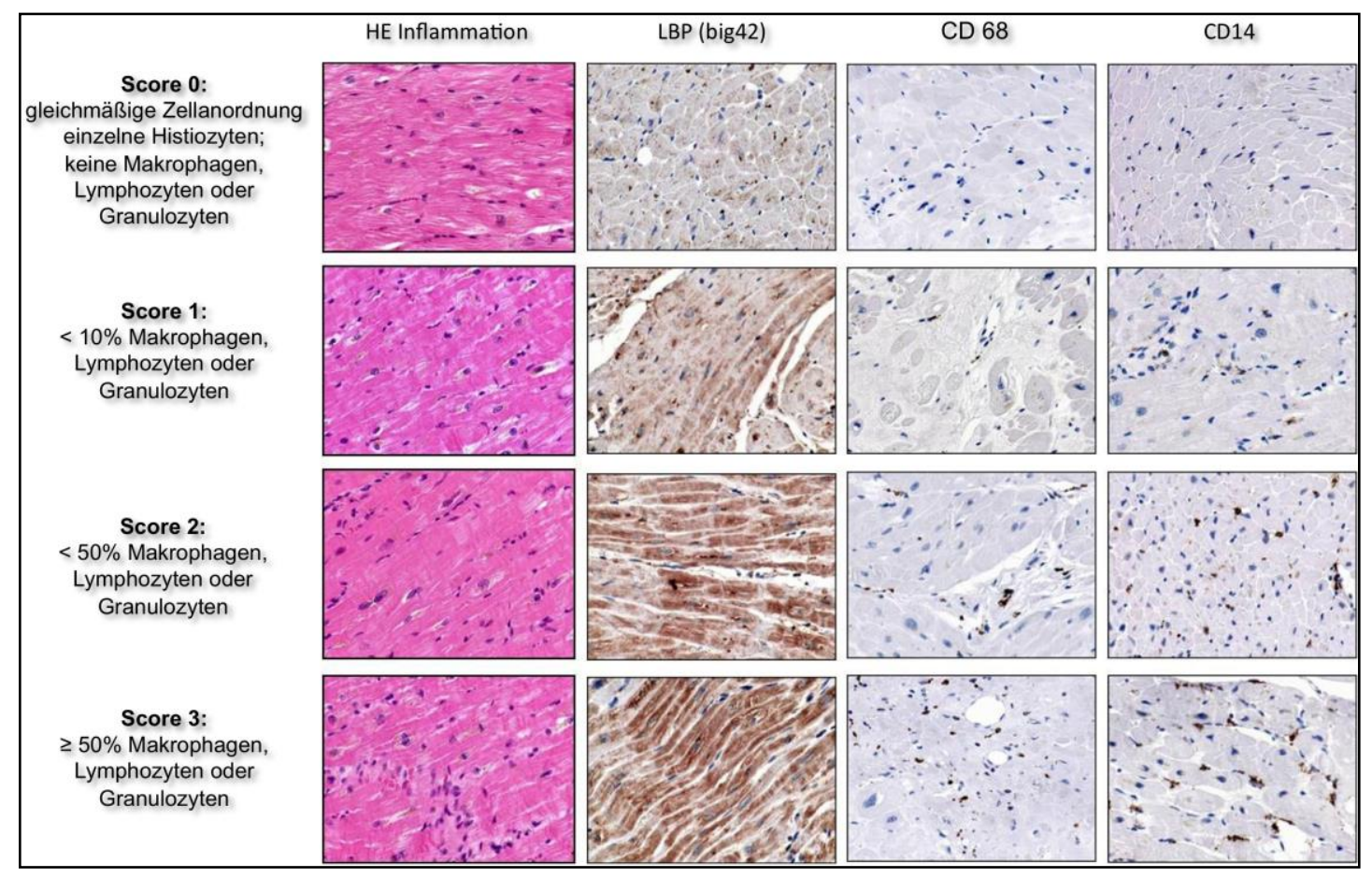

Abbildung 7 Scores für: HE-Inflammation, LBP (big42), CD14 und CD68 


\section{Ergebnisse}

\subsection{Patienten}

In die Untersuchung wurden zehn Patienten $(\mathrm{m}=6, \mathrm{w}=4)$ mit einem Durchschnittsalter von $68.9 \pm 12.1(38-80)$ Jahren einbezogen. Neun der zehn Patienten gaben an, innerhalb des letzen Jahres einen Zahnarzt aufgesucht zu haben. Bei fünf Patienten wurde eigenen Angaben zufolge in der Vergangenheit eine Parodontalbehandlung durchgeführt. Unter den Patienten waren sieben Nichtraucher und drei Raucher. Die Anzahl an Pack Years lag bei Letzteren im Median bei $20 \pm 1,73$ (17-20). Alle Patienten erhielten eine operative Versorgung mit einem Aortenklappenersatz; bei fünf Patienten wurde zusätzlich ein Aorto-Coronarer-Venen-Bypass durchgeführt. Als Grund für die Operation wurden verschiedene kardiale Erkrankungen genannt. Ein Patient zeigte eine koronare Herzerkrankung (KHK) mit Aortenklappeninsuffizienz. Bei einem Patienten wurde als Erkrankung ein Aortenvitium angegeben. Bei den weiteren 8 Patienten wurde eine Aortenklappenstenose in Verbindung mit weiteren kardialen Erkrankungen aufgeführt. Davon kamen am häufigsten vor: arterieller $\mathrm{Hy}$ pertonus ( $n=6)$, koronare Herzerkrankung $(n=4)$, Klappeninsuffizienz $(n=3)$, Vorhofflimmern ( $n=2)$. Wie in Abb. 8 dargestellt, zählten zu den weiteren kardialen Diagnosen instabile Angina Pectoris Symptomatik, Koronarsklerose, diastolische Dysfunktion, Zustand nach Infarkt, Herzrhythmusstörung und Mitralvitium. Diese wurden jeweils ein Mal angegeben.

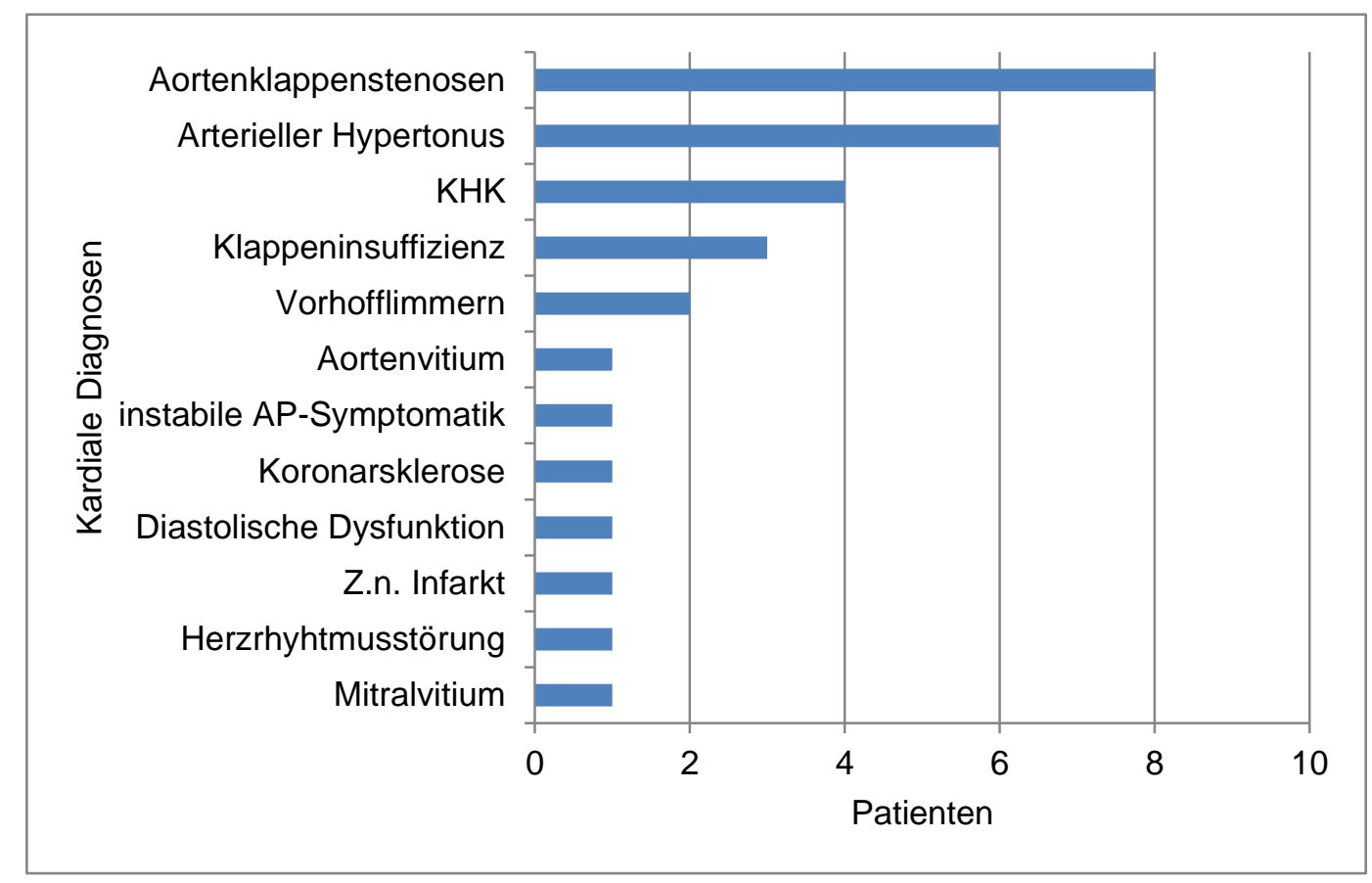

Abbildung 8 Kardiale Diagnosen.

(KHK: Koronare Herzerkrankung, sowohl 1- als auch 3-Gefäß-KHK, AP-Symptomatik: Angina Pectoris-Symptomatik) 
Als nicht primär kardiale Erkrankungen wurden Adipositas und Niereninsuffizienz bei jeweils zwei Patienten diagnostiziert. Weitere Erkrankungen wie Zustand nach Apoplex, rheumatische Arthritis, Diabetes mellitus, Epilepsie, Hyperlipoproteinämie, Hyperthyreose, kompensierte Niereninsuffizienz und Osteoporose, konnten einmal festgestellt werden.

Neun Patienten gaben an, regelmäßig Medikamente einzunehmen. Davon nahmen regelmäßig acht Patienten $\beta 1$-Adrenorezeptorenblocker, sechs Patienten Cholesterin-Synthese-Hemmer, fünf Patienten Antikoagulantien und jeweils vier Patienten ACE-Hemmer und Thrombozytenaggregationshemmer. Analgetika und Diuretika nahmen jeweils drei Patienten ein, Angiotensin II Antagonisten und Protonenpumpenblocker jeweils zwei Patienten. Weitere Medikamente, die jeweils einmal eingenommen wurden, waren Allopurinol, Antirheumatika, Corticosteroide und Schilddrüsenmedikamente (Abb. 9).

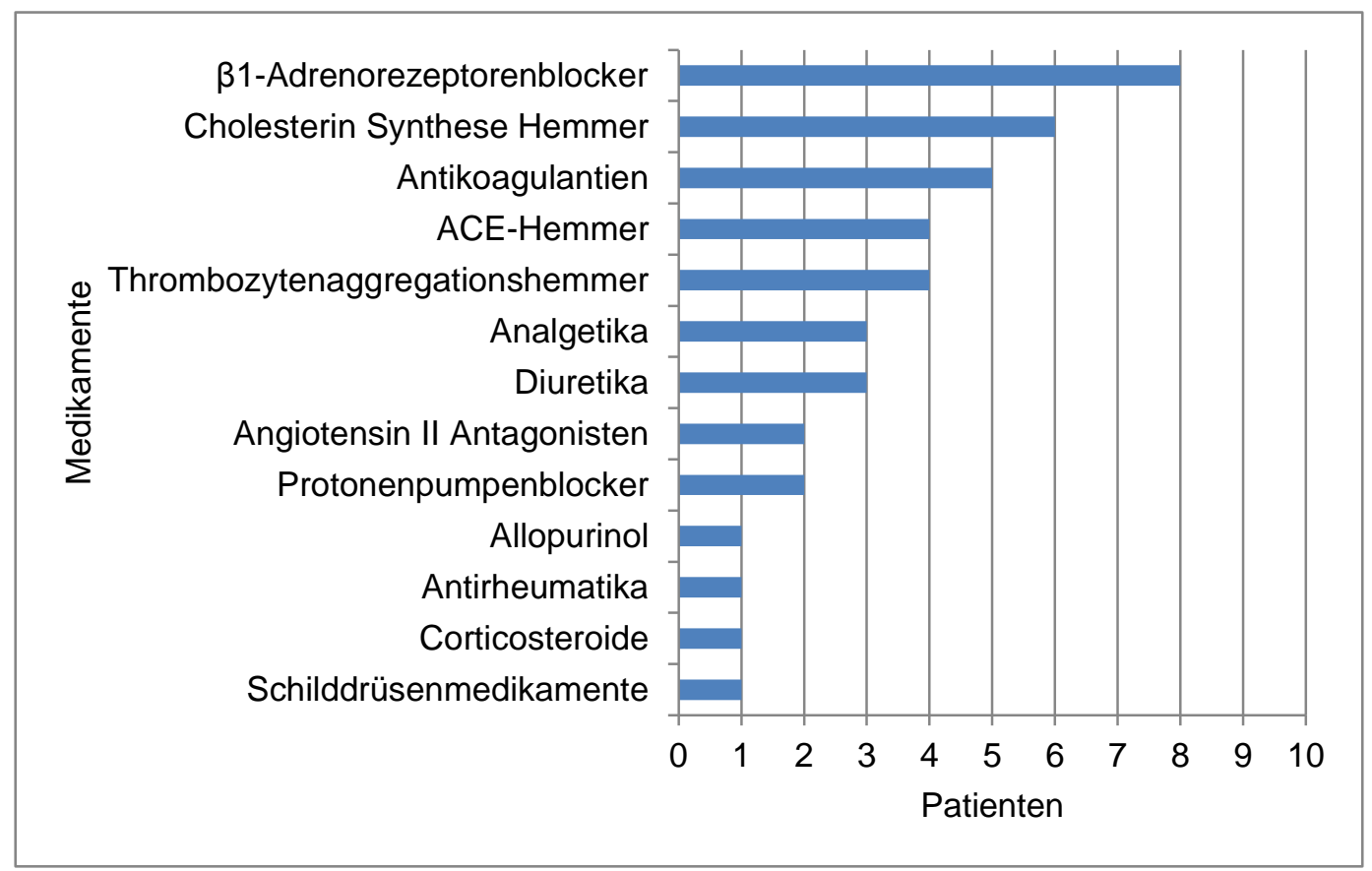

Abbildung 9 Eingenommene Medikamente

Die präoperativ gewonnenen Entzündungswerte im Blut zeigten bei den Teilnehmern einen deutlich erhöhten CRP-Wert von $138.50 \pm 76.58$ (4.20 - 247.60). Der Normwert für das Zentrallabor, Abteilung Klinische Chemie, Universitätsmedizin Göttingen liegt bei $\leq 8,0 \mathrm{mg} / \mathrm{l}$.

\subsection{Zahnärztliche Befunde}

Die Ergebnisse der zahnmedizinischen Untersuchung sind in Tabelle 7 einzeln für jeden Patienten aufgeführt. Der durchschnittliche DMF-T lag bei 23.0 \pm 4.0 ; dabei war 


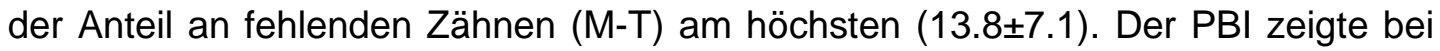
allen Patienten eine leichte gingivale Entzündung (Median=1). Laut dem erhobenen Parodontalstatus wiesen sieben Patienten eine ausgeprägte und zwei eine moderate Parodontitis auf. Ein Patient zeigte eine milde Parodontitis, jedoch bei einem Restzahnbestand von nur sechs Zähnen.

\begin{tabular}{|c|c|c|c|c|c|c|c|c|c|c|c|c|}
\hline \multirow{2}{*}{\multicolumn{2}{|c|}{$\begin{array}{l}\text { Mundgesundheitspa- } \\
\text { rameter }\end{array}$}} & \multicolumn{11}{|c|}{ Patienten } \\
\hline & & 1 & 2 & 3 & 4 & 5 & 6 & 7 & 8 & 9 & 10 & 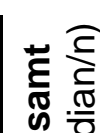 \\
\hline \multirow{4}{*}{ Zahnstatus } & DMF-T & 20 & 25 & 24 & 28 & 18 & 21 & 19 & 28 & 22 & 16 & 21,5 \\
\hline & D-T & 1 & 0 & 3 & 1 & 11 & 0 & 0 & 0 & 3 & 0 & 0,5 \\
\hline & M-T & 11 & 11 & 20 & 22 & 5 & 18 & 7 & 14 & 9 & 9 & 11,0 \\
\hline & F-T & 8 & 14 & 11 & 5 & 2 & 3 & 12 & 14 & 10 & 7 & 7,5 \\
\hline $\begin{array}{c}\text { Entzün- } \\
\text { dungsindex }\end{array}$ & PBI & 1 & 1 & 2 & 3 & 3 & 0 & 0 & 1 & 1 & 2 & 1 \\
\hline \multirow{3}{*}{$\begin{array}{l}\text { Parodontal- } \\
\text { status }\end{array}$} & $\begin{array}{c}\text { keine/ } \\
\text { milde } \\
\text { Parodon- } \\
\text { titis }\end{array}$ & & & & $X$ & & & & & & & 1 \\
\hline & $\begin{array}{c}\text { leichte } \\
\text { Paro- } \\
\text { dontitis }\end{array}$ & & $X$ & & & & & & & $x$ & & 2 \\
\hline & $\begin{array}{c}\text { schwere } \\
\text { Paro- } \\
\text { dontitis }\end{array}$ & $X$ & & $x$ & & $X$ & $X$ & $X$ & $x$ & & $x$ & 7 \\
\hline
\end{tabular}

Tabelle 7 Mundgesundheitsparameter: Zahnstatus, Entzündungsindex, Parodontalstatus. (DMF-T: Anzahl der zerstörten, fehlenden und gefüllten Zähne, D-T: zerstörte Zähne, M-T: fehlende Zähne, F-T: gefüllte Zähne, PBI: Papillen-Blutungs-Index, n: Anzahl, X=Diagnose des Parodontalstatus)

\subsection{Ergebnisse der mikrobiologischen Analyse der DNA-Proben}

\subsubsection{Markerkeimanalytik}

Bei allen oralen Proben der zehn Patienten (100\%) war DNA der untersuchten parodontopathogenen Bakterien in einem erheblichen Maße festzustellen (Abb. 10, Tab. 8). Dabei imponierte die stark erhöhte Anzahl von Bakterien des roten Komplexes $(P g, T f, T d)$. Die Prävalenz betrug $70-100 \%$. 


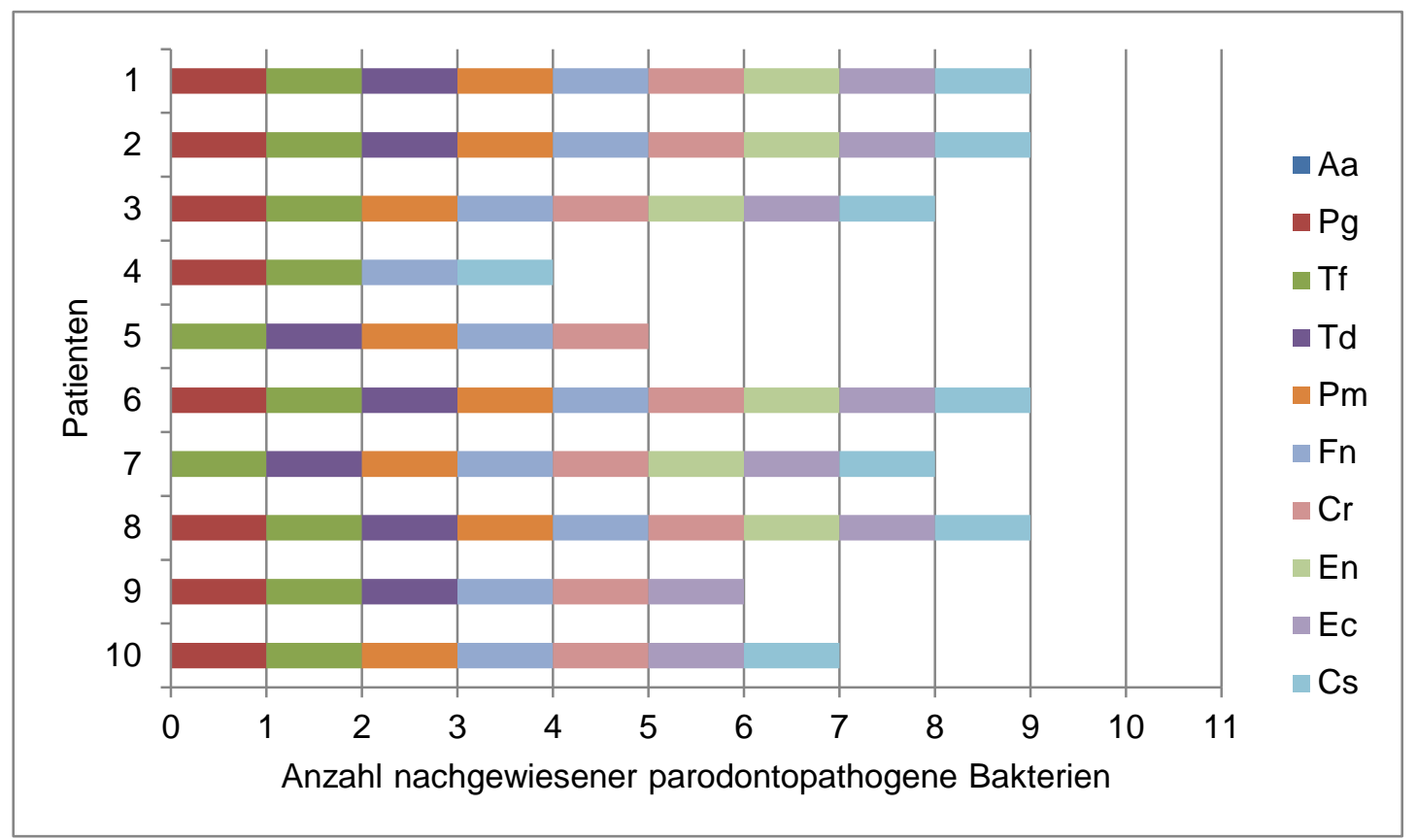

Abbildung 10 Am Herzgewebe nachgewiesene parodontopathogene Bakterien

In deutlich geringerer Prävalenz war ein Nachweis in den Herzgeweben detektierbar; davon konnte der Nachweis aller elf untersuchter Bakterien mit einer Prävalenz von $10-40 \%(\mathrm{~V}=\mathrm{K}=0-20 \%)$ am häufigsten im Atrium erbracht werden (Tab. 8).

\begin{tabular}{|c|c|c|c|c|}
\hline \multirow{2}{*}{$\begin{array}{c}\text { Parodonto- } \\
\text { pathogene }\end{array}$} & \multicolumn{4}{|c|}{$\begin{array}{c}\text { Prävalenz der mikrobiologischen Nachweise } \\
\text { (Anzahl der pos. Proben in \%) }\end{array}$} \\
\cline { 2 - 5 } & oral & Atrium & Ventrikel & Klappe \\
\hline Aa & 0 & 40 & 0 & 0 \\
\hline Pg & 80 & 40 & 0 & 0 \\
\hline Tf & 100 & 20 & 0 & 0 \\
\hline Td & 70 & 20 & 10 & 0 \\
\hline Pi & 70 & 20 & 20 & 0 \\
\hline Pm & 80 & 10 & 10 & 0 \\
\hline Fn & 100 & 10 & 10 & 20 \\
\hline Cr & 90 & 30 & 20 & 10 \\
\hline En & 60 & 20 & 10 & 0 \\
\hline Ec & 80 & 10 & 10 & 0 \\
\hline Cs & 80 & 10 & 10 & 0 \\
\hline
\end{tabular}

Tabelle 8 Prävalenz der nachgewiesenen parodontopathogenen Bakterien 
In den oralen Proben zeigte sich für alle Patienten eine ähnliche Verteilung der untersuchten Bakterien; in Atrium, Ventrikel und Klappe lag hingegen eine unterschiedliche, bzw. heterogene Verteilung vor (Tab. 9).

\begin{tabular}{|c|c|c|c|c|c|c|c|c|c|c|c|}
\hline \multirow{2}{*}{$\begin{array}{c}\text { Parodontopathogene } \\
\text { Bakterien }\end{array}$} & \multirow{2}{*}{$\begin{array}{l}\text { Entnahme- } \\
\text { stelle }\end{array}$} & \multicolumn{10}{|c|}{ Patient } \\
\hline & & 1 & 2 & 3 & 4 & 5 & 6 & 7 & 8 & 9 & 10 \\
\hline \multirow{4}{*}{$\mathrm{Aa}$} & oral & & & & & & & & & & \\
\hline & $A$ & & & & $X$ & & & $X$ & & $X$ & $\mathrm{X}$ \\
\hline & $\mathrm{V}$ & & & & & & & & & & \\
\hline & $\mathrm{K}$ & & & & & & & & & & \\
\hline \multirow{4}{*}{$\mathrm{Pg}$} & oral & $x$ & $X$ & $x$ & $X$ & & $x$ & & $X$ & $x$ & $x$ \\
\hline & $\bar{A}$ & & & & & $x$ & & $x$ & & $x$ & $x$ \\
\hline & $\mathrm{V}$ & & & & & & & & & & \\
\hline & $\mathrm{K}$ & & & & & & & & & & \\
\hline \multirow{4}{*}{ Tf } & oral & $x$ & $X$ & $X$ & $x$ & $X$ & $x$ & $X$ & $X$ & $X$ & $x$ \\
\hline & A & & & & & & & $X$ & & $X$ & \\
\hline & V & & & & & & & & & & \\
\hline & $\mathrm{K}$ & & & & & & & & & & \\
\hline \multirow{4}{*}{ Td } & oral & $x$ & $\mathrm{X}$ & & & $x$ & $x$ & $x$ & $x$ & $x$ & \\
\hline & $A$ & & & & & & & $x$ & & $X$ & \\
\hline & $\mathrm{V}$ & & & & & & & & & $x$ & \\
\hline & $\mathrm{K}$ & & & & & & & & & & \\
\hline \multirow{4}{*}{$\mathbf{P i}$} & oral & $x$ & $x$ & $x$ & & $X$ & $x$ & $x$ & & $x$ & \\
\hline & $A$ & & & & & & & $X$ & & $x$ & \\
\hline & $\mathrm{V}$ & & & & & $\mathrm{X}$ & & & & $X$ & \\
\hline & $\mathrm{K}$ & & & & & & & & & & \\
\hline \multirow{4}{*}{ Pm } & oral & $x$ & $\mathrm{X}$ & $x$ & & $x$ & $x$ & $\mathrm{X}$ & $X$ & & $\mathrm{x}$ \\
\hline & $A$ & & & $x$ & & & & & & & \\
\hline & V & & & $X$ & & & & & & & \\
\hline & $\mathrm{K}$ & & & & & & & & & & \\
\hline \multirow{4}{*}{ Fn } & oral & $X$ & $X$ & $X$ & $X$ & $\bar{X}$ & $X$ & $X$ & $X$ & $X$ & $x$ \\
\hline & $A$ & & & $x$ & & & & & & & \\
\hline & $\mathrm{V}$ & & & $x$ & & & & & & & \\
\hline & $\mathrm{K}$ & & & & & & & & & & \\
\hline \multirow{4}{*}{$\mathrm{Cr}$} & oral & $x$ & $X$ & $x$ & & $X$ & $x$ & $x$ & $x$ & $x$ & $X$ \\
\hline & $A$ & $x$ & & $\mathrm{X}$ & & & & & & $x$ & \\
\hline & V & $X$ & & $X$ & & & & & & & \\
\hline & $\mathrm{K}$ & $\mathrm{X}$ & & & & & & & $x$ & & \\
\hline \multirow{4}{*}{ En } & oral & $x$ & $\mathrm{X}$ & $x$ & & & $x$ & $X$ & $X$ & & \\
\hline & $A$ & & & $x$ & & & & & & $\mathrm{X}$ & \\
\hline & $\mathrm{V}$ & & & $\mathrm{X}$ & & & & & & & \\
\hline & $\mathrm{K}$ & & & & & & & & $x$ & & \\
\hline \multirow{4}{*}{ Ec } & oral & $\mathrm{X}$ & $X$ & $\mathrm{X}$ & & & $\mathrm{X}$ & $\mathrm{X}$ & $X$ & $X$ & $\mathrm{X}$ \\
\hline & $A$ & & & & & & & & & $X$ & \\
\hline & $\mathrm{V}$ & & & $x$ & & & & & & & \\
\hline & $\mathrm{K}$ & & & & & & & & & & \\
\hline \multirow{4}{*}{ Cs } & oral & $x$ & $X$ & $x$ & $x$ & & $x$ & $X$ & $x$ & & $x$ \\
\hline & $A$ & & & & & & & & & $x$ & \\
\hline & $\mathrm{V}$ & & & $\bar{X}$ & & & & & & & \\
\hline & $\mathrm{K}$ & & & & & & & & & & \\
\hline
\end{tabular}

Tabelle 9 Verteilung der mikrobiologischen Funde im Mund und am Herzen.

(A: Atrium, V: Ventrikel, K: Klappe) 
Bei fünf Patienten waren DNA-Nachweise der stark parodontalpathogenen Bakterien ( $A a, P g, T f, T d$ ) im Atrium oder Ventrikel festzustellen; zwei dieser Patienten wiesen die fünf Bakterienbefunde im Atrium gemeinsam auf (Tab. 9). Bei lediglich drei Patienten (Patient: 2, 4, und 6) war keine Bakterien-DNA der untersuchten Bakterien im Atrium, Ventrikel oder Klappe zu finden (Tab. 9).

Bis auf Aa lagen alle Bakterien, die aus den parodontalen Taschen analysiert wurden, in durchwegs erhöhter Konzentration vor (Tab. 10). Die höchste Konzentration an Bakterien aus dem Herzgewebe war Score 1.

\begin{tabular}{|c|c|}
\hline $\begin{array}{c}\text { Parodontopathogene } \\
\text { Bakterien }\end{array}$ & $\begin{array}{c}\text { Mikrobiologische Analyse der oralen Proben } \\
\text { (Median Score } \pm \text { Standardabweichung, Bandbreite aller } \\
\text { Werte) }\end{array}$ \\
\hline Aa & $0,0 \pm 0,0(0-0)$ \\
\hline Pg & $4,0 \pm 1,6(0-4)$ \\
\hline Tf & $3,0 \pm 0,3(2-3)$ \\
\hline Td & $2,0 \pm 1,7(0-4)$ \\
\hline Pi & $3,5 \pm 1,9(0-4)$ \\
\hline Pm & $2,0 \pm 1,1(0-3)$ \\
\hline Fn & $3,0 \pm 1,0(1-4)$ \\
\hline Cr & $2,5 \pm 1,3(0-4)$ \\
\hline En & $1,0 \pm 0,7(0-2)$ \\
\hline Ec & $3,0 \pm 1,3(0-4)$ \\
\hline Cs & $2,0 \pm 1,4(0-4)$ \\
\hline
\end{tabular}

Tabelle 10 Score der mikrobiologischen Analysen oraler Proben aller 10 Patienten im Median (Score 0-4)

\subsubsection{Genetische Untersuchung des IL-1-Polymorphismus}

Die Bestimmung der IL-1-Genotypen zeigte, dass alle Patienten eine Veränderung in den IL-1-Genen selbst (Genotyp 2, n=4), im IL-1-Rezeptor (Genotyp 4, n=5) oder bei beiden aufweisen (Genotyp 3, $n=1$ ) (Tab. 11). 


\begin{tabular}{|c|c|c|}
\hline Genotyp & Allel & $\begin{array}{l}\text { Anzahl der Patienten } \\
\qquad(\mathrm{n}=10)\end{array}$ \\
\hline \multirow{3}{*}{ IL-1A -C889 } & homozygot negativ & $n=3$ \\
\hline & heterozygot & $\mathrm{n}=6$ \\
\hline & homozygot postiv & $\mathrm{n}=1$ \\
\hline \multirow{3}{*}{ IL-1B +C3953 } & homozygot negativ & $\mathrm{n}=4$ \\
\hline & heterozygot & $\mathrm{n}=5$ \\
\hline & homozygot postiv & $\mathrm{n}=1$ \\
\hline \multirow{3}{*}{ IL-1RN +T2018 } & homozygot negativ & $\mathrm{n}=4$ \\
\hline & heterozygot & $\mathrm{n}=4$ \\
\hline & homozygot postiv & $\mathrm{n}=2$ \\
\hline \multirow{4}{*}{ Genotyp } & 1 & $\mathrm{n}=0$ \\
\hline & 2 & $\mathrm{n}=4$ \\
\hline & 3 & $\mathrm{n}=1$ \\
\hline & 4 & $\mathrm{n}=5$ \\
\hline
\end{tabular}

Tabelle 11 Genetische Untersuchung IL-1-Polymorphismus

\subsection{Ergebnisse der proteinchemischen Laboranalyse}

\subsubsection{Western Blot am Herzgewebe}

Im Western Blot konnte für Atrium, Ventrikel und Klappe das LBP (big42) in unterschiedlicher Quantität nachgewiesen werden. Dabei war bei allen Patienten (100\%) der Nachweis von LBP in einem der drei Gewebe möglich. Die höchsten Mengen waren im Median bei 1,60 $\pm 0,89$ für die Klappe $(n=10)$ festzustellen; bei Atrium $(0.25 \pm 0,14 ; n=9)$ und Ventrikel $(0,10 \pm 0,12 ; n=8)$ traten annähernd gleiche Mengen auf (Tab. 12). Auch proBNP NT wurde in geringen Mengen im Atrium bei einem Median von 0,06 $\pm 0,14(n=6)$ und im Ventrikel von $0,03 \pm 0,12$ (Tab. 12) bestimmt. 


\begin{tabular}{|c|c|c|c|}
\hline 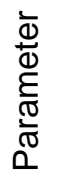 & 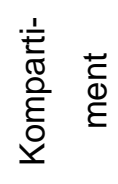 & $\begin{array}{l}\text { Median Score } \pm \text { Standardabwei- } \\
\text { chung, Bandbreite aller Werte }\end{array}$ & $\begin{array}{l}\text { Zahl der Patienten mit positiven } \\
\text { Funden } n=10\end{array}$ \\
\hline \multirow{3}{*}{ 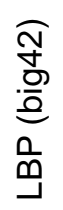 } & A & $0,25 \pm 0,14(0,00-0,40)$ & $n=9$ \\
\hline & V & $0,10 \pm 0,12(0,00-0,32)$ & $n=8$ \\
\hline & K & $1,60 \pm 0,89(0,91-3,83)$ & $n=10$ \\
\hline \multirow{2}{*}{ 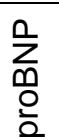 } & A & $0,06 \pm 0,14(0,0-0,42)$ & $n=6$ \\
\hline & V & $0,03 \pm 0,12(0,00-0,32)$ & $n=4$ \\
\hline
\end{tabular}

Tabelle 12 Western Blot-Analyse. Median von LBP und BNP am Herzgewebe

Die Patienten mit den Nummern 6,8,10 zeigten deutlich erhöhte Werte sowohl von LBP als auch von BNP, vor allem im Atrium (Tab. 13).

\begin{tabular}{|c|c|c|c|c|c|c|c|c|c|c|c|}
\hline \multirow{2}{*}{ 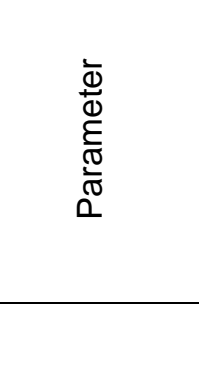 } & 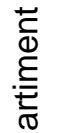 & \multicolumn{10}{|c|}{ Patient } \\
\hline & & 1 & 2 & 3 & 4 & 5 & 6 & 7 & 8 & 9 & 10 \\
\hline \multirow{3}{*}{ LPB (big42) } & A & 0.12 & 0.1 & 0.2 & 0.36 & 0 & 0.4 & 0.22 & 0.39 & 0.28 & 0.35 \\
\hline & $\mathbf{V}$ & 0.1 & 0 & 0.06 & 0.12 & 0.06 & 0.32 & 0.09 & 0.23 & 0 & 0.31 \\
\hline & K & 2,47 & 1,52 & 3,83 & 1,96 & 0,91 & 2,9 & 1,41 & 1,37 & 1,67 & 1,27 \\
\hline \multirow{2}{*}{ BNP } & A & 0,02 & 0,06 & 0,06 & 0,04 & 0,06 & 0,30 & 0,00 & 0,42 & 0,09 & 0,18 \\
\hline & V & 0,03 & 0,00 & 0,26 & 0,03 & 0,02 & 0,11 & 0,18 & 0,00 & 0,00 & 0,32 \\
\hline
\end{tabular}

Tabelle 13 Western Blot-Analyse von LBP und BNP am Herzgewebe, alle Ergebnisse

Vergleicht man die Werte für LBP und proBNP NT im Atrium, kann man mögliche Wechselbeziehungen erkennen (Abb. 11). 


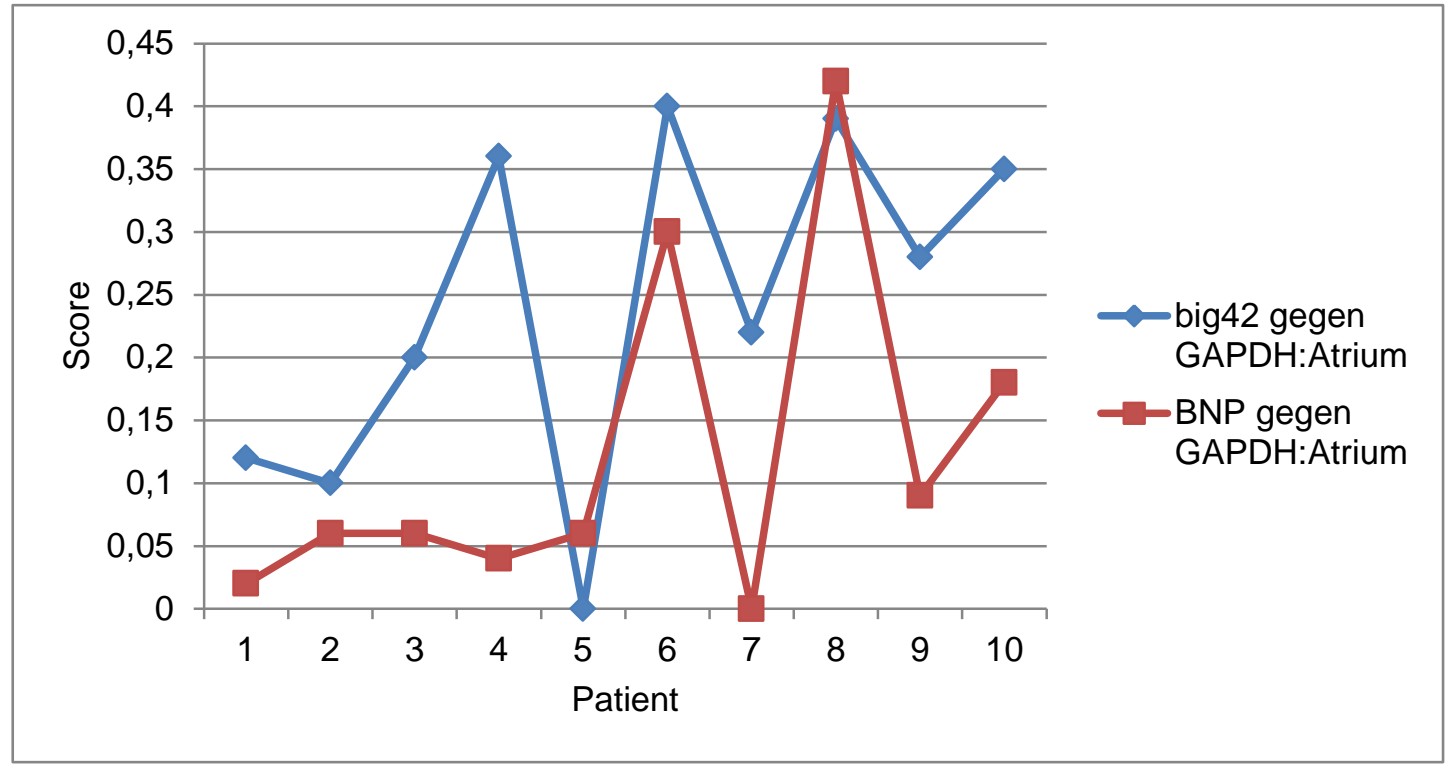

Abbildung 11 Vergleich LBP (big42) gegen proBNP NT im Atrium

Wie Abb. 12 zeigt, waren bei den Patienten, bei denen $\mathrm{Pg}$ an der Herzklappe nicht nachweisbar war, auch die Entzündungswerte erniedrigt. Dies lässt vermuten, dass das gefundene LBP durch Pg entstanden ist. Ferner zeigt Abb. 12, dass LBP nicht nur im Atrium, sondern auch in ähnlichen Mengen im Ventrikel nachgewiesen werden konnte.

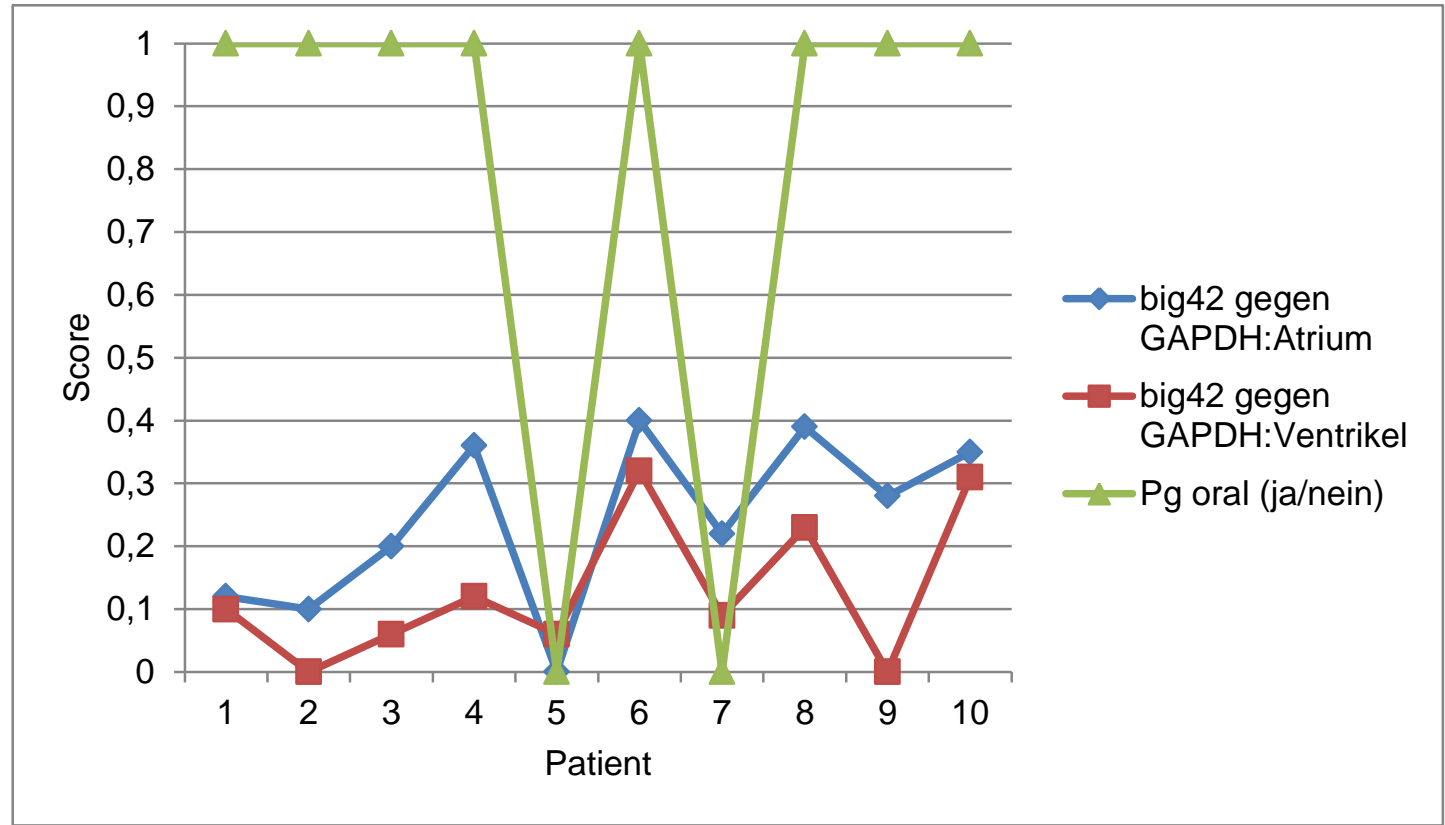

Abbildung 12 Vergleich von LBP ( big42 ) an Atrium und Ventrikel mit oralem Nachweis von $P g$.

(1: positiv, 0: negativ) 


\subsubsection{ELISA des Blutserums}

Die Blutseren der Patienten wurden mit dem ELISA-Testverfahren auf LBP und proBNP NT untersucht. Dabei wurde LBP im Median bei 4,25 gemessen (Tab. 14).

\begin{tabular}{|c|c|c|}
\hline Kompartiment & $\begin{array}{c}\text { Median Score } \pm \text { Stan- } \\
\text { dardabweichung, Bandbreite } \\
\text { aller Werte }\end{array}$ & $\begin{array}{c}\text { Zahl der Patienten mit patholo- } \\
\text { gischem Befund } \mathrm{n}=10\end{array}$ \\
\hline LBP (big42) in $\mu \mathrm{g} / \mathrm{ml}$ & $\begin{array}{c}4,25 \pm 3,82(3,20-15,90) \\
\text { proBNP NT in pg/ml }\end{array}$ & $\begin{array}{c}685,6 \pm 719,76(140,8- \\
2119)\end{array}$ \\
\hline
\end{tabular}

Tabelle 14 ELISA-Median von LBP und BNP am Herzgewebe

Lediglich bei einer Testperson ( $n=1)$ konnte eine erhöhte Konzentration $(15,9 \mu \mathrm{g} / \mathrm{ml}$ = Grenzwert des Zentrallabors, Abteilung Klinische Chemie, Universitätsmedizin Göttingen) festgestellt werden (Tab. 15). Der Median für BNP lag erwartungsgemäß relativ hoch bei 685,6 pg/ml (Tab. 15). Als Grenzwert wird vom Hersteller 100 pg/ml für Männer und $150 \mathrm{pg} / \mathrm{ml}$ für Frauen angegeben. Alle Patienten wiesen einen erhöhten Wert auf (Tab. 15). Damit entsprach das Ergebnis insofern den Erwartungen als bei allen Patienten eine Herzinsuffizienz vorgelegen hatte.

\begin{tabular}{|c|c|c|c|c|c|c|c|c|c|c|}
\hline 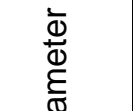 & \multicolumn{10}{|c|}{ Patient } \\
\hline & 1 & 2 & 3 & 4 & 5 & 6 & 7 & 8 & 9 & 10 \\
\hline $\begin{array}{c}\text { LBP } \\
\mu \mathrm{g} / \mathrm{ml}\end{array}$ & 6,6 & 3,2 & 4,3 & 7,8 & 7,5 & 15,9 & 3,5 & 4,1 & 4,1 & 4,2 \\
\hline $\begin{array}{c}\text { BNP } \\
\mathrm{pg} / \mathrm{ml}\end{array}$ & 1023,00 & 211,80 & 346,90 & 2119,00 & 150,00 & 713,90 & 1975,00 & 657,30 & 1070,00 & 140,80 \\
\hline Geschl. & 1 & 1 & 1 & 1 & 1 & 0 & 0 & 0 & 1 & 0 \\
\hline
\end{tabular}

Tabelle 15 ELISA von LBP und BNP am Herzgewebe, alle Ergebnisse.

(Geschlecht: 0=weiblich, 1=männlich, Werte überhalb des Grenzwertes wurden blau hinterlegt) 


\subsubsection{Histologie und Immunhistochemie am Herzgewebe}

Tabelle 16 gibt einen Überblick über die histologischen und immunhistochemischen Ergebnisse, entsprechend des Scoring für den HE-Infammation, LBP, CD14 und CD68 für jeden einzelnen Patienten.

\begin{tabular}{|c|c|c|c|c|c|c|c|c|c|c|c|}
\hline \multirow{2}{*}{$\begin{array}{l}\bar{d} \\
\frac{\omega}{\omega} \\
\frac{\bar{\sigma}}{\sigma} \\
\bar{\sigma} \\
\alpha\end{array}$} & 窇 & \multicolumn{10}{|c|}{ Patient } \\
\hline & & 1 & 2 & 3 & 4 & 5 & 6 & 7 & 8 & 9 & 10 \\
\hline \multirow{3}{*}{$\begin{array}{c}\text { HE- } \\
\text { Inflammation }\end{array}$} & A & 2 & 2 & 2 & 3 & 3 & 3 & 2 & 3 & 2 & 3 \\
\hline & V & 2 & 2 & 2 & 2 & 2 & 3 & 2 & 2 & 2 & 2 \\
\hline & $\mathrm{K}$ & 3 & 2 & 3 & 3 & 3 & 3 & 2 & 2 & 2 & 2 \\
\hline \multirow{2}{*}{ LBP (big42) } & A & 2 & 2 & 2 & 2 & 3 & 2 & 1 & 3 & 2 & 2 \\
\hline & $\mathbf{V}$ & 2 & 1 & 2 & 2 & 2 & 1 & 1 & 2 & 2 & 2 \\
\hline \multirow{2}{*}{ CD14 } & A & 1 & 2 & 2 & 3 & 2 & 2 & 2 & 3 & 2 & 3 \\
\hline & V & 2 & 1 & 2 & 1 & 1 & 2 & 2 & 2 & 2 & 1 \\
\hline \multirow{2}{*}{ CD68 } & A & 1 & 2 & 3 & 2 & 1 & 3 & 2 & 3 & 1 & 2 \\
\hline & V & 1 & 1 & 2 & 2 & 2 & 2 & 2 & 1 & 1 & 2 \\
\hline
\end{tabular}

Tabelle 16 Ergebnisse der histologischen und immunhistochemischen Untersuchung für alle Patienten

Die morphologisch-inflammatorische Untersuchung an den HE-Schnitten zeigte eine erhöhte extrazelluläre Inflammation (Zelleinwanderung) mit einem medianen HE-Score von 3 bei Atrium und Klappe sowie 2 beim Ventrikel.

Die immunhistochemischen Parameter LBP (big42), CD14 und CD68 zeigten nach einem vorläufigen Screening bei allen Patienten positive Befunde. Das Scoring zeigte für alle Parameter sowohl im Atrium als auch im Ventrikel einen Median von 2.

Ein Vergleich der HE- Inflammation mit der LBP Konzentration am Atrium mit dem Grad der Parodontitis zeigt eine gewisse Korrelation (Abb. 13). Lediglich bei Patient Nr. 5 entspricht die LBP Konzentration nicht den Entzündungszeichen. 


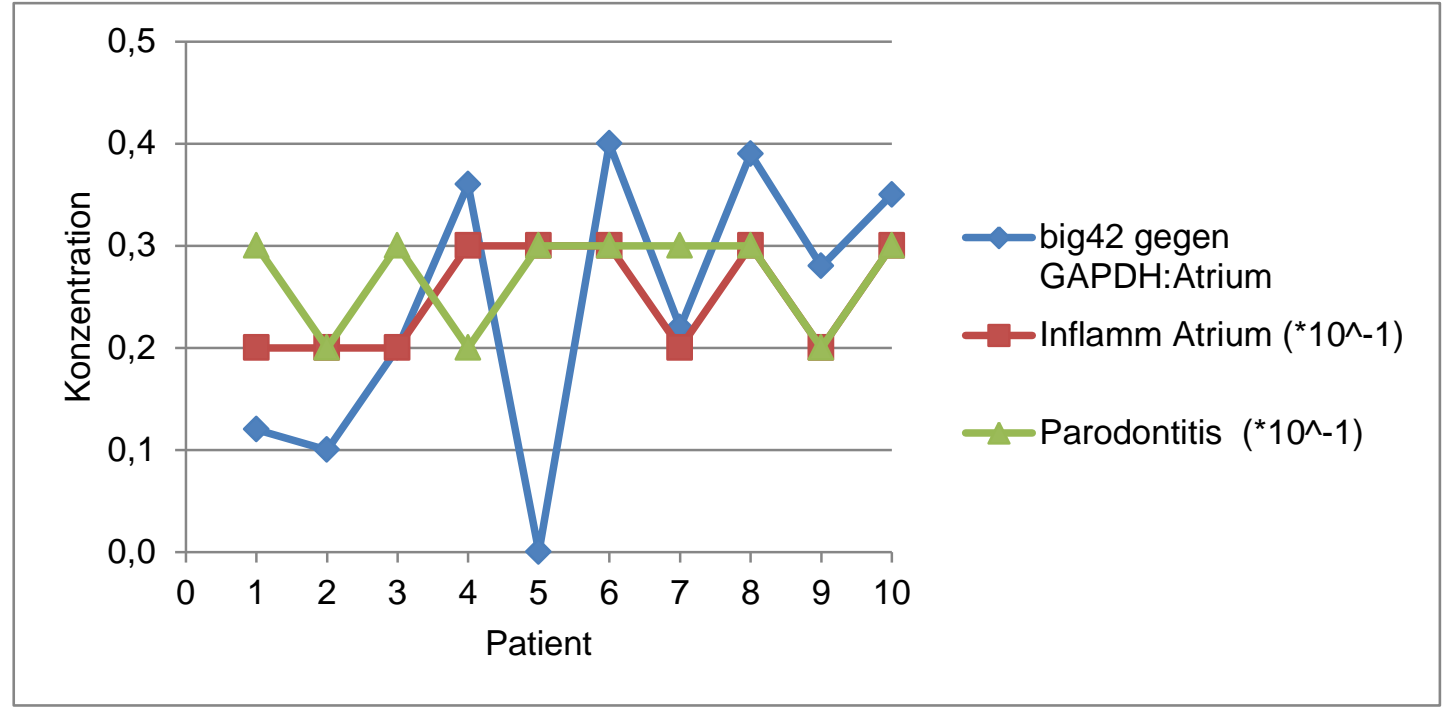

Abbildung 13 Vergleich der histologischen Auswertung des HE-Inflammationsgrades mit der Proteinanalyse von LBP (big42; beides Atrium) und dem Grad der Parodontitis.

Zur besseren grafischen Darstellung wurden die histologischen Scores sowie der Grad der Parodontitis mit $10^{-1}$ multipliziert. 


\section{Diskussion}

Die vorliegende Pilotstudie untersuchte anhand klinischer, mikrobiologischer, proteinbiochemischer und immunhistochemischer Parameter mögliche Hinweise auf klinische Zusammenhänge zwischen Parodontitis und Herzinsuffizienz. Hierfür kamen verschiedene labordiagnostische Verfahren zum Einsatz, um geeignete Parameter für weitere Studien zu bestimmen. Die Ergebnisse zeigen eine Vielzahl neuer Erkenntnisse. Zum einen wurde der Nachweis oralpathogener Bakterien-DNA in Myokardproben (Atrium und Ventrikel) mit einer Prävalenz von 10-40\% erbracht; zum anderen wurde LBP auf protein- als auch immunhistochemischer Ebene sowohl in Atrium, Ventrikel und an der Herzklappe gefunden. Schließlich konnte der Nachweis lokaler Entzündungsparameter (HE-Inflammations-Scoring) mit erhöhter extrazellulärer inflammatorischer Zelleinwanderung in allen drei untersuchten Herzgeweben erbracht werden. In Atrium und Ventrikel wurden zudem der LPSBindungsprotein-Rezeptor (CD14) und Makrophagen (CD68) gefunden. Daneben ergab die zahnärztliche Untersuchung, dass neun der zehn Patienten eine moderate bis schwere Parodontitis aufwiesen. In den oralen Biofilmproben konnten parodontalpathogene Bakterien des roten Komplexes mit einer hohen Prävalenz detektiert werden (Pg: 80\%, Tf: 100\%, Td: 70\%).

\subsection{Patienten}

Das Studiendesign, das labortechnische Untersuchungen am Herzgewebe beinhaltete, war auf eine Testgruppe von zehn Personen ausgelegt. Davon waren vier weiblich und sechs männlich. Das Alter betrug im Median 71,5 Jahre. Das Alter und der höhere Anteil Männer entspricht somit dem klassischen Risikopatienten für Herzerkrankungen (McMurray und Stewart 2000).

Alle Patienten litten unter fortgeschrittenen Herzinsuffizienz als Folge eines Aortenvitiums. Sie wurden deshalb einer operativen Maßnahme zugeführt, bei der Material für die Studie gewonnen werden konnte. Die häufigste Herzklappenerkrankung in den entwickelten Ländern ist die Aortenklappenstenose (Beckmann et al. 2010). Somit überrascht es nicht, dass diese bei acht von zehn Patienten in dieser Studie diagnostiziert wurde. Als pathogenetische Faktoren für diese Erkrankung werden diskutiert: 1. progrediente, sklerotisch-degenerative Veränderungen mit einer ähnlichen Pathogenese wie bei der Atherosklerose (Messika-Zeitoun et al. 2007), oder 2. eine rheumatisch bedingte Adhäsion der Kommissuren mit einer inflammatorischen Schädigung des Klappenapparats (Classen et al. 2004). 


\subsection{Zahnärztliche Befunde}

Für die Erfassung der Mundgesundheit wurden sowohl Karies- (DMF-T) als auch Parodontalindizes erhoben. Im Vergleich zu den Ergebnissen der Deutschen Mundgesundheitsstudie DMS IV 2006 (Micheelis und Schiffner 2006) (DMF-T = 22,1) deutet der in dieser Studie erhobene DMF-T mit 24,5 auf einen eher schlechten Mundgesundheitszustand der Patienten hin.

Der Entzündungsgrad der Gingiva wurde mit dem PBI gemessen. Mit einem Median von eins fiel dieser allerdings relativ niedrig aus. Dieses Ergebnis ist insofern überraschend, da der insgesamt schlechte Zahn- und Parodontalstatus einen deutlich höheren Entzündungsgrad vermuten ließe. Eine mögliche Erklärung hierfür könnte das Rauchverhalten der Patienten bieten: Raucher zeigen aufgrund von Veränderungen im vaskulären und zellulären Metabolismus eine Minderdurchblutung der Gingiva. Dadurch wird der Nachweis eines inflammatorischen Geschehens erschwert (Palmer 1999). Die zu erwartende Korrelation mit dem Rauchverhalten konnte in dieser Untersuchung allerdings nicht bestätigt werden (Biddle et al. 2001). Eine andere mögliche Erklärung für den relativ niedrigen Entzündungsindex könnte darin liegen, dass der letzte Zahnarztbesuch bei neun Patienten innerhalb des letzten Jahres stattgefunden hatte. Bei fünf Patienten war in der Vergangenheit eine Parodontalbehandlung erfolgt.

Auch Messungenauigkeiten kommen als Ursache in Frage. Die Sondierung wird generell beeinflusst von Sondierungstechnik, Sondierdruck, Größe der Sonde und Anstellwinkel der Sonde. Zudem können subgingivale Konkremente und überstehende Füllungsränder die Messung verfälschen (Listgarten 1980).

Ein besseres Maß für die Parodontalgesundheit als der PBI stellt der Parodontalstatus dar. Die Einteilung erfolgt nach der Definition der Parodontitis von Page und Eke (2007). Sieben Patienten litten demnach unter einer schweren und drei unter einer moderaten Parodontitis. Damit wiesen alle Studienteilnehmer eine Form von parodontaler Destruktion auf. Messungenauigkeiten bei der Messung von parodontalen Taschen liegen in der Literatur bei 0,5-1,3 mm (Haffajee 1996). Die bei dieser Studie ermittelten Werte liegen aber mit einem Median von 6,5 und einem CAL von 8 deutlich im pathologischen Bereich (Page und Eke 2007). Somit sind Messungenauigkeiten als Ursache für diese Ergebnisse nicht relevant. 


\subsection{Mikrobiologische Untersuchung}

\subsubsection{Mikrobiologische Untersuchung des Mundes}

Der Nachweis von oralen Bakterien wird heute üblicherweise über PCR-Verfahren erbracht, deren Anwendung relativ einfach und kostengünstig ist. Das Handling dieses Verfahrens ist gegenüber einer Zellkultur deutlich zuverlässiger, da man keine lebenden, evtl. auch noch anaeroben Organismen - wie z.B. Pg - transportiert, sondern lediglich deren DNA. Es wurde bewiesen, dass die PCR genau so sicher den Nachweis erbringt wie die Zellkultur (Eick und Pfister 2002; Boutaga et al. 2003; Haffajee et al. 2009).

Der für eine aggressive Form der Parodontitis stehende Keim Aac wurde bei keinem Patienten nachgewiesen. Dafür war die Anzahl der paradontopathogenen Bakterien vermehrt und auch deren Konzentration deutlich erhöht. Gerade die besonders virulenten Keime, also Tf und $P g$ (Genco 1996), waren auffallend deutlich öfter zu finden. Tf war bei jedem Patienten in einer stark erhöhten (Score 2-3) Konzentration vorhanden (Prävalenz 100\%). Pg war lediglich bei zwei Proben nicht nachweisbar (Prävalenz $80 \%$ ), bei den anderen jedoch in einer sehr stark erhöhten Konzentration (Median 4).

Aufgrund des Verteilungsmusters der Bakterien im Mund kann man demnach bei den Patienten dieser Studie von einer chronischen Parodontitis ausgehen. Dies deckt sich mit dem gesuchten Krankheitsbild einer chronischen Erkrankung wie der Herzinsuffizienz. Einschränkend muss man hinzufügen, dass das Auftreten bestimmter parodontopathogener Bakterien, wie Aac. oder $\mathrm{Pg}$ alleine, keine Aussage zur Art der Erkrankung zulassen (Mombelli et al. 2002; Sbordone und Bortolaia 2003).

\subsubsection{Mikrobiologische Untersuchung des Herzgewebes}

Zum Vergleich der Bakterienlast im Mund mit der am Herzgewebe eignet sich besonders die PCR-Analyse. Hierbei konnte, ähnlich wie schon bei den oralen Proben, bei allen zehn Patienten parodontopathogene Bakterien (Prävalenz $=100 \%$ ) nachgewiesen werden. Bei allen Patienten in dieser Studie wurde die größte Anzahl von Keimen im Atrium detektiert (Prävalenz Atrium $=70 \%$, Ventrikel $=40 \%$, Klappe $=$ $20 \%$ ). Auffallend ist der ausgeprägte Unterschied in der Prävalenz der parodontopathogenen Bakterien zwischen Atrium-, Ventrikel- und Aortenklappe. Eigentlich hätte man erwartet, dass an der Klappe, die soweit pathologisch verändert war, dass sie operativ entfernt werden musste, die höchste Prävalenz an parodontalpathogenen Bakterien nachzuweisen gewesen wäre. Ganz im Gegenteil fanden sich aber an der 
Klappe nur $\mathrm{Cr}$ und En und kein Erreger aus dem hochpathogenen roten Komplex, die aber alle im Atrium nachgewiesen werden konnten. Auch im Ventrikel konnten aus dem roten Komplex nur $T d$ nachgewiesen werden, dazu aber alle anderen in dieser Studie untersuchten parodontopathogegen Bakterien. Dies könnte ein Hinweis darauf sein, dass die für die Parodontitis bedeutsamen Erreger bei der Besiedlung der Herzklappen eine eher untergeordnete Rolle spielen. Allerdings konnte mit der hierbei verwendeten PCR-Analyse nur eine geringe Konzentration an Bakterien nachgewiesen werden. Somit ist die Keimbelastung insgesamt als gering einzustufen. Diese Ergebnisse sind damit der erstmals beschriebene Nachweis parodontalpathogener Bakterien-DNA im humanen Myokardgewebe.

Bislang gibt es keine humanen klinischen Studien, die den Nachweis oraler Bakterien (-DNA) im Myokard aufzeigen konnten oder systematisch untersucht haben. Lediglich in Arterioskleroseplaques (Haraszthy et al. 2000; Ott et al. 2006; Aimetti et al. 2007) und Herzklappen (Nakano et al. 2009) wurden bisher Bakterien nachgewiesen. Nakano et al. (2009) untersuchten bei 203 Patienten kardiales Gewebe, das sowohl von den Herzklappen als auch von Teilen der Aortenwand stammte. Dabei wurden Primer für $\mathrm{Aac}, \mathrm{Pg}, \mathrm{Tf}, \mathrm{Td}, \mathrm{Pi}$, Cr sowie für sechs Streptokokkenarten verwendet. Auch er konnte Parodontopathogene nachweisen, allerdings mit einer deutlich geringeren Prävalenz (35\% Aac, 15\% Pg) als in der vorliegenden Studie.

\subsubsection{Vergleich der oralen und kardialen mikrobiellen Nachweise}

Die Messverfahren zeigten eine hohe Bakterienkonzentration bei den oralen Proben (Medianscore 2,5) und eine geringe am Herzen (maximal Score 1). Von weiteren Untersuchungen mit der real-time PCR als Referenzverfahren (Morillo et al. 2003) wurde abgesehen, da das verwendete semiquantitative Nachweisverfahren mit einer Sensitivität für $P g$ von 96,4\% (Eick et al. 2011) sehr zuverlässig ist. Limitierend bezüglich der Genauigkeit des Messergebnisses könnte eine mögliche Verunreinigung der Proben mit Stoffen wie Hämoglobim, Laktoferrin, Immunglobulin G oder Kollagen gewesen sein (Jentsch et al. 2004; Hanioka et al. 2005; Eick et al. 2011). Der Hain microlDent (Hain Lifescience, Nehren, Deutschland) ist ein Test, der speziell für die Mundhöhle entwickelt wurde. Im parodontalen Sulkus lassen sich auch beim Gesunden parodontopathogene Bakterien nachweisen (Conrads 1999). Daher erfolgt bei dem microlDent ein cut-off ab $10^{3}$ bei Aac bzw. $10^{4}$ (entspricht Score 0) bei allen anderen Genomäquivalenten (Eick und Pfister 2002). Es ist nicht bekannt, wie hoch die Konzentration parodontopathogener Bakterien beim gesunden Herz liegt. Es ist plausibel, dass schon der Nachweis geringer Bakterienkonzentrationen einen Hinweis auf einen krankhaften Zusammenhang geben kann. 
Wie bereits oben beschrieben, zeigte sich beim Vergleich der drei Kompartimente die höchste Konzentration im Atrium und die niedrigste an der Klappe. Dies ist insofern überraschend, da man die stärkste Konzentration im Bereich der pathologisch veränderten Klappen erwartet hätte. Diese Ergebnisse legen nahe, dass die gesuchten parodontopathogene Bakterien besser am Endothel des Herzmuskels als am Endothel der Herzklappe anhaften. Andererseits ist es vorstellbar, dass gerade bei der Aortenstenose das strömende Blut und damit die parodontopathogenen Bakterien im linken Vorhof länger verweilen und damit leichter „andocken“ können als es im Bereich der verengten Klappe möglich ist, wo das Blut mit deutlich höherer Geschwindigkeit vorbeifließt (Dasi et al. 2009).

\subsubsection{Genetische Untersuchung}

Neben beeinflussbaren Risikofaktoren wie Rauchen und Mundhygiene werden seit einiger Zeit auch die angeborenen Faktoren für das Entstehen einer Parodontitis intensiv diskutiert. Kornman (1997) konnte einen Genotyp des IL-1 Zytokins mit dem Schweregrad der Parodontitis in Zusammenhang bringen. Er zeigte, dass beide Isoformen einen Polymorphismus aufweisen können, der verstärkt bei Patienten mit ausgeprägter Parodontitis vorkommt. Dabei handelt es sich um Position -899 bei IL1A, sowie +3953 bei IL-1B (wird auch als +3954 bezeichnet) (Laine et al. 2010). Zusammen mit einem Polymorphismus an Postiion +2018 des IL-1 Rezeptors IL$1 \mathrm{RN}$ konnten zwei weitere Genotypen erkannt werden.

In zahlreichen Folgestudien wurden diese Zusammenhänge überprüft. Die Studienlage ist aber bis heute uneindeutig. Die Gruppe um Lang und Tonetti haben 122 Veröffentlichungen verglichen und sind zu dem Schluss gekommen, dass man nicht von einer Evidenz ausgehen kann (Huynh-Ba et al. 2007). Laine et al. (2010) hingegen gehen davon aus, dass ein Zusammenhang nur bei bestimmten ethnischen Gruppen herzustellen ist. Nach aktueller Studienlage ist eine Assoziation zwischen IL-1-Polymorphismus und Parodontitis bei Kaukasiern wahrscheinlich (Kebschull et al. 2010; McGuire und Nunn 1999; Socransky et al. 2000; Agrawal et al. 2006; López et al. 2005; McDevitt et al. 2000). Bei Afro-Amerikanern hingegen trifft dies nicht zu (Walker 2000). Studien aus Indien konnten zwar Tendenzen feststellen, jedoch keine signifikante Relation herstellen (Archana et al. 2012; Masamatti et al. 2012).

Zhou et al. (2012) haben eine Meta-Analyse veröffentlicht, die Zusammenhänge zwischen koronarer Herzerkrankung und IL-1-Polymorphismen untersucht. Die dreizehn untersuchten Studien sprechen allerdings gegen einen Zusammenhang. 
Bei den hier präsentierten Ergebnissen wurde der GenoType IL-1-Test (Hain Lifescience, Nehren, Deutschland) modifiziert angewendet. Anstelle eines Sulkusabstriches wurde auf Plasma zurückgegriffen, was aber kein unübliches Verfahren darstellt (Archana et al. 2012; Stashenko et al. 2011). Bei unserer Untersuchung hatten alle Patienten eine mittlere bis schwere Parodontitis. Keiner wies den IL-1Genotyp 1 mit normaler Entzündungsreaktion und ohne Risiko für progressive $\mathrm{Pa}$ rodontitis auf. Bei vier Patienten wurde eine erhöhte (entspricht Genotyp 2) und bei einem Patienten eine stark erhöhte Entzündungsreaktion (entspricht Genotyp 3) nachgewiesen; bei fünf Patienten bestand eine verminderte Entzündungshemmung (entspricht Genotyp 4). Dieser Befund würde zum überdurchschnittlich ausgeprägten Grad der Parodontitis passen. Die Tatsache, dass lediglich vier der Patienten unter einer KHK litten, kann die Analyse von Zhou et al. (2012) weder bestätigen noch widerlegen. Keiner der Patienten wies den Genotyp 1 auf; somit ist nach den Erkenntnissen dieser Studie eine Korrelation von genetischem Risiko für eine Herzinsuffizienz und IL-1-Polymorphismus bzw. Parodontitis durchaus möglich.

\subsection{Proteinnachweis}

\subsubsection{Proteinnachweis am Herzgewebe (Western Blot, Immunhistochemie und Histochemie)}

Parodontopathogene Bakterien können den Herzmuskel auf verschiedene Weise schädigen. Lee et al. (2005, 2006a, 2006b) untersuchten in einer In-vitro-Studie die Mechanismen und Auswirkungen von LPS, einem Endotoxin gram-negativer Bakterien, am Herzmuskel. Diese und weitere Studien (Wu et al. 2008) konnten Auswirkungen von LPS für Hypertrophie und Apoptose von Kardiomyocyten feststellen. Wie oben (siehe 2.3) aufgeführt, zeigt Kebschull et al. (2010) ein Modell für eine mögliche Schädigung des Herzmuskels durch die Aktivierung des Immunsystems mit einer Expression von Zytokinen (TNF-a, IL-1, IL-6 und CD14). Dies kann zu einem negativ inotropen Effekt auf das Myokard führen, was eine Hypertrophie und schließlich ein Remodeling des Myokards zur Folge hat (Seixas-Cambão und LeiteMoreira 2009). Auch bei degenerativen Aortenklappenveränderungen wird ein aktiver Entzündungsprozess am Endokard angenommen (Parolari et al. 2009).

Wang und Ohura (2002) konnten zeigen, dass LPS von parodontalpathogenen Bakterien, wie Porphyromonas gingivalis, über LBP an CD 14 und im weiteren an Tolllike-receptor (TLR4) von gingivalen Fibroblasten bindet und nachfolgend sekundäre Signalwege aktiviert werden. Durch diesen Vorgang werden im Weiteren parodontale Makrophagen angeregt (Zhou et al. 2005). Nach heutigen Erkenntnissen kann 
LPS nicht nur myokardrelevante Mediatoren in Immunzellen induzieren, sondern auch Myokardzellen selbst manipulieren (Bozkurt et al. 1998; Baumgarten et al. 2001 2002; Nemoto et al. 2002).

Wenn man nun von einer direkten Verbindung von LPS zu dem Krankheitsbild der Herzinsuffizienz ausgeht, so müssten die Bakterien eine Schädigung im Myokard des Ventrikels verursachen. Mit der Proteinanalyse konnte bei allen Herzklappen, bei neun von zehn Atrien und bei acht Ventrikeln, LPS-bindendes-Protein nachgewiesen werden. Dabei waren die Konzentrationen bei den Herzklappen deutlich höher (Median 1,60 +- 0,89) als im Herzmuskel (Median Atrium Ventrikel). Allerdings ist bekannt, dass selbst niedrige Mengen Endotoxin (vergleichbar mit den Mengen von Herzinsuffizienz-Patienten in vivo) in der Lage sind, signifikante Mengen von TNF zu produzieren (In-vitro) (Sharma et al. 2005a). Somit ist es durchaus vorstellbar, dass auch die gefundene geringe Konzentration von LBP zu einer durch LPS hervorgerufenen Schädigung führen kann.

In der hier vorliegenden Studie wurde der LBP Marker big42 der Fa. Biometec verwendet. Dieser bindet LPS und löst über TLR-4 und CD14 die oben aufgeführte Inflammationskaskade aus, welche für das Endotoxin der meisten gram-negativen Bakterien gilt, so auch für Aac, Fn und auch E.coli (Yoshimura et al. 2002; Liu et al. 2008). Die zwei wichtigsten Isoformen von Pg, die durch ihre lonenmasse gekennzeichnet sind (Kumada et al. 1995), reagieren aber antagonistisch zu TLR-4 (Yoshimura et al. 2002) und können nur an TLR-2 gebunden werden (Kebschull et al. 2010). Wie Yoshimura zeigen konnte, sind die lokalen Auswirkungen zwar ähnlich, allerdings gilt dies nicht für das Herz (Yoshimura et al. 2002). Hier zeigt das LPS von $\mathrm{Pg}$ im Gegensatz zu dem von E.colikeine pathologischen Auswirkungen.

Eine Assoziation mit Aac oder Fn ist aber durchaus möglich. Nakano (2009) hat in einer ähnlichen Arbeit 203 Patienten auf primär orale Bakterien am Herzen oder an herznahen Gewebe untersucht. Dabei war das am häufigsten gefundene gramnegative Bakterium das Aac. Das Patientenkollektiv der vorliegenden Pilotstudie zeigte zwar keine orale Belastung mit Aac, jedoch konnten an vier Proben des Atriums dieser Keim isoliert werden.

Bei der Pathogenese der LPS-bedingten Myokarddysfunktion spielt die Myokardexpression von proinflammatorischen Mediatoren eine entscheidende Rolle (Bozkurt et al. 1998; Mann 2002). Insbesondere CD 14 nimmt in diesem Zusammenhang eine wichtige Rolle ein (Wright et al. 1990; Fearns et al. 1995; Kopp und Medzhitov 1999; Cowan et al. 2000). Zudem gilt CD 14 für verschiedene Zelltypen als ein möglicher LPS-binding-Rezeptor (Fearns et al. 1995). Entsprechend sind LBP und CD 
14 wichtige Parameter zur Beurteilung LPS-bedingter immunologischer Veränderungen im Myokard.

Beim Vergleich der aktuellen Studienlage mit den ersten Ergebnissen unserer klinischen Studien ist zu berücksichtigen, dass die bisher vorliegenden Untersuchungen durch den Umstand limitiert sind, dass die Mechanismen in Tierversuchen (z.B. Mäusen, Raten) oder Zellkulturen aufgezeigt wurden. Darüber hinaus gibt es überwiegend den Nachweis auf Proteinebene durch Western Blot oder PCR-Analyse. Dabei konnten diese Untersuchungen zeigen, dass der LPS-Effekt in Kardiomyocyten überwiegend von CD 14 vermittelten LPS-Antwort abhängig ist (Comstock et al. 1998; Knuefermann et al. 2002). Baumgarten et al. (2006) und Panaro et al. (2008) stellten in diesem Zusammenhang fest, dass es in Anwesenheit von LPS zu einer gesteigerten CD14 Expression in Kardiomyocyten kommt. Dagegen zeigten Cowan et al. (2000), dass es durch bakterielle Toxine unabhängig von CD 14 zur Aktivierung von Kardiomyocyten-Signal-Transduktionswegen kommen kann.

Die in unserer Studie erzielten Ergebnisse konnten zunächst ein erhöhtes Vorliegen von LBP (big42) auf der Proteinebene für alle drei Herzgewebe (Atrium, Ventrikel, Klappe) aufzeigen; dies spricht für ein Vorliegen von (unspezifischen) LPS am humanen Myokard. Des Weiteren konnten wir erstmals einen positiven (erhöhten) LBP-Nachweis in Kardiomyocyten sowohl im Atrium als auch im Ventrikel auf immunhistochemischer Ebene feststellen. Durch den immunhistochemischen Nachweis von CD 14 konnten wir die bisher bekannten Erkenntnisse einer erhöhten CD 14-Expression in Myokardzellen bei vorliegenden LPS (hier über LBP) bestätigen. Bezüglich der klinischen Rückkopplung ist anzumerken, dass durch eine LPSinduzierte CD 14 Expression eine links-ventrikuläre Dysfunktion begünstigt werden kann (Knuefermann et al. 2002). In einer klinischen Studie von Conraads et al. (2004) konnte gezeigt werden, dass eine LPS-Stimulation mit einer erhöhten CD 14 Expression (im Blut) einhergeht, welche im Weiteren zu einer immunologischen Dysbalance bei chronischen Herzerkrankungen führen kann. Diese Erkenntnisse sind für die Interpretation der ersten Erkenntnisse unserer Pilotstudie von Bedeutung. Dabei ist zu berücksichtigen, dass nicht die Bakterien selbst, sondern die exprimierten LPS einen negativen Effekt auslösen könnten. Erst durch den Zerfall der Bakterien werden die in ihrer äußeren Hülle befindlichen Lipopolysaccharide (LPS) freigesetzt (Raetz 1990). Dies ist aufgrund der hohen Prävalenz der parodontal erkrankten Patienten und der mikrobiologischen Befunde plausibel.

In der weiteren Betrachtung eines inflammatorischen Prozesses konnte ein erhöhter Nachweis von CD68 in den Myokardproben immunhistochemisch nachgewiesen werden. CD 68 ist ein Marker für das Vorliegen einer chronischen Entzündung, der 
auf Monozyten/Makrophagen exprimiert wird. Devaux et al. (1997) konnten an humanen Herzproben zeigen, dass CD68 bei verschiedenen chronischen unspezifischen inflammatorischen Herzerkrankungen festzustellen ist. Dabei steht das Vorliegen von CD68 und CD14 anscheinend in einem engen Zusammenhang; so wird CD14 vor allem auf Makrophagen (CD68) exprimiert. Der zusätzlich angewendete HE-Score bestätigt die gesteigerte inflammatorische Zelleinwanderung, die die vorliegenden immunhistochemischen Ergebnisse zeigen. Somit konnten erstmals detektierte Befunde der ausgewählten Parameter am humanen Myokardproben aufgezeigt und in einen systematischen Zusammenhang gebracht werden.

Luchner et al. (1998) fand Ende der 1990er Jahre heraus, dass die Genexpression von BNP an unterschiedlichen Orten erfolgt. Im Anfangsstadium einer Herzinsuffizienz erfolgt die Ausschüttung hauptsächlich im Atrium. Bei einer manifesten Herzinsuffizienz verschiebt sich die Expression hauptsächlich zum Ventrikel hin. In unserer Studie wiesen sechs Patienten im Atrium höhere Werte auf als im Ventrikel. Diese Ergebnisse würden bestätigen, dass BNP nicht gleichmäßig in beiden Kompartimenten gebildet wird.

\subsubsection{Proteinnachweis im Blut}

LBP wird als Akute-Phase-Protein bei einer Entzündung verstärkt ausgeschüttet (Myc et al. 1997). In niedriger Konzentration kommt es auch beim Gesunden vor (Pavcnik-Arnol et al. 2004). Bei verschiedenen Krankheiten wurde die Bedeutung von LBP als Biomarker identifiziert, z.B. für das Colorektale Karzinomrisiko (Chen et al. 2011), das Systemic Inflammatory Response Syndrom (Myc et al. 1997) und bei Sepis (Blairon et al. 2003; Pavcnik-Arnol et al. 2004; Lepper et al. 2007).

Die in dieser Studie untersuchten Serum-Proben auf LBP waren nur bei einem Patienten - nach Berner et al. (2002) - mit 15,9 $\mu \mathrm{g} / \mathrm{ml}$ grenzwertig leicht erhöht. Dieser Befund steht im Gegensatz zum erhöhten Nachweis von LBP im Gewebe. Auch als Biomarker für die Herzinsuffizienz kommt LBP nicht in Frage. Die BNP-Werte, die bei allen Patienten erwartungsgemäß im pathologischen Bereich (Luchner et al. 2003) lagen, konnten mit den Werten des LBP in dieser Studie nicht in Zusammenhang gebracht werden.

\subsection{Stärken und Schwächen der Studie}

Bei der Beurteilung der Ergebnisse bleibt zu berücksichtigen, dass erst zehn Patienten in die Pilotstudie eingebunden wurden. Entsprechend lassen die Ergebnisse keine Schlussfolgerungen hinsichtlich definitiver Zusammenhänge von Parodontitis und Herzinsuffizienz zu. Bei der Beurteilung der mikrobiologischen Ergebnisse 
(Prävalenzen) an den Myokardproben ist zu berücksichtigen, dass der verwendete mikrobiologische Test (mit PCR-Analyse) ein Nachweisverfahren zur Identifizierung der DNA oraler Bakterien in der Mundhöhle ist und somit eine geringe Sensitivität für humanes Myocardgewebe besteht. Jedoch diente diese Nachweismethode einer ersten Orientierung. Zudem konnten erstmals parodontalpathogene Bakterien am humanen Myokard nachgewiesen werden. Des Weiteren konnten wir mit den bisherigen Untersuchungsparametern nicht eindeutig verifizieren, ob der LBP-Nachweis durch die oralen Bakterien bedingt ist. Hierfür wäre nachfolgend ein spezifischer LPS-Nachweis notwendig.

\subsection{Schlussfolgerung}

Aufbauend auf den Ergebnissen dieser Pilotstudie sollten Folgeuntersuchungen die Ergebnisse bestätigen. Dabei gilt es zu klären, ob parodontalpathogene BakterienDNA im Myokard nachgewiesen werden können und ihre Toxine (LPS) an Myokardgewebe binden sowie im Weiteren Entzündungsreaktionen in den Myokardzellen verursachen. Die ausgewählten Parameter LBP, CD14 und CD 68 stellen dafür geeignete Parameter dar. Somit könnte der Studienaufbau an einem größeren Patientenkollektiv zur Klärung möglicher (Kausal-)Zusammenhänge von Parodontitis und Herzinsuffizienz einen Beitrag leisten.

Bei allen untersuchten Patienten lag eine Herzinsuffizienz vor, welche letztlich die Indikation zur operativen Klappenrevision darstellte. Für ein ideales Modell wäre es wünschenswert, eine Patientengruppe zu finden, bei der zwar eine Herzinsuffizienz vorliegt, welche aber nicht ausschließlich in Zusammenhang mit einer Aortenstenose steht. 


\section{Zusammenfassung}

Ziel der Studie: Ziel dieser Pilotstudie war die Verifizierung eines Studienmodells sowohl mit geeigneten klinischen, mikrobiologischen, proteinbiochemischen als auch mit immunhistochemischen Parametern zur Klärung möglicher klinischer Zusammenhänge zwischen Parodontitis und Herzinsuffizienz.

Material und Methoden: Für die Studie wurden zehn Patienten ausgewählt, denen aufgrund einer Aortenklappenersatzoperation Herzgewebe entnommen wurde. Das im Rahmen der Operation abgenommene Blut sowie das entnommene Gewebe aus Klappe, Atrium und Ventrikel wurde zur weiteren Analyse im Labor gesichert. Bei den teilnehmenden Patienten wurden sowohl der Zahn- und der Parodontalstatus erhoben als auch Proben aus parodontalem Sulkus und von der Wangenschleimhaut genommen. Diese Proben wurden mit mikro- und molekularbiologischen Verfahren auf parodontopathogene Bakterien und IL-1-Polymorphismen untersucht. Das oben beschriebene Herzgewebe wurde mit dem Western Blot-Verfahren proteinchemisch analysiert. Hiermit erfolgte der Nachweis von LBP und proBNP NT. Zusätzlich wurde versucht, LBP und proBNP NT mit dem ELISA-Verfahren auch im Blut der Patienten nachzuweisen. Des Weiteren wurden die Gewebeproben histologisch und immunhistochemisch aufbereitet und auf HE-Inflammation, LBP, CD14 und CD68 gescored.

Ergebnisse: Bei allen Patienten konnte eine stark bis sehr stark erhöhte Anzahl von Bakterien $\left(>10^{4}\right)$ des roten Komplexes nachgewiesen werden. Dieselben Bakterien wurden an Atrium und Ventrikel gefunden. Es scheint also, dass Bakterien aus der Mundhöhle den Weg zum Herzen finden und sich am Gewebe dort anlagern können.

Alle Patienten hatten einen IL-1-Genotyp, der mit einem erhöhten genetischen Parodontitisrisiko oder einer verminderten genetischen Entzündungshemmung einhergeht. Bei den Untersuchungen am Herzgewebe wurden die höchsten Konzentrationen von LBP am Klappengewebe gefunden, was im Gegensatz zur Prävalenz der parodontopathogenen Bakterien steht. proBNP NT wurde bei sechs (Atrium) bzw. vier (Ventrikel) Proben mit einem erhöhten Wert gemessen.

Die Untersuchung des Blutserums auf LPS und BNP zeigte, dass kein Zusammenhang zu der LBP-Konzentration am Herzen oder dem Inflammationsgrad hergestellt werden kann. Allerdings bestätigten die erhöhten BNP-Werte eine Herzinsuffizienz bei allen Patienten.

Die histologische Laboranalyse ergab, dass die Entzündungsparameter CD14 und CD 68 ebenfalls in erhöhter Konzentration exprimiert waren. 
Alle untersuchten Patienten wiesen bei erhöhtem genetischen Parodontitisrisiko eine moderate bis schwere Parodontitis auf. Die gewonnenen Ergebnisse zeigen, dass sowohl die parodontopathogenen Bakterien aus der Mundhöhle als auch deren Toxin, das Lipopolysaccharid, nicht nur an der Klappe, sondern auch im Herzmuskel von Atrium und Ventrikel nachgewiesen werden können. Die hierfür angewandten labortechnischen Untersuchungsmethoden, PCR, Western Blot und Immunhistochemie konnten sinnvoll eingesetzt werden.

Die Studie zeigte das Vorhandensein von oraler Bakterien-DNA im humanen Myokard, wo auch das LBP protein- und immunhistochemisch nachgewiesen wurde. In weiteren immunhistochemischen Analysen wurde darüber hinaus CD14 (LBPBinding-Rezeptor) und CD 68 (Makrophagen) erfasst. Weitere Untersuchungen sind jedoch erforderlich. Hierbei könnte das vorgestellte Modell einen Weg darstellen. 


\section{Anhang}

\subsection{Formulare}

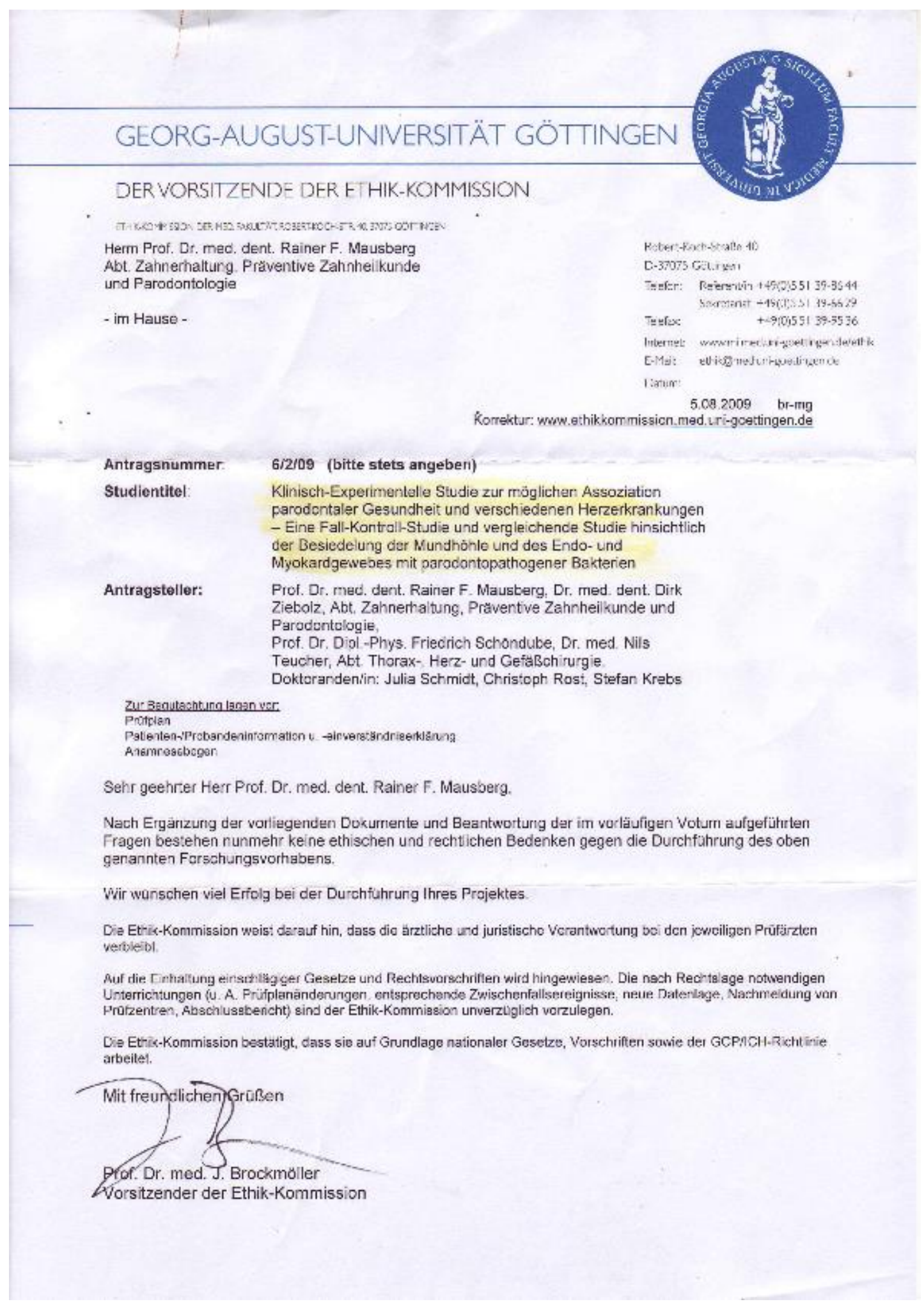

\section{Abbildung 14 Ethikvotum}


Prof. Dr. med. dent. Rainer F. Mausberg; Georg-August-Universitāt Göttingen, Zentrum Zahn-, Mund- und Kieferheilkunde; Abteilung Zahnerhaltung und Präventive Zahnheilkunde und Parodontologie; Robert-Koch-Str. 40, 37075 Göttingen; Tel.: 0551/3922877

\section{Patientenaufklärung}

Klinisch - Experimentelle Studie zur mōglichen Assoziation parodontaler Gesundheit und verschiedenen Herzerkrankungen

\section{Sehr geehrte Patientin, sehr geehrter Patient!}

Parodontitis ist eine Zahnfleischerkrankung mit Verlust des Zahnhalteapparates bis hin zum Abbau des Kieferknochens. Als Folge kōnnen betroffene Zāhne verloren gehen. Die Entzündung des Zahnhalteapparates entwickelt sich aus einer Entzūndung des Zahnfleisches. Dabei spielen viele verschiedene Faktoren eine Rolle: Plaque, bestimmte Bakterien, körpereigene Abwehr, aber auch systemische Erkrankungen oder Medikamente. Die Entzündung des Zahnhalteapparates lässt sich mit Hilfe von Sonden (ggf. Messung von Zahnfleischtaschen) und Röntgenbildern, die den Knochenabbau zeigen, diagnostizieren. Zahnfleischbluten und zunehmende Lockerung des Zahnes können weitere Hinweise geben. Bakterielle und mikrobielle Untersuchungen kōnnen zudem eine genauere Auskunft ūber Krankheitszustand und Risikofaktoren geben.

Grund dieser Studie ist die Öberprūfung der klinischen Zusammenhānge von systemischen Erkrankungen (in diesem Fall verschiedene Herzerkrankungen) mit Erkrankungen des Zahnhalteapparates. Ziel dieser rein wissenschaftlichen Untersuchung soll es sein, Patienten mit Herzerkrankung hinsichtlich mōglicher Zusammenhānge zwischen der Parodontitis und der Herzerkrankungen zu untersuchen. Mit Ihrer Teilnahme können Sie uns helfen herauszufinden, ob und welche Zusammenhänge zwischen den beiden Erkrankungen existieren.

Um Aussagen über den jeweiligen Mundhygiene- und Entzūndungszustand zutreffen zu können, werden spezielle Indizes erhoben, die sich aus einem Kariesindex DMF-T, einem Entzündungsindex PBI und dem Parodontalstatus (Messung der Zahnfleischtaschen; Feststellung der Zahnlockerung) zusammensetzen. Zusätzlich erfolgt die Bestimmung von vorhandenen Bakterien mittels Papierspitzen. Die Untersuchungen an Ihren Zāhnen und an Ihrem Zahnfleisch führt ein Doktorand (9. Semester Zahnheilkunde) der Abt. Zahnerhaltung, Präventiven Zahnheilkunde uns Parodontologie der Universitātsmedizin Gōttingen nach Absprache mit lhrem betreuendem Arzt durch.

\section{Abbildung 15 Patientenaufklärung Seite 1}


Des Weiteren bitten wir Sie, einige Fragen zu Ihrem Allgemeinzustand, Lebensgewohnheiten und Parodontalzustand zu beantworten. Bitte versuchen Sie diese Fragen wahrheitsgemāß und möglichst genau zu beantworten.

Der Zeitraum der Untersuchung ist ein Tag nach der Operation geplant und wird bei Ihnen auf Station am Bett durchgeführt. Der Mehraufwand an Zeit pro Untersuchung betrāgt ca. 15 Minuten; es entstehen für Sie keine zusätzlichen Kosten. Risiken und Nebenwirkungen bei der Durchführung der Untersuchung sind nicht zu erwarten bzw. bestehen nicht, da keine Medikamente, operative Eingriffe oder Anfertigungen von Rōntgenaufnahmen notwendig sind. Im Rahmen der postoperativen Maßnahmen sind Sie antibiotisch abgedeckt und es erübrigt sich eine eventuell notwendige Endokarditisprophylaxe.

Ihre personenbezogenen Daten unterliegen dem Datenschutz und werden vom Leiter der Prüfung nicht weitergegeben. Sie werden anonymisiert behandelt, nur zu Untersuchungszwecken verwendet und nach der Auswertung vernichtet.

Wir bitten um die freiwillige Teilnahme an der Studie. Sie können jederzeit die Teilnahme widerrufen, ohne Angabe von Grūnden und ohne Nachteile erwarten zu müssen. Nach Ihrem Widerruf erfolgt unverzūglich die Vernichtung Ihrer personenbezogenen Daten.

Für Rückfragen stehen Ihnen der Studienleiter und der durchführende Zahnarzt unter o.g. Telefonnummern zur Verfügung.

Vielen Dank fūr Ihre Teilnahme.

Abbildung 16 Patientenaufklärung Seite 2 
Prof. Dr. med. dent. Rainer F. Mausberg; Georg-August-Universitāt Göttingen, Zentrum Zahn-, Mund- und Kieferheilkunde; Abteilung Zahnerhaltung; Präventive Zahnheilkunde und Parodontologie; Robert-Koch-Str. 40, 37075 Gōttingen; Tel.: 0551/3922877

\section{Einverständniserklärung}

Klinisch - Experimentelle Studie zur mōglichen Assoziation parodontaler Gesundheit und verschiedenen Herzerkrankungen*

Ich, wurde von meinem Arzt vollständig über Wesen,

Bedeutung und Tragweite der klinischen Untersuchung mit dem Titel:

„Klinisch - Experimentelle Studie zur möglichen Assoziation parodontaler Gesundheit und verschiedenen Herzerkrankungen"

aufgeklärt.

Mir ist bekannt, dass bei dieser Untersuchung personenbezogene Daten, insbesondere der medizinische Befund über mich erhoben, gespeichert und ausgewertet werden sollen. Die Verwendung der Angaben über meine Gesundheit erfolgt nach gesetzlichen Bestimmungen und setzt vor der Teilnahme an der Klinischen Prüfung die folgende freiwillig abgegebene Einwilligungserklärung voraus.

Ich hatte ausreichend Zeit, mich zur Teilnahe an dieser Untersuchung zu entscheiden und weiß, dass die Teilnahme freiwillig ist.

Mir ist bekannt, dass ich jederzeit und ohne Angaben von Gründen diese Zustimmung widerrufen kann, ohne dass sich dieser Entschluss nachteilig auswirkt.

Ich habe eine Kopie der Patienteninformation und dieser Einwilligungserklärung erhalten.

Ich erkläre hiermit meine freiwillige Teilnahme an dieser Studie.

Ort und Datum

Ort und Datum
Unterschrift des Teilnehmers

Unterschrift des Prüfarztes

\section{Abbildung 17 Einverständniserklärung}


Prof. Dr. med. dent. Rainer F. Mausberg; Georg-August-Universität Göttingen, Zentrum Zahn-, Mund- und Kieferheilkunde; Abteilung Zahnerhaltung und Präventive Zahnheilkunde und Parodontologie; Robert-Koch-Str. 40, 37075 Göttingen; Tel.: 0551/3922877

Anamnesebogen

„Klinisch - Experimentelle Studie zur mōglichen Assoziation parodontaler Gesundheit und verschiedenen Herzerkrankungen*

Pat.-Nr.

Datum:

Bitte beantworten Sie die folgenden Fragen bzw. kreuzen Sie Zutreffendes an.

Mehrfachantworten sind möglich. Die gewissenhafte Beantwortung ist eine Voraussetzung für den Erfolg der Studie!

1. Sind Sie in ständiger ãrztlicher Behandlung?

ja nein

Wenn ja, weswegen?

[] []

2. Leiden Sie an einer Herzerkrankung? (z.B. A. pectoris, Endokarditis, Klappenfehler)

[] []

3. Müssen Sie ständig Medikamente einnehmen?

[ ] [ ]

Wenn ja, welche?

(z.B. zur Blutzuckersenkung; gegen Herzbeschwerden, Bluthochdruck; zur Hemmung der Blutgerinnung; Rheumamittel; Beruhigungs-/Schlaftabletten)

4. Sind Sie zur Zeit in ärztlicher Behandlung?

Wenn ja, weswegen?

5. Wann sind Sie zum letzten Mal zahnärztlich untersucht worden?

6. Sind Ihre Zähne temperaturempfindlich?

7. Blutet Ihr Zahnfleisch?

8. Bemerken Sie Stellungsveränderungen Ihrer Zāhne?

9. Haben Sie manchmal einen schlechten Geschmack im Mund?

10. Haben Sie wegen Zahnlockerung bzw. Zahnfleischbeschwerden schon einmal einen Zahnarzt aufgesucht? Wenn ja, was wurde gemacht?

11. Wurde bei Ihnen bereits eine "Parodontose"-Behandlung durchgeführt? Wenn ja, wann?

12. Rauchen Sie oder haben Sie geraucht?

13. Wie viel Zigaretten/ Schachteln pro Tag etwa? ......... Zigaretten/ Tag, ......... Schachteln/ Tag

14. Wie ist Ihr derzeitiges Gewicht? $\mathrm{kg}$

15 Wie groß sind Sie? m

\section{Abbildung 18 Anamnesebogen}




\subsection{Materiallisten}

\subsubsection{Molekularbiologische Untersuchung}

\begin{tabular}{|l|l|}
\hline Chemikalien & Hersteller \\
\hline Ethanol (100\%) & Merck KGaA, Darmstadt, Deutschland \\
\hline Ficoll-Lösung: Bicoll & Biochrom AG, Berlin, Deutschland \\
\hline PBS-Puffer & Invitrogen, Darmstadt, Deutschland \\
\hline
\end{tabular}

Tabelle 17 Verwendete Chemikalien für die molekularbiologischen Untersuchungen

\begin{tabular}{|l|l|}
\hline Hilfsmittel & Hersteller \\
\hline micolDent und microlDent plus & $\begin{array}{l}\text { Hain Lifescience GmbH, Nehren, } \\
\text { Deutschland }\end{array}$ \\
\hline Genotype IL-1 VER1.0 & $\begin{array}{l}\text { Hain Lifescience GmbH, Nehren, } \\
\text { Deutschland }\end{array}$ \\
\hline HotStarTaqPlus (DNA-Polymerase) & Qiagen GmbH, Hilden, Deutschland \\
\hline Pipette: Multipette plus & Eppendorf AG, Hamburg, Deutschland \\
\hline QIAamp DNA Mini Kit & Qiagen GmbH, Hilden, Deutschland \\
\hline Sarpette & Sarstedt AG, Nümbrecht, Deutschland \\
\hline Stabpipette & Sarstedt AG, Nümbrecht, Deutschland \\
\hline Zentrifugenröhrchen & Sarstedt AG, Nümbrecht, Deutschland \\
\hline
\end{tabular}

Tabelle 18 Verwendete Hilfsmittel für die molekularbiologischen Untersuchungen

\begin{tabular}{|l|l|}
\hline Geräte & Hersteller \\
\hline MS2-Minishaker & $\begin{array}{l}\text { IKA-Werke GmbH, Staufen, } \\
\text { Deutschland }\end{array}$ \\
\hline sterile Werkbank: Airclean PCR Workstation & Airclean Systems, Raleigh, USA \\
\hline TwinCubator & $\begin{array}{l}\text { Hain Lifescience GmbH, Nehren, } \\
\text { Deutschland }\end{array}$ \\
\hline Zentrifuge: Heraeus Biofuge primo R & $\begin{array}{l}\text { Thermo Scientific, Bonn, Deutsch- } \\
\text { land }\end{array}$ \\
\hline Zentrifuge: Centrifuge 5415 R & $\begin{array}{l}\text { Eppendorf AG, Hamburg, Deutsch- } \\
\text { land }\end{array}$ \\
\hline
\end{tabular}

Tabelle 19 Verwendete Geräte für die molekularbiologischen Untersuchungen 


\subsubsection{Proteinchemische Untersuchung}

\begin{tabular}{|c|c|}
\hline Chemikalien & Hersteller \\
\hline 1. Antikörper: big42 antibody to human LBP & $\begin{array}{l}\text { Biometec } \mathrm{GmbH} \text {, Greifswald, Deutsch- } \\
\text { land }\end{array}$ \\
\hline 1-Butanol & Roth $\mathrm{GmbH}$, Karlsruhe, Deutschland \\
\hline 2. Antikörper: goat anti mouse HRP & $\begin{array}{l}\text { Thermo Fisher Scientific, Waltham, } \\
\text { USA }\end{array}$ \\
\hline Acrylamid (Rotiphorese Gel) & Roth GmbH, Karlsruhe, Deutschland \\
\hline Ammoniumperoxidsulfat (APS) & Roth GmbH, Karlsruhe, Deutschland \\
\hline Bromphenolblau & Roth GmbH, Karlsruhe, Deutschland \\
\hline Dithiothreitol (DTT) & Merck KGaA, Darmstadt, Deutschland \\
\hline $\begin{array}{l}\text { Glycerinaldehyd-3-phosphat-Dehydrogenase } \\
\text { (GAPDH) }\end{array}$ & Hy-Test Ltd., Turku, Finnland \\
\hline Glycerol & $\begin{array}{l}\text { Sigma-Aldrich } \mathrm{GmbH} \text {, Steinheim, } \\
\text { Deutschland }\end{array}$ \\
\hline Mercaptoethanol & Roth $\mathrm{GmbH}$, Karlsruhe, Deutschland \\
\hline Methanol & chem solute \\
\hline Natriumchlorid $(\mathrm{NaCl})$ & Roth GmbH, Karlsruhe, Deutschland \\
\hline Natriumdodecylsulfat (SDS) & Roth $\mathrm{GmbH}$, Karlsruhe, Deutschland \\
\hline Natriumfluorid (NaF) & Roth $\mathrm{GmbH}$, Karlsruhe, Deutschland \\
\hline Natriumpyrophosphat & Roth $\mathrm{GmbH}$, Karlsruhe, Deutschland \\
\hline Ponceau S & Roth $\mathrm{GmbH}$, Karlsruhe, Deutschland \\
\hline Starting Block (TBS) Blocking Buffer & $\begin{array}{l}\text { Thermo Fisher Scientific, Waltham, } \\
\text { USA }\end{array}$ \\
\hline Sucrose & $\begin{array}{l}\text { Sigma-Aldrich } \mathrm{GmbH} \text {, Steinheim, } \\
\text { Deutschland }\end{array}$ \\
\hline Tetramethylethylendiamin (TEMED) & Roth GmbH, Karlsruhe, Deutschland \\
\hline Trichloressigsäure (20\%) & Roth GmbH, Karlsruhe, Deutschland \\
\hline Trishydroxymethylaminomethan (TRIS) & Roth GmbH, Karlsruhe, Deutschland \\
\hline Triton X-100 & Roth GmbH, Karlsruhe, Deutschland \\
\hline Tween20 & Roth GmbH, Karlsruhe, Deutschland \\
\hline
\end{tabular}

Tabelle 20 Verwendete Chemikalien für die proteinchemischen Untersuchungen 


\begin{tabular}{|c|c|}
\hline Hilfsmittel & Hersteller \\
\hline BCA-Proteinassay-Kit & $\begin{array}{l}\text { Thermo Fisher Scientific, Waltham, } \\
\text { USA }\end{array}$ \\
\hline Eppendorf Tubes (1,5 ml und $2 \mathrm{ml}$ ) & $\begin{array}{l}\text { Eppendorf AG, Hamburg, Deutsch- } \\
\text { land }\end{array}$ \\
\hline Gelloadertips & $\begin{array}{l}\text { Eppendorf AG, Hamburg, Deutsch- } \\
\text { land }\end{array}$ \\
\hline Glasplatten: Spacer Plate und Short Plate $(0,75 \mathrm{~mm})$ & $\begin{array}{l}\text { Bio-Rad GmbH, München, Deutsch- } \\
\text { land }\end{array}$ \\
\hline Kaleidoscope (Proteingrößenmarker) & $\begin{array}{l}\text { Bio-Rad GmbH, München, Deutsch- } \\
\text { land }\end{array}$ \\
\hline Küvette: Uvette & $\begin{array}{l}\text { Eppendorf AG, Hamburg, Deutsch- } \\
\text { land }\end{array}$ \\
\hline Mini Trans-Blot Cell & $\begin{array}{l}\text { Bio-Rad GmbH, München, Deutsch- } \\
\text { land }\end{array}$ \\
\hline Mini-PROTEAN Tetra System & $\begin{array}{l}\text { Bio-Rad GmbH, München, Deutsch- } \\
\text { land }\end{array}$ \\
\hline Mörser & $\begin{array}{l}\text { W. Haldenwanger, Waldkraiburg, } \\
\text { Deutschland }\end{array}$ \\
\hline OrthoMedium Curix Screens (Filmkassette) & $\begin{array}{l}\text { Agfa GmbH, Düsseldorf, Deutsch- } \\
\text { land }\end{array}$ \\
\hline Pistillen & $\begin{array}{l}\text { W. Haldenwanger, Waldkraiburg, } \\
\text { Deutschland }\end{array}$ \\
\hline Protease Inhibitor Cocktail & $\begin{array}{l}\text { Sigma-Aldrich } \mathrm{GmbH} \text {, Steinheim, } \\
\text { Deutschland }\end{array}$ \\
\hline Research Pipette 0,5-10 $\mu \mathrm{l}$ & $\begin{array}{l}\text { Eppendorf AG, Hamburg, Deutsch- } \\
\text { land }\end{array}$ \\
\hline Research Pipette 10-100 $\mu \mathrm{l}$ & $\begin{array}{l}\text { Eppendorf AG, Hamburg, Deutsch- } \\
\text { land }\end{array}$ \\
\hline SuperRX Fuji Medical X-Ray Film & $\begin{array}{l}\text { Fujifilm GmbH, Düsseldorf, Deutsch- } \\
\text { land }\end{array}$ \\
\hline SuperSignal West Pico Chemiluminescent Substrate & $\begin{array}{l}\text { Thermo Fisher Scientific, Waltham, } \\
\text { USA }\end{array}$ \\
\hline TipOne Filter Tips (Pipettenspitzen) & $\begin{array}{l}\text { STARLAB GmbH, Ahrensburg, } \\
\text { Deutschland }\end{array}$ \\
\hline Transferpipette S 100-1000 $\mu \mathrm{l}$ & $\begin{array}{l}\text { Brand GmbH, Wertheim, Deutsch- } \\
\text { land }\end{array}$ \\
\hline Whatman Filterpapier (3mm CHR) & Roth $\mathrm{GmbH}$, Karlsruhe, Deutschland \\
\hline
\end{tabular}




\begin{tabular}{|l|l|}
\hline Hilfsmittel & Hersteller \\
\hline $\begin{array}{l}\text { Whatman PROTRAN Nitrocellulose Transfer Mem- } \\
\text { brane }\end{array}$ & Roth GmbH, Karlsruhe, Deutschland \\
\hline Zentrifugenröhrchen ECO & Roth GmbH, Karlsruhe, Deutschland \\
\hline
\end{tabular}

Tabelle 21 Verwendete Hilfsmittel für die proteinchemischen Untersuchungen

\begin{tabular}{|l|l|}
\hline Geräte & Hersteller \\
\hline Bio Doc Analyze & $\begin{array}{l}\text { Biometra GmbH, Göttingen, Deutsch- } \\
\text { land }\end{array}$ \\
\hline BioMate5 & $\begin{array}{l}\text { Thermo Spectronic, Dreieich, Deutsch- } \\
\text { land }\end{array}$ \\
\hline Centrifuge 5415 R & Eppendorf AG, Hamburg, Deutschland \\
\hline MS2 Minishaker & IKA GmbH, Staufen, Deutschland \\
\hline Röntgenfilm-Entwicklungsmaschine: SRX-101A & $\begin{array}{l}\text { Konica Minolta, Langenhagen, } \\
\text { Deutschland }\end{array}$ \\
\hline Polymax 1040 (Plattformschüttler) & $\begin{array}{l}\text { Heidolph Instruments GmbH, Schwab- } \\
\text { ach, Deutschland }\end{array}$ \\
\hline Standard Power Pack P25 & $\begin{array}{l}\text { Biometra GmbH, Göttingen, Deutsch- } \\
\text { land }\end{array}$ \\
\hline ThermoStat plus & \begin{tabular}{l} 
Eppendorf AG, Hamburg, Deutschland \\
\hline
\end{tabular}
\end{tabular}

Tabelle 22 Verwendete Geräte für die proteinchemischen Untersuchungen

\begin{tabular}{|l|l|}
\hline Software & Hersteller \\
\hline BioDocAnalyze BDA U-205 Ser.Nr.660748627-0 & $\begin{array}{l}\text { Biometra GmbH, Göttingen, Deutsch- } \\
\text { land }\end{array}$ \\
\hline VISIONlite Quant Version 1.0 & $\begin{array}{l}\text { Thermo Spectronic, Dreieich, Deutsch- } \\
\text { land }\end{array}$ \\
\hline
\end{tabular}

Tabelle 23 Verwendete Software für die proteinchemischen Untersuchungen 


\subsubsection{ELISA}

\begin{tabular}{|l|l|}
\hline Chemikalien & Hersteller \\
\hline big42 antibody to human LBP & $\begin{array}{l}\text { Biometec } \mathrm{GmbH}, \text { Greifswald, } \\
\text { Deutschland }\end{array}$ \\
\hline Tween20 & Roth $\mathrm{GmbH}$, Karlsruhe, Deutschland \\
\hline Natriumchlorid $(\mathrm{NaCl})$ & Roth GmbH, Karlsruhe, Deutschland \\
\hline proBNP II & $\begin{array}{l}\text { Roche Diagnostics, Mannheim, } \\
\text { Deutschland }\end{array}$ \\
\hline
\end{tabular}

Tabelle 24 Verwendete Chemikalien für den ELISA-Test

\begin{tabular}{|l|l|}
\hline Geräte & Hersteller \\
\hline Elecsys 2010 & $\begin{array}{l}\text { Roche Diagnostics, Mannheim, } \\
\text { Deutschland }\end{array}$ \\
\hline
\end{tabular}

Tabelle 25 Verwendete Geräte für den ELISA-Test

\subsubsection{Histologie}

\begin{tabular}{|c|c|}
\hline Chemikalien & Hersteller \\
\hline AK Diluent S2022 & $\begin{array}{l}\text { DakoCytomation, Hamburg, Deutsch- } \\
\text { land }\end{array}$ \\
\hline Aqua Bidest & $\begin{array}{l}\text { Apotheke, Universitätsmedizin } \\
\text { Göttingen }\end{array}$ \\
\hline Chloralhydrat & Merck, Darmstadt, Deutschland \\
\hline Chloroform & $\begin{array}{l}\text { Apotheke, Universitätsmedizin } \\
\text { Göttingen }\end{array}$ \\
\hline Chromogen DAB K3468 & $\begin{array}{l}\text { DakoCytomation, Hamburg, Deutsch- } \\
\text { land }\end{array}$ \\
\hline Dako Pen S200230-2 & $\begin{array}{l}\text { DakoCytomation, Hamburg, Deutsch- } \\
\text { land }\end{array}$ \\
\hline Eisessig & Merck, Darmstadt, Deutschland \\
\hline Entellan 1.07961.0100 & Merck, Darmstadt, Deutschland \\
\hline Envison & $\begin{array}{l}\text { DakoCytomation, Hamburg, Deutsch- } \\
\text { land }\end{array}$ \\
\hline Eosin & Merck, Darmstadt, Deutschland \\
\hline $\begin{array}{l}\text { Ethanol 99\% (vergällt 1\%) in verschiedenen Kon- } \\
\text { zentrationen }\end{array}$ & $\begin{array}{l}\text { Apotheke, Universitätsmedizin } \\
\text { Göttingen }\end{array}$ \\
\hline Flüssiger Stickstoff & Apotheke, Universitätsmedizin \\
\hline
\end{tabular}




\begin{tabular}{|c|c|}
\hline Chemikalien & Hersteller \\
\hline & Göttingen \\
\hline Formalin Solution $10 \%$ Neutral buffered & $\begin{array}{l}\text { Sigma Diagnostics, Saint Quentin } \\
\text { Fallavier Cedex, Frankreich }\end{array}$ \\
\hline Formalin Solution $10 \%$ Neutral buffered & Roth, Karlsruhe, Deutschland \\
\hline Hämalaun & $\begin{array}{l}\text { Apotheke, Universitätsmedizin } \\
\text { Göttingen }\end{array}$ \\
\hline Hämatoxylin krist. & Merck, Darmstadt, Deutschland \\
\hline Kalialaun & Merck, Darmstadt, Deutschland \\
\hline Na-Jodat & Merck, Darmstadt, Deutschland \\
\hline $\mathrm{NaCl} 1367.1000$ & $\begin{array}{l}\text { Th. Geyer GmbH\&Co Kg., Renningen, } \\
\text { Deutschland }\end{array}$ \\
\hline Paraplast Plus $\left(65^{\circ} \mathrm{C}\right)$ & $\begin{array}{l}\text { Sherwood Medical Co., Norfolk, Ne- } \\
\text { braska, USA }\end{array}$ \\
\hline Primär- AK CD14 NCL-CD14-223 & $\begin{array}{l}\text { Leica Biosystems, Newcastle Upon } \\
\text { Tyne, UK }\end{array}$ \\
\hline Primär- AK CD68 M0876 & $\begin{array}{l}\text { DakoCytomation, Hamburg, Deutsch- } \\
\text { land }\end{array}$ \\
\hline Sekundär- AK Mouse- anti- Rabbit M0633 & $\begin{array}{l}\text { DakoCytomation, Hamburg, Deutsch- } \\
\text { land }\end{array}$ \\
\hline Sekundär- AK Rabbit- anti- Mouse P0260 & $\begin{array}{l}\text { DakoCytomation, Hamburg, Deutsch- } \\
\text { land }\end{array}$ \\
\hline $\begin{array}{l}\text { Target Retrieval Solution pH } 6 \text { für CD14 und biG42 } \\
(\text { Citrat pH6) }\end{array}$ & $\begin{array}{l}\text { DakoCytomation, Hamburg, Deutsch- } \\
\text { land }\end{array}$ \\
\hline Target Retrieval Solution pH 9 für CD68 (Citrat pH9) & $\begin{array}{l}\text { DakoCytomation, Hamburg, Deutsch- } \\
\text { land }\end{array}$ \\
\hline Target Retrieval Solution pH 9 S3307 & $\begin{array}{l}\text { DakoCytomation, Hamburg, Deutsch- } \\
\text { land }\end{array}$ \\
\hline Tris AE15.2 & Roth, Karlsruhe, Deutschland \\
\hline $\begin{array}{l}\text { Wasserstoffperoxid 3\%ig, Dako REAL, Pe- roxi- } \\
\text { dase-Blocking Solution S2023 }\end{array}$ & $\begin{array}{l}\text { DakoCytomation, Hamburg, Deutsch- } \\
\text { land }\end{array}$ \\
\hline Xylol & $\begin{array}{l}\text { Apotheke, Universitätsmedizin } \\
\text { Göttingen }\end{array}$ \\
\hline Zitronensäure & Merck, Darmstadt, Deutschland \\
\hline
\end{tabular}

Tabelle 26 Verwendete Chemikalien für die histologischen Untersuchungen 


\begin{tabular}{|c|c|}
\hline Geräte & Hersteller \\
\hline Ausgießstation & Leica Camera AG, Solms, Deutschland \\
\hline Cup, graduated conical test tubes, PP $30 \times 115,50 \mathrm{ml}$ & Schuett24, Göttingen, Deutschland \\
\hline Deckglas $24 \times 24 \mathrm{~mm}$ & $\begin{array}{l}\text { Menzel Gläser, Braunschweig, } \\
\text { Deutschland }\end{array}$ \\
\hline Einbettautomat TP 1020 & Leica Camera AG, Solms, Deutschland \\
\hline Kamera C-4040 & Olympus, Hamburg, Deutschland \\
\hline Klinge Mikrotome Blades S 35 & Feather, Osaka, Japan \\
\hline Kühlplatte KUNZ CP-4 & Leica Camera AG, Solms, Deutschland \\
\hline Kühlschrank & Bosch, Stuttgart, Deutschland \\
\hline Magnete & Roth, Karlsruhe, Deutschland \\
\hline Magnetmischer, MR 3002C & Heidolgh, Schwabach, Deutschland \\
\hline Mikroskop BH 2 & Olympus, Hamburg, Deutschland \\
\hline Mikroskop MBL 2000 & Krüss Optronic, Hamburg, Deutschland \\
\hline MS2 Minishaker & IKA, Staufen, Deutschland \\
\hline pH-Messgerät, inoLab & WTW, Weilheim, Deutschland \\
\hline Pipette 1003130 & Eppendorf, Hamburg, Deutschland \\
\hline Pipette Reference 2500 & Eppendorf, Hamburg, Deutschland \\
\hline Pipette Research 0,5-10 $\mu$ l, 4745572 & Eppendorf, Hamburg, Deutschland \\
\hline Pipette Research 10-100 $\mu$ l, 3619472 & Eppendorf, Hamburg, Deutschland \\
\hline Pipette Research 100- $1000 \mu$ l, 4786522 & Eppendorf, Hamburg, Deutschland \\
\hline Pipettenspitzen & Roth, Karlsruhe, Deutschland \\
\hline Schlittenmikrotom SM $2000 \mathrm{R}$ & Leica Camera AG, Solms, Deutschlano \\
\hline $\begin{array}{l}\text { Silanisierte Objektträger Microskope Slides Super- } \\
\text { frost Excellence }\end{array}$ & $\begin{array}{l}\text { Erie Scientific Company, Portsmouth, } \\
\text { New Hampshire, USA }\end{array}$ \\
\hline Universal- Einbettkassetten & $\begin{array}{l}\text { R.Langenbrinck, Emmendingen, } \\
\text { Deutsch- land }\end{array}$ \\
\hline Waage, BL1505 & Sartorius, Göttingen, Deutschland \\
\hline
\end{tabular}

Tabelle 27 Verwendete Geräte für die histologischen Untersuchungen 


\subsection{Abbildungsverzeichnis}

Abbildung 1 Ätiologie der Parodontitis ............................................................. 10

Abbildung 2 Entwickung von Komplexen ....................................................... 12

Abbildung 3 Pathogenese der menschlichen Parodontitis................................... 13

Abbildung 4 Aufnahme und Abbau von BNP................................................. 20

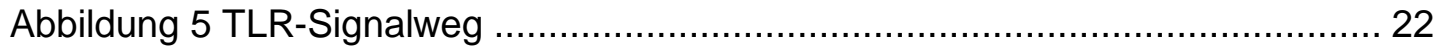

Abbildung 6 Entwickelter Röntgenfilm mit sichtbarem Bandenmuster von LBP und

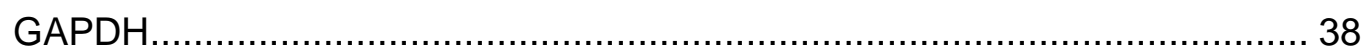

Abbildung 7 Scores für: HE-Inflammation, LBP (big42), CD14 und CD68 ............. 41

Abbildung 8 Kardiale Diagnosen.............................................................. 42

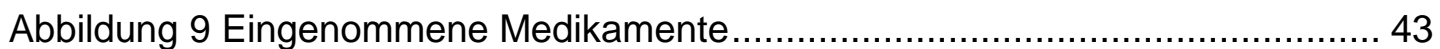

Abbildung 10 Am Herzgewebe nachgewiesene parodontopathogene Bakterien.... 45

Abbildung 11 Vergleich LBP (big42) gegen proBNP NT im Atrium ....................... 50

Abbildung 12 Vergleich von LBP ( big42 ) an Atrium und Ventrikel mit oralem

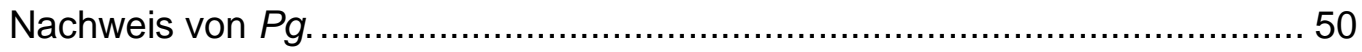

Abbildung 13 Vergleich der histologischen Auswertung des HE-Inflammationsgrades mit der Proteinanalyse von LBP (big42; beides Atrium) und dem Grad der

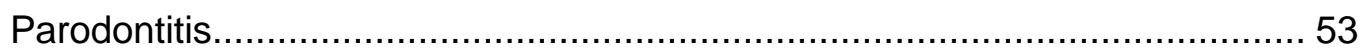

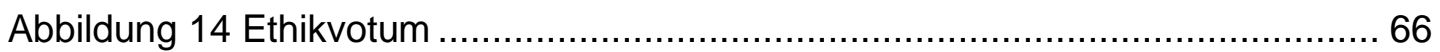

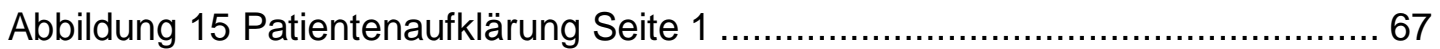

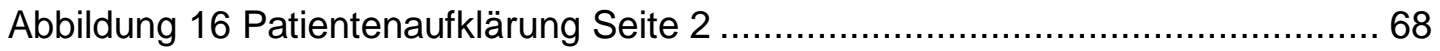

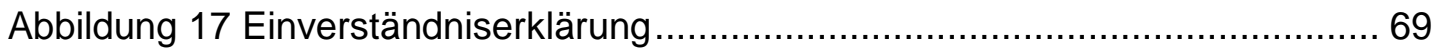

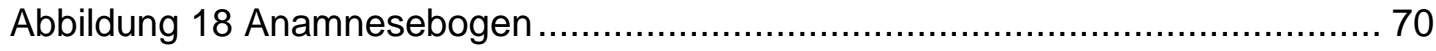




\subsection{Tabellenverzeichnis}

Tabelle 1 Einteilung der Parodontitis nach Schweregrad (Page und Eke 2007) .... 27

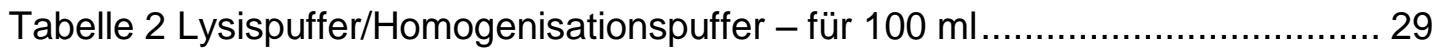

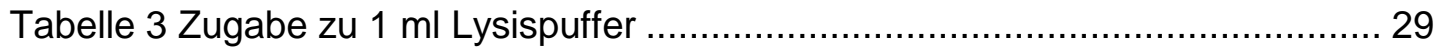

Tabelle 4 Verfärbungsgrad der Membran mit entsprechender Keimkonzetration und

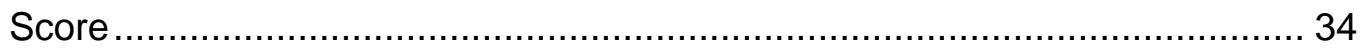

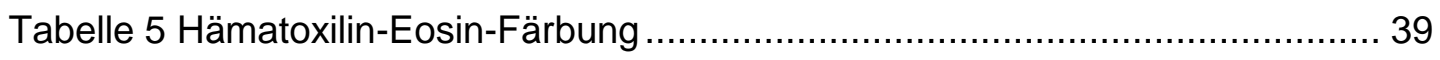

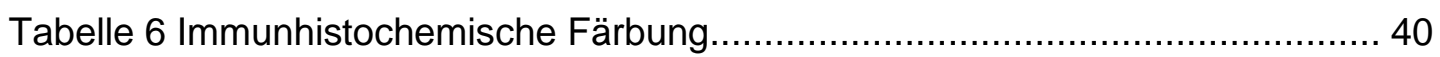

Tabelle 7 Mundgesundheitsparameter: Zahnstatus, Entzündungsindex,

Parodontalstatus.

Tabelle 8 Prävalenz der nachgewiesenen parodontopathogenen Bakterien ... 45

Tabelle 9 Verteilung der mikrobiologischen Funde im Mund und am Herzen. 46

Tabelle 10 Score der mikrobiologischen Analysen oraler Proben aller 10 Patienten

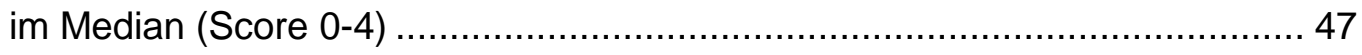

Tabelle 11 Genetische Untersuchung IL-1-Polymorphismus............................... 48

Tabelle 12 Western Blot-Analyse. Median von LBP und BNP am Herzgewebe ..... 49

Tabelle 13 Western Blot-Analyse von LBP und BNP am Herzgewebe, alle Ergebnisse 49

Tabelle 14 ELISA-Median von LBP und BNP am Herzgewebe 51

Tabelle 15 ELISA von LBP und BNP am Herzgewebe, alle Ergebnisse. 51

Tabelle 16 Ergebnisse der histologischen und immunhistochemischen

Untersuchung für alle Patienten. 52

Tabelle 17 Verwendete Chemikalien für die molekularbiologischen Untersuchungen

Tabelle 18 Verwendete Hilfsmittel für die molekularbiologischen Untersuchungen 71

Tabelle 19 Verwendete Geräte für die molekularbiologischen Untersuchungen..... 71

Tabelle 20 Verwendete Chemikalien für die proteinchemischen Untersuchungen 72

Tabelle 21 Verwendete Hilfsmittel für die proteinchemischen Untersuchungen ..... 74

Tabelle 22 Verwendete Geräte für die proteinchemischen Untersuchungen .......... 74

Tabelle 23 Verwendete Software für die proteinchemischen Untersuchungen....... 74

Tabelle 24 Verwendete Chemikalien für den ELISA-Test.................................... 75

Tabelle 25 Verwendete Geräte für den ELISA-Test ......................................... 75

Tabelle 26 Verwendete Chemikalien für die histologischen Untersuchungen......... 76

Tabelle 27 Verwendete Geräte für die histologischen Untersuchungen ................. 77 


\section{Literaturverzeichnis}

Agrawal AA, Kapley A, Yeltiwar RK, Purohit HJ (2006):

Assessment of single nucleotide polymorphism at IL-1A+4845 and IL-1B+3954 as genetic susceptibility test for chronic periodontitis in Maharashtrian ethnicity.

J Periodontol $\underline{77}, 1515-1521$

Aimetti M, Romano F, Nessi F (2007):

Microbiologic analysis of periodontal pockets and carotid atheromatous plaques in advanced chronic periodontitis patients.

J Periodontol $\underline{78}, 1718-1723$

Al-Nawas B, Block M, Ertl G, Franzen D, Gohlke-Bärwolf C, Herrmann M, Werdan K (2010):

Kommentierte Zusammenfassung der Leitlinien der European Society of Cardiology zur infektiösen Endokarditis (Neuauflage 2009).

Kardiologe 4(4), 285-294

Amar S, Gokce N, Morgan S, Loukideli M, Van Dyke TE, Vita JA (2003):

Periodontal disease is associated with brachial artery endothelial dysfunction and systemic inflammation.

Arterioscler Thromb Vasc Biol 23, 1245-1249

Angeli F, Verdecchia P, Pellegrino C, Pellegrino RG, Pellegrino G, Prosciutti L, Giannoni C, Cianetti S, Bentivoglio M (2003):

Association between disease and left ventricle mass in essential hypertension. Hypertension 41(3), 488-492

Arbes SJ, Slade GD, Beck JD (1999):

Association between extent of periodontal attachment loss and self-reported history of heart attack: an analysis of NHANES III data.

J Dent Res $\underline{78}, 1777-1782$

Archana PM, Salman AA, Kumar TS, Saraswathi PK, Panishankar KH, \& Kumarasamy $P$ (2012):

Association between interleukin-1 gene polymorphism and severity of chronic periodontitis in a south indian population group.

$\mathrm{J}$ Indian Soc Periodontol 16, 174-8

Armitage GC (1999):

Development of a classification system for periodontal diseases and conditions.

Ann Periodontol 4, 1-6

Baumgarten G, Knuefermann P, Nozaki N, Sivasubramanian N, Mann DL, Vallejo JG (2001):

In vivo expression of proinflammatory mediators in the adult heart after endotoxin administration: the role of toll-like receptor-4.

$\mathrm{J}$ Infect Dis $\underline{183}, 1617-1624$

Baumgarten G, Knuefermann P, Kalra D, Gao F, Taffet GE, Michael L, Blackshear PJ, Carballo E, Sivasubramanian N, Mann DL (2002):

Load-dependent and -independent regulation of proinflammatory cytokine and cytokine receptor gene expression in the adult mammalian heart.

Circulation $\underline{105}$, 2192-2197 
Baumgarten G, Kim SC, Stapel H, Vervölgyi V, Bittig A, Hoeft A, Meyer R, Grohé C, Knuefermann P (2006):

Myocardial injury modulates the innate immune system and changes myocardial sensitivity.

Basic Res Cardiol 101, 427-435

Bay M, Kirk V, Parner J et. al (2003):

NT-proBNP: a new diagnostic screening tool to differentiate between patients with normal and reduced left ventricular systolic function.

Heart $\underline{89}$, 150-154

Beck JD, Elter JR, Heiss G, Couper D, Mauriello SM, Offenbacher S (2001):

Relationship of periodontal disease to carotid artery intima media wall thickness: the Atherosclerosis Risk in Communities (ARIC) Study.

Arterioscler Thromb Vasc Biol 21, 1816-1822

Beckmann E, Grau JB, Sainger R, Poggio P, Ferrari G (2010):

Insights into the use of biomarkers in calcific aortic valve disease.

The Journal of Heart Valve Disease $\underline{19}, 441-52$

Berner R, Fürll B, Stelter F, Dröse J, Müller HP, Schütt C (2002):

Elevated levels of lipopolysaccharide-binding protein and soluble CD14 in plasma in neonatal early-onset sepsis.

Clin Diagn Lab Immunol $\underline{9}(2), 440-445$

Biddle AJ, Palmer RM, Wilson RF, Watts TL (2001):

Comparison of the validity of periodontal probing measurements in smokers and non-smokers.

J Clin Periodontol 28 (8), 806-812

Blairon L, Wittebole X, Laterre PF (2003):

Lipopolysaccharide-binding protein serum levels in patients with severe sepsis due to gram-positive and fungal infections.

$\mathrm{J}$ Infect Dis 187(2), 287-291

Blaizot A, Vergnes JN, Nuwwareh S, Amar J, Sixou M (2009):

Periodontal diseases and cardiovascular events: meta-analysis of observational studies.

Int Dent J $\underline{59}, 197-209$

Boutaga K, van Winkelhoff AJ, Vandenbroucke-Grauls CM, Savelkoul PH (2003):

Comparison of real-time PCR and culture for detection of Porphyromonas gingivalis in subgingival plaque samples.

J Clin Microbiol 41(11), 4950-4954

Bozkurt B, Kribbs SB, Clubb FJ Jr, Michael LH, Didenko VV, Hornsby PJ, Seta Y, Oral H, Spinale FG, Mann DL (1998):

Pathophysiologically relevant concentrations of tumor necrosis factor-alpha promote progressive left ventricular dysfunction and remodeling in rats.

Circulation 97, 1382-1391

Bruneau BG, Piazza LA, de Bold AJ (1997):

BNP gene expression is specifically modulated by stretch and ET-1 in a new model of isolated rat atria.

Am Physiological Soc 273(6 Pt 2), H2678-86 
Brunner M, Giovanni ES, Lang NP (2002):

Aggressive Parodontitis.

Parodontologie 13(4), 321-343

Burgemeister S, Schlagenauf U:

Chronische Parodontitis. In: Parodontalerkrankungen: Klassifikation und Charakterisierung. Hrsg. v. Lang NP; Quintessenz, Berlin 2003, 59-62

Chen R, Luo FK, Wang YL, Tang JL, Liu YS (2011):

LBP and CD14 polymorphisms correlate with increased colorectal carcinoma risk in han chinese.

World J Gastroenterol 17(18), 2326-2331

Classen M, Diehl V, Kochsiek K:

Innere Medizin. 5. Auflage; Urban \& Fischer, München 2004

Cobe HM (1954):

Transitory bacteremia.

Oral Surg Oral Med Oral Pathol $\underline{7}, 609-615$

Comstock KL, Krown KA, Page MT, Martin D, Ho P, Pedraza M, Castro EN, Nakajima N, Glembotski CC, Quintana PJ, Sabbadini RA (1998):

LPS-induced TNF-alpha release from and apoptosis in rat cardiomyocytes: obligatory role for CD14 in mediating the LPS response.

J Mol Cell Cardiol $\underline{30}$, 2761-2775

Conrads G (1999):

Molekularbiologische Verfahren in der Anaerobier-, speziell Parodontitiserregerdiagnostik.

Mikrobiologie $\underline{9}, 165-169$

Conraads VM, Bosmans JM, Schuerwegh AJ, Goovaerts I, De Clerck LS, Stevens WJ, Bridts $\mathrm{CH}$, Vrints CJ (2005):

Intracellular monocyte cytokine production and CD 14 expression are up-regulated in severe vs mild chronic heart failure.

J Heart Lung Transplant 24, 854-859

Cohn JN, Ferrari R, Sharpe N (2000):

Cardiac remodeling - concepts and clinical implications: a consensus paper from an international forum on cardiac remodeling. Behalf of an International Forum on Cardiac Remodeling.

J Am Coll Cardiol 35, 569-582

Cowan DB, Poutias DN, Del Nido PJ, McGowan FX Jr. (2000):

CD14-independent activation of cardiomyocyte signal transduction by bacterial endotoxin.

Am J Physiol Heart Circ Physiol 279, H619-29

The Criteria Committee of the New York Heart Association:

Nomenclature and Criteria for Diagnosis of Diseases of the Heart and Great Vessels. 9th edition Little, Brown \& Co, Boston 1994

Dahlén G, Lindhe J, Sato K (1992):

The effect of supragingival plaque control on the subgingival microbiota in subjects with periodontal disease.

J Clin Periodontol $\underline{19}$, 802-809 
D'Aiuto F, Ready D, Tonetti MS (2004):

Periodontal disease and C-reactive protein- associated cardiovascular risk.

J Periodontal Res $\underline{39}$, 236-241

D'Aiuto F, Graziani F, Tetè S, Gabriele M, Tonetti MS (2005):

Periodontitis: from local infection to systemic diseases.

Int J Immunopathol Pharmacol $\underline{18}, 1-11$

Dasi LP, Simon HA, Sucosky P, Yoganathan AP (2009):

Fluid mechanics of artificial heart valves.

Clin Exp Pharmacol Physiol 36(2), 225-237

de Lemos JA, McGuire DK, Drazner MH (2003):

B-type natriuretic peptide in cardiovascular disease.

The Lancet 362(9380), 316-322

DeStefano F, Anda RF, Kahn HS, Williamson DF, Russell CM (1993):

Dental disease and risk of coronary heart disease and mortality.

BMJ $\underline{306}, 688-691$

Desvarieux M, Demmer RT, Rundek T, Boden-Albala B, Jacobs DR Jr, Sacco RL, Papapanou PN (2005):

Periodontal microbiota and carotid intima-media thickness: the Oral Infections and Vascular Disease Epidemiology Study (INVEST).

Circulation 111, 576-582

Devaux B, Scholz D, Hirche A, Klövekorn WP, Schaper J (1997):

Upregulation of cell adhesion molecules and the presence of low grade inflammation in human chronic heart failure.

Eur Heart J $\underline{18}$, 470-479

DGP: Deutsche Gesellschaft für Parodontologie (Hrsg.):

Klassifikation der Parodontalerkrankungen. Quintessenz, Berlin 2002

DGParo: Deutsche Gesellschaft für Parodontologie (Hrsg.):

Die Klassifikation der Parodontalerkrankungen. Quintessenz, Berin 2013

Dietrich T, Jimenez M, Krall Kaye EA, Vokonas PS, Garcia RI (2008):

Age-dependent associations between chronic periodontitis/edentulism and risk of coronary heart disease.

Circulation $\underline{117}$, 1668-1674

Diwan A, Tran T, Misra A, Mann DL (2003):

Inflammatory mediators and the failing heart: a translational approach.

Curr Mol Med $\underline{3}, 161-182$

Eick S, Pfister W (2002):

Comparison of microbial cultivation and a commercial PCR based method for detection of periodontopathogenic species in subgingival plaque samples.

J Clin Periodontol 299(7), 638-644

Eick S, Straube A, Guentsch A, Pfister W, Jentsch H (2011):

Comparison of real-time polymerase chain reaction and dna-strip technology in microbiological evaluation of periodontitis treatment.

Diagn Microbiol Infect Dis $\underline{69}(1), 12-20$ 
Ellis JS, Averley PA, Preshaw PM, Steele JG, Seymour RA, Thomason JM (2007): Change in cardiovascular risk status after dental clearance.

Br Dent J 202, 543-544

Fearns C, Kravchenko VV, Ulevitch RJ, Loskutoff DJ (1995):

Murine CD14 gene expression in vivo: extramyeloid synthesis and regulation by lipopolysaccharide.

J Exp Med 181, 857-866

Forner L, Larsen T, Kilian M, Holmstrup P (2006):

Incidence of bacteremia after chewing, tooth brushing and scaling in individuals with periodontal inflammation.

J Clin Periodontol 33, 401-407

Gaengler P, Goebel G, Kurbad A, Kosa W (1988):

Assessment of periodontal disease and dental caries in a population survey using the CPITN, GPM/T and DMF/T Indizes.

Community Dent Oral Epidemiol 16, 236-239

Genco RJ (1996):

Current view of risk factors for periodontal diseases.

J Periodontol 67(10 Suppl), 1041-1049

Gioannini L, Teghanemt A, Zhang D, Levis N, Weiss P (2005):

Monomeric endotoxin:protein complexes are essential for TLR4-dependent cell activation.

J Endotoxin Res 11(2), 117-123

Grau AJ, Becher H, Ziegler CM, Lichy C, Buggle F, Kaiser C, Lutz R, Bültmann S, Preusch M, Dörfer CE (2004):

Periodontal disease as a risk factor for ischemic stroke.

Stroke $\underline{35}, 496-501$

Guthmiller JM, Novak KF:

Periodontal Diseases.

In: Polymicrobial Diseases. Hrsg. Brogden KA, Guthmiller JM; ASM Press,

Washington (DC), 2002, Chapter 8

Haffajee AD (1996):

Microbial risk indicators for periodontal attachment loss.

J Periodontal Res $\underline{26}, 293$

Haffajee AD, Socransky SS (2005):

Microbiology of periodontal diseases: introduction.

Periodontol $2000 \underline{38}, 9-12$

Haffajee AD, Yaskell T, Torresyap G, Teles R, Socransky S (2009):

Comparison between polymerase chain reaction-based and checkerboard DNA hybridization techniques for microbial assessment of subgingival plaque samples. J Clin Periodontol $\underline{36}(8), 642-649$

Hanioka T, Matsuse R, Shifemoto Y, Ojima M, Shizukuishi S (2005):

Relationship between periodontal disease status and combination of biochemical assays of gingival crevicular fluid.

J Periodontal Res $\underline{40}$ (4), 331-338 
Holness CL, Simmons DL (1993):

Molecular cloning of CD68, a human macrophage marker related to lysosomal glycoproteins.

Blood 81(6), 1607-13

Haraszthy VI, Zambon JJ, Trevisan M, Zeid M, Genco RJ (2000):

Identification of periodontal pathogens in atheromatous plaques.

J Periodontol $\underline{71}, 1554-1560$

Hoppe UC, Erdmann E (2004):

Leitlinien zur Therapie der chronischen Herzinsuffizienz.

Z Kardiol $\underline{90}$, 218-237

Hunter W (1900):

Oral sepsis as a cause of disease.

Br Med J 2(2065), 215

Huynh-Ba G, Lang NP, Tonetti MS, Salvi GE (2007):

The association of the composite IL-1 genotype with periodontitis progression and/or treatment outcomes: a systematic review.

$\mathrm{J}$ Clin Periodontol 34, 305-317

Jentsch H, Sievert Y, Göcke R (2004):

Lactoferrin and other markers from gingival crevicular fluid and saliva before and after periodontal treatment.

J Clin Periodontol 31(7), 511-514

Joshipura KJ, Rimm EB, Douglass CW, Trichopoulos D, Ascherio A, Willett WC (1996):

Poor oral health and coronary heart disease.

J Dent Res $\underline{75}, 1631-1636$

Kebschull M, Demmer RT, Papapanou PN (2010):

"Gum bug, leave my heart alone!"--epidemiologic and mechanistic evidence linking periodontal infections and atherosclerosis.

J Dent Res 89, 879

Keijser BJ, Zaura E, Huse SM, van der Vossen JM, Schuren FH, Montijn RC, ten Cate JM Crielaard W (2008):

Pyrosequencing analysis of the oral microflora of healthy adults.

J Dent Res 87, 1016-1020

Kinane DF, Riggio MP, Walker KF, MacKenzie D, Shearer B (2005):

Bacteraemia following periodontal procedures.

J Clin Periodontol $\underline{32}, 708-713$

Kopp EB, Medzhitov R (1999):

The Toll-receptor family and control of innate immunity.

Curr Opin Immunol 11,13-18

Kornman KS, Page RC, Tonetti S (1997):

The host response to the microbial challenge in periodontitis: assembling the players.

Periodontol 14 , 33-53 
Krum H, Abraham WT (2009):

Heart failure.

Lancet $\underline{373}(9667), 941-55$

Knuefermann P, Nemoto S, Misra A, Nozaki N, Defreitas G, Goyert SM, Carabello BA, Mann DL, Vallejo JG (2002):

CD14-deficient mice are protected against lipopolysaccharide-induced cardiac inflammation and left ventricular dysfunction.

Circulation 106, 2608-2615

Kumada H, Haishima Y, Umemoto T, Tanamoto K (1995):

Structural study on the free lipid A isolated from lipopolysaccharide of porphyromonas gingivalis.

J Bacteriol, 177(8), 2098-2106

Laemmli UK (1970):

Cleavage of structural proteins during the assembly of the head of bacteriophage T4.

Nature 227, 680-685

Laine ML, Loos BG, Crielaard W (2010):

Gene polymorphisms in chronic periodontitis.

Int J Dent 2010, 324719

Lang NP, Bartold PM, Cullinan M, Jeffcoat M, Mombelli A, Murakami S et al. (1999): International workshop for a classification of periodontal disease and conditions.

Census report aggressive periodontitis.

Ann Periodontol 4, 53

Lange DE, Plagmann HC, Eenboom A, Promesberger A (1977):

Clinical evaluation processes for the objectification of oral hygiene.

Dtsch Zahnärztl Z $\underline{32}, 44$

Lederhuber HC, Lange V:

Basics Kardiologie. 2. Auflage; Elsevier, Urban \& Fischer, München 2010

Lee SD, Kuo WW, Lin DY, Chen TH, Kuo WH, Hsu HH, Chen JZ, Liu JY, Yeh YL, Huang CY (2005):

Role of calcineurin in Porphyromonas gingivalis-induced myocardial cell hypertrophy and apoptosis.

J Biomed Sci 13(2), 251-260

Lee SD, Wu CC, Chang YC, Chang SH, Wu CH, Wu JP, Hwang JM, Kuo WW, Liu JY, Huang CY (2006a):

Porphyromonas gingivalis-induced cellular hypertrophy and MMP-9 activity via different signaling pathways in $\mathrm{H} 9 \mathrm{c} 2$ cardiomyoblast cells.

J Periodontol $\underline{77}(4), 684-691$

Lee SD, Wu CC, Kuo WW, Lin JA, Hwang JM, Lu MC, Chen LM, Hsu HH, Wang CK, Chang SH, Huang CY (2006b):

Porphyromonas gingivalis-related cardiac cell apoptosis was majorly co-activated by p38 and extracellular signal-regulated kinase pathways.

J Periodontal Res $\underline{41}(1)$, 39-46 
Lepper PM, Schumann C, Triantafilou K, Rasche FM, Schuster T, Frank H, Schneider EM, Triantafilou M, von Eynatten M (2007):

Association of lipopolysaccharide-binding protein and coronary artery disease in men.

J Am Coll Cardiol 1, 25-31

Li HL, Suzuki J, Bayna E, Zhang FM, Dalle Molle E, Clark A, Engler RL, Lew WY (2002):

Lipopolysaccharide induces apoptosis in adult rat ventricular myocytes via cardiac AT(1) receptors.

Am J Physiol Heart Circ Physiol 283:2, H461-7

Libby P, Ridker PM, Maseri A (2002):

Inflammation and artheroclerosis.

Circulation $\underline{105}, 1135-1143$

Lindhe J, Ranney R, Lamster I, Charles A, Chung C, Flemming T, Kinane D, Listgarten M, Löe H, Schoor R (1999):

Consensus Report: Chronic Periodontitis.

Ann Periodontol $\underline{4}, 38$

Lindhe J, Lang NP, Karring T:

Clinical Periodontology and Implant Dentistry, 5th Edition; Wiley-Blackwell, Hoboken 2008

Listgarten MA (1980):

Periodontal probing: what does it mean?

J Clin Periodontol $\underline{7}, 165-176$

Liu R, Desta T, Raptis M, Darveau RP, Graves DT (2008):

$P$. Gingivalis and E. Coli lipopolysaccharides exhibit different systemic but similar local induction of inflammatory markers.

J Periodontol $\underline{79}(7), 1241-1247$

Löe H, Theilade E, Jensen SB (1965):

Experimental Gingivitis in man.

J Periodontol $\underline{36}, 177-187$

Löffler, Petrides, Heinrich:

Biochemie \& Pathobiochemie. 8. Auflage; Springer, Heidelberg 2007

Loos BG (2005):

Systemic markers of inflammation in periodontitis.

J Periodontol 76, 2106-2115

López NJ, Jara L, Valenzuela CY (2005):

Association of interleukin-1 polymorphisms with periodontal disease.

J Periodontol $\underline{76}$, 234-243

Luchner A, Stevens TL, Borgeson DD, Redfield M, Wei CM, Porter JG, Burnett JC (1998):

Differential atrial and ventricular expression of myocardial BNP during evolution of heart failure.

Am J Physiol 274(5 Pt 2), H1684-9 
Luchner A, Holmer S, Schunkert H, Riegger GA (2003):

Bedeutung der Herzinsuffizienzmarker BNP und NT-proBNP für die Klinik.

Dtsch Arztebl 2003 100(50), A-3314 / B-2757 / C-2577

Madsen KL (1974):

Effect of chlorbexidene mouthrinse and periodontal treatment upon bacteremia produced by oral hygiene procedures.

Scan J Dent Res 82, 1-7

Maisel A (2001):

B-type natriuretic peptide levels: a potential novel „white-count“ for congestive heart failure.

J Card Fail ㄱ, 183-193

Manau C, Echeverria A, Agueda A (2008):

Periodontal disease definition may determine the association between periodontitis and pregnancy outcomes.

J Clin Periodontol $\underline{35}$, 385-379

Mann DL (2002):

Inflammatory mediators and the failing heart: past, present, and the foreseeable future.

Circ Res $\underline{91}, 988-998$

Masamatti SS, Kumar A, Baron TK, Mehta DS, Bhat K (2012):

Evaluation of interleukin -1B (+3954) gene polymorphism in patients with chronic and aggressive periodontitis: A genetic association study.

Contemp Clin Dent $\underline{3}(2), 144-149$

McDevitt MJ, Wang HY, Knobelman C, Newman MG, Di Giovine FS, Timms J, Duff GW, Kornman KS (2000):

Interleukin-1 genetic association with periodontitis in clinical practice.

J Periodontol $\underline{71}, 156-163$

McGuire MK, Nunn ME (1999):

Prognosis versus actual outcome. IV. The effectiveness of clinical parameters and IL-1 genotype in accurately predicting prognoses and tooth survival.

J Periodontol 1 , 49-56

McMurray JJ, Stewart S (2000):

Epidemiology, aetiology, and prognosis of heart failure.

Heart $\underline{83}(5), 596-602$

Mealey BL (1999):

Influence of periodontal infections on systemic health.

J Periodontol 2000 21, 197-209

Mealey BL, Oates TW (2006):

Diabetes mellitus and periodontal diseases.

J Periodontol $\underline{77}(8), 1289-1303$

Messika-Zeitoun D, Bielak LF, Peyser PA, Sheedy PF, Turner ST, Nkomo VT, Breen JF, Maalouf J, Scott C, Tajik AJ, Enriquez-Sarano M (2007):

Aortic valve calcification: determinants and progression in the population.

Arterioscler Thromb Vasc Biol 27(3), 642 
Meyer DH, Fives-Taylor PM (1998):

Oral pathogens: from dental plaque to cardiac disease.

Current opinion in microbiology $1(1), 88-95$

Micheelis W, Schiffner U:

Vierte Deutsche Mundgesundheitsstudie (DMS IV). Institut der Deutschen Zahnärzte (Band 31); Deutscher Ärzte-Verlag, Köln 2006

Miller MB, Bassler BL (2001):

Quorum sensing in bacteria.

Annu Rev Microbiol 55, 165-199

Mombelli A, Casagni F, Madianos PN (2002):

Can presence or absence of periodontal pathogens distinguish between subjects with chronic and aggressive periodontitis? A systematic review.

J Clin Periodontol 29 (3),10-21

Morillo JM, Lau L, Sanz M, Herrera D, Silva A (2003):

Quantitative real-time PCR based on single copy gene sequence for detection of Actinobacillus actinomycetemcomitans and Porphyromonas gingivalis.

J Periodontal Res $\underline{38}(5), 518-524$

Myc A, Buck J, Gonin J, Reynolds B, Hammerling U, Emanuel D (1997):

The level of lipopolysaccharide-binding protein is significantly increased in plasma in patients with the systemic inflammatory response syndrome.

Clin Diagn Lab Immunol 4(2), 113-116

Nakagawa O, Ogawa Y, Itoh H, Suga S, Komatsu Y, Kishimoto I, Nishino K, Yoshimasa T, Nakao K (1995):

Rapid transcriptional activation and early mRNA turnover of brain natriuretic peptide in cardiocyte hypertrophy. Evidence for brain natriuretic peptide as an „emergency“ cardiac hormone against ventricular overload.

J Clin Invest $\underline{96}, 1280-1287$

Nakano K, Nemoto H, Nomura R, Inaba H, Yoshioka H, Taniguchi K, Amano A, Ooshima T (2009):

Detection of oral bacteria in cardiovascular specimens.

Oral Microbiol Immunol 24, 64-8

Nemoto S, Vallejo JG, Knuefermann P, Misra A, Defreitas G, Carabello BA, Mann DL (2002):

Escherichia coli LPS-induced LV dysfunction: role of toll-like receptor-4 in the adult heart.

Am J Physiol Heart Circ Physiol 282, H2316-23

Newman MG, Takei HH, Klokkevold PR, Carranza FA:

Carranza's Clinical Periodontology. 10th Edition; Saunders/Elsevier, St. Louis 2006

Niederbichler AD, Hoesel LM, Ipaktchi K, Olivarez L, Erdmann M, Vogt PM, Su GL, Arbabi S, Westfall MV, Wang SC, Hemmila MR (2011):

Burn-induced heart failure: lipopolysaccharide binding protein improves burn and endotoxin-induced cardiac contractility deficits.

J Surg Res $\underline{165}$, 128-35 
Nishimura F, Iwamoto Y, Soga Y (2007):

The periodontal host response with diabetes.

Periodontol $2000 \underline{43}(1), 245-253$

Oethringer M:

Mikrobiologie und Immunologie. Gustav Fischer Verlag, Stuttgart, Jena, Lübeck, Ulm (1997)

Okell CC, Elliott SD (1935):

Bacteraemia and oral sepsis: with special reference to the aetiology of subacute endocarditis.

Lancet 2, $869-872$

Ott SJ, El Mokhtari NE, Musfeldt M, Hellmig S, Freitag S, Rehman A, Kühbacher T, Nikolaus S, Namsolleck P, Blaut M, Hampe J, Sahly H, Reinecke A, Haake N, Günther R, Krüger D, Lins M, Herrmann G, Fölsch UR, Simon R, Schreiber S (2006): Detection of diverse bacterial signatures in atherosclerotic lesions of patients with coronary heart disease.

Circulation $\underline{113}(7)$, 929-937

Page RC, Kornman KS (1997):

The pathogenesis of human periodontitis: an introduction. Periodontol 2000 14, 911

Page RC, Eke PI (2007):

Case definitions for use in population-based surveillance of periodontitis.

J Periodontol $\underline{78}(7)$ 1387-1399

Palmer RM, Scott DA, Meekin TN, Poston RN, Odell EW, Wilson RF (1999):

Potential mechanisms of susceptibility to periodontitis in tobacco smokers.

J Periodontal Res 34(7), 363-369

Panaro MA, Cianciulli A, Gagliardi N, Mitolo Cl, Acquafredda A, Cavallo P, Mitolo V (2008):

CD14 major role during lipopolysaccharide-induced inflammation in chick embryo cardiomyocytes.

FEMS Immunol Med Microbiol $\underline{53}, 35-45$

Parolari A, Loardi C, Mussoni L, Cavallotti L, Camera M, Biglioli P, Tremoli E, Alamanni $F$ (2009):

Nonrheumatic calcific aortic stenosis: an overview from basic science to pharmacological prevention.

Eur J Cardiothorac Surg $\underline{35}$, 493-504

Paster BJ, Boches SK, Galvin JL, Ericson RE, Lau CN, Levanos VA, Sahasrabudhe A, Dewhirst FE (2001):

Bacterial diversity in human subgingival plaque.

J Bacteriol 183(12), 3770-3783

Pauriah M, Khan F, Lim TK, Elder DH, Godfrey V, Kennedy G, Belch JJ, Booth NA, Struthers AD, Lang CC (2012):

B-type natriuretic peptide is an independent predictor of endothelial function in man. Clin Sci (Lond) $\underline{123}$ (5), 307-12 
Pavcnik-Arnol M, Hojker S, Derganc M (2004):

Lipopolysaccharide-binding protein in critically ill neonates and children with suspected infection: comparison with procalcitonin, interleukin-6, and C-reactive protein.

Intensive Care Med, $\underline{30}(7), 1454-1460$

Pfisterer M, Buser P, Rickli H, Gutmann M, Erne P, Rickenbacher P, Vuillomenet A, Jeker U, Dubach P, Beer H, Yoon SI, Suter T, Osterhues HH, Schieber MM, Hilti P, Schindler R, Brunner-La Rocca HP; TIME-CHF Investigators (2009):

BNP-guided vs symptom-guided heart failure therapy: the Trial of Intensified vs Standard Medical Therapy in Elderly Patients With Congestive Heart Failure (TIMECHF) randomized trial.

JAMA 301(4), 383-392

Piconi S, Trabattoni D, Luraghi C, Perilli E, Borelli M, Pacei M, Rizzardini G, Lattuada A, Bray DH, Catalano M, Sparaco A, Clerici M (2009):

Treatment of periodontal disease results in improvements in endothelial dysfunction and reduction of the carotid intima-media thickness.

FASEB J $\underline{23}, 1196-1204$

Plagmann $\mathrm{HC}$ :

Lehrbuch der Parodontologie. Hanser Verlag, München 1998

Pucar A, Milasin J, Lekovic V, Vukadinovic M, Ristic M, Putnik S, Kenney EB (2007):

Correlation between atherosclerosis and periodontal putative pathogenic bacterial in-fections in coronary and internal mammary arteries.

J Periodontol $\underline{78}, 677-82$

Pussinen PJ, Jousilahti P, Alfthan G, Palosuo T, Asikainen S, Salomaa V (2003): Antibodies to periodontal pathogens are associated with coronary heart disease. Arterioscler Thromb Vasc Biol 23(7), 1250-1254

Raetz CR (1990):

Biochemistry of endotoxins.

Annu Rev Biochem 모, 129-170

Rateitschak KH, Rateitschak EM, Wolf HF:

Parodontologie. 3. Auflage; Georg-Thieme-Verlag, Stuttgart 2012

Rauchhaus M, Coats AJ, Anker SD (2000):

The endotoxin-lipoprotein hypothesis.

Lancet 356(9233), 930-933

Rauchhaus M:

Pathophysiologie der Herzinsuffizienz - traditionelle Paradigmen und innovative Konzepte. Med. Habil.-Schr., Berlin 2008

Rickenbacher P (2001):

Herzinsuffizienz: Epidemiologie, Pathophysiologie.

Swiss Medical Forum 1(2), 4-9

Rise E, Smith JF, Bell J (1969):

Reduction of bacteremia after oral manipulations.

Arch Otolaryngol $\underline{90}(2), 198-201$ 
Rosenstein ED, Greenwald RA, Kushner LJ, Weissmann G (2004):

Hypothesis: the humoral immune response to oral bacteria provides a stimulus for the development of rheumatoid arthritis.

Inflammation $\underline{28}(6)$ 311-318

Roth GA, Aumayr K, Giacona MB, Papapanou PN, Schmidt AM, Lalla E (2009):

Porphyromonas gingivalis infection and prothrombotic effects in human aortic smooth muscle cells.

Thromb Res 123(5), 780-784

Sbordone L, Bortolaia C (2003):

Oral microbial biofilms and plaque-related diseases: microbial communities and their role in the shift from oral health to disease

Clin Oral Investig $\underline{7}(4), 181-188$

Scannapieco FA (1998):

Position paper of The American Academy of Periodontology: periodontal disease as a potential risk factor for systemic diseases.

J Periodontol $\underline{69}(7), 841-850$

Schenkein H (1999):

The pathogenesis of periodontal diseases.

J Periodontol $\underline{70}(4)$, 457-470

Schmitto JD, Ortmann P, Vorkamp T, Heidrich F, Kolat P, Popov AF, Doerge H, Grossmann M, Seipelt R, Ramadori G, Schöndube AF (2008):

Histological changes in a model of chronic heart failure induced by multiple sequential coronary microembolization in sheep.

J Cardiovasc Surg (Torino) 49 (4), 533-537

Sconyers JR, Crawford JJ, Moriarty JD (1973):

Relationship of bacteremia to toothbrushing in patients with periodontitis.

J Am Dent Assoc 87(3), 616 - 622

Seixas-Cambão M, Leite-Moreira AF (2009):

Pathophysiology of chronic heart failure.

Rev Port Cardiol 28 (4), 439-471

Senni M, Redfield MM (2001):

Heart failure with preserved systolic function A different natural history?

J Am Coll Cardiol 38(5), 1277-1282

Seta Y, Shan K, Bozkurt B, Oral H, Mann DL (1996):

Basic mechanisms in heart failure: the cytokine hypothesis.

J Card Fail 2(3), 243-249

Seymour GJ, Ford PJ, Cullinan MP, Leishman S, Yamazaki K (2007):

Relationship between periodontal infections and systemic disease.

Clin Microbiol Infect 13(4), 3-10

Sharma R, von Haehling S, Rauchhaus M, Bolger AP, Genth-Zotz S, Doehner W, Oliver B, Poole-Wilson PA, Volk HD, Coats AJ, Adcock IM, Anker SD (2005a):

Whole blood endotoxin responsiveness in patients with chronic heart failure: the importance of serum lipoproteins.

Eur J Heart Fail $\underline{7}(4)$, 479-84 
Sharma R, Bolger AP, Rauchhaus M, von Haehling S, Doehner W, Adcock IM, Barnes PJ, Poole-Wilson PA, Volk H, Coats AJS (2005b):

Cellular endotoxin desensitization in patients with severe chronic heart failure.

Eur J Heart Fail $\underline{7}(4)$, 865-868

Silbernagl S, Despopoulos A:

Taschenatlas der Physiologie. 6., korrigierte Auflage; Thieme, Stuttgart 2003

Silver JG, Martin AW, McBride BC (1977):

Experimental transient bacteraemias in human subjects with varying degrees of plaque accumulation and gingival inflammation.

J Clin Periodontol 4(2), 92-99

Slavkin HC (1999):

Does the mouth put the heart at risk?

J Am Dent Assoc 130(1), 109-113

Slavkin HC, Baum BJ (2000):

Relationship of dental and oral pathology to systemic illness.

JAMA 284(10), 1215-1217

Socransky SS, Haffajee AD (1992):

The bacterial etiology of destructive periodontal disease: current concepts.

J Periodontol 63(4), 322-331

Socransky SS, Haffajee AD, Cugini MA, Smith C, Kent Jr RL (1998):

Microbial complexes in subgingival plaque.

J Clin Periodontol 25(2), 134-144

Socransky SS, Haffajee AD, Smith C, Duff GW (2000):

Microbiological parameters associated with IL-1 gene polymorphisms in periodontitis patients.

J Clin Periodontol 27(11), 810-818

Southerland JH, Taylor GW, Moss K, Beck JD, Offenbacher S (2006):

Commonality in chronic inflammatory diseases: periodontitis, diabetes and coronary artery disease.

Periodontol 2000 40, 130-143

Spahr A, Klein E, Khuseyinova N, Boeckh C, Muche R, Kunze M, Rothenbacher D, Pezeshki G, Hoffmeister A, Koenig W (2006):

Periodontal infections and coronary heart disease: Role of periodontal bacteria and importance of total pathogen burden in the coronary event and periodontal disease (CORODONT) study.

Arch Intern Med 166(5), 554-559

Stashenko P, Van Dyke T, Tully P, Kent R, Sonis S, Tanner AC (2011):

Inflammation and genetic risk indicators for early periodontitis in adults.

J Periodontol 82(4), 588-596

Statistisches Bundesamt (Destatis):

Todesursachen in Deutschland 2010. Fachserie 12, Reihe 4 - Todesursachenstatistik 2010, Wiesbaden 2011 
Staudt A, Landsberger M, Staudt Y, Felix SB (2002):

Die Rolle der Zytokine bei der Herzinsuffizienz.

Herz 27, 691-698

Swedberg K, Cleland J, Dargie H, Drexler H, Follath F, Komajda M, Tavazzi L, Smiseth OA, Gavazzi A, Haverich A, Hoes A, Jaarsma T, Korewicki J, Lévy S, Linde C, Lopez-Sendon JL, Nieminen MS, Piérard L, Remme WJ; Task Force for the Diagnosis and Treatment of Chronic Heart Failure of the European Society of Cardiology (2005):

Guidelines for the diagnosis and treatment of chronic heart failure: executive summary (update 2005): The Task Force for the Diagnosis and Treatment of Chronic Heart Failure of the European Society of Cardiology.

Eur Heart J 26 (11), 1115-1140

Tabia PV, Bassada NF, Marbury GE (1981):

Effectivness of supragingival plaque cotrol on the development of subgingival plaque and gingival inflammation in patients with moderate pocket depth.

J Periodontol $\underline{52}(2), 88-93$

Tang K, Lin M, Wu Y, Yan F (2011):

Alterations of serum lipid and inflammatory cytokine profiles in patients with coronary heart disease and chronic periodontitis: a pilot study.

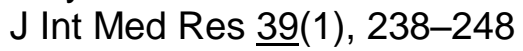

Taylor BA, Tofler GH, Carey HM, Morel-Kopp MC, Philcox S, Carter TR, Elliott MJ, Kull AD, Ward C, Schenck K (2006):

Full-mouth tooth extraction lowers systemic inflammatory and thrombotic markers of cardiovascular risk.

J Dent Res $\underline{85}(1), 74-78$

Tonetti MS, D'Aiuto F, Nibali L, Donald A, Storry C, Parkar M, Suvan J, Hingorani AD, Vallance P, Deanfield J (2007):

Treatment of periodontitis and endothelial function.

N Engl J Med 356(9), 911-920

Tonetti MS (2009):

Periodontitis and risk for atherosclerosis: an update on intervention trials.

J Clin Periodontol 36 (10), 15-19

Tsioufis C, Kasiakogias A, Thomopoulos C, Stefanadis C (2011):

Periodontitis and blood pressure: the concept of dental hypertension.

Atherosclerosis $\underline{219}(1), 1-9$

Valle R, Aspromonte N, Milani L, Peacock FW, Maisel AS, Santini M, Ronco C (2011):

Optimizing fluid management in patients with acute decompensated heart failure (ADHF): the emerging role of combined measurement of body hydration status and brain natriuretic peptide (BNP) levels.

Heart Fail Rev 16(6), 519-29

Walker SJ, Van Dyke TE, Rich S, Kornman KS, di Giovine FS, Hart TC (2000):

Genetic polymorphisms of the IL-1alpha and IL-1beta genes in African-American

LJP patients and an African-American control population.

J Periodontol 71(5), 723-728 
Wang PL, Ohura K (2002):

Porphyromonas gingivalis lipopolysaccharide signaling in gingival fibroblasts-CD14 and Toll-like receptors.

Crit Rev Oral Biol Med 13(2), 132-42

Weil J, Schunkert H (2006):

Pathophysiologie der chronischen Herzinsuffizienz.

Clin Res Cardiol 95(4), 1-17

Wilson W, Taubert KA, Gewitz M, Lockhart PB, Baddour LM, Levison M, Bolger A, Cabell CH, Takahashi M, Baltimore RS, Newburger JW, Strom BL, Tani LY, Gerber M, Bonow RO, Pallasch T, Shulman ST, Rowley AH, Burns JC, Ferrieri P, Gardner T, Goff D, Durack DT (2007):

Prevention of Infective Endocarditis. Guidelines From the American Heart Association. A Guideline From the American Heart Association Rheumatic Fever, Endocarditis, and Kawasaki Disease Committee, Council on Cardiovascular Disease in the Young, and the Council on Clinical Cardiology, Council on Cardiovascular Surgery and Anesthesia, and the Quality of Care and Outcomes Research Interdisciplinary Working Group.

Circulation 116(15), 1736-1754

Wohlfeil M, Scharf S, Siegelin Y, Schacher B, Oremek GM, Sauer-Eppel H, Schubert R, Eickholz P (2012):

Increased systemic elastase and C-reactive protein in aggressive periodontitis.

Clin Oral Invest 16(4), 1199-1207

Wright SD, Ramos RA, Tobias PS, Ulevitch RJ, Mathison JC (1990):

CD14, a receptor for complexes of lipopolysaccharide (LPS) and LPS binding protein.

Science $\underline{249}(4975), 1431-1433$

Wu HC, Yeh YL, Kuo WW, Huang SK, Kuo WH, Hsieh DJ, Wu CL, Tsai CH, Lee SD, Huang CY (2008):

P38 mitogen-activated protein kinase pathways are involved in the hypertrophy and apoptosis of cardiomyocytes induced by Porphyromonas gingivalis conditioned medium.

Cell Biochem Funct 26 (2), 246-255

Ximénez-Fyvie LA, Haffajee AD, Socransky SS (2000):

Microbial composition of supra- and subgingival plaque in subjects with adult periodontitis.

J Clin Periodontol 27 (10), 722-732

Yamazaki K, Honda T, Domon H, Okui T, Kajita K, Amanuma R, Kudoh C, Takashiba S, Kokeguchi S, Nishimura F, Kodama M, Aizawa Y, Oda H (2007):

Relationship of periodontal infection to serum antibody levels to periodontopathic bacteria and inflammatory markers in periodontitis patients with coronary heart disease.

Clin Exp Immunol 149(3), 445-452

Yoshimura A, Kaneko T, Kato Y, Golenbock DT, Hara Y (2002):

Lipopolysaccharides from periodontopathic bacteria porphyromonas gingivalis and capnocytophaga ochracea are antagonists for human toll-like receptor 4 .

Infect Immun 70(1), 218-225 
Zhou L., Cai, J., Liu, G., Wei, Y., \& Tang, H. (2012):

Associations between interleukin-1 gene polymorphisms and coronary heart disease risk: A meta-analysis.

PLoS One $\underline{7}(9)$, e45641

Zhou Q, Desta T, Fenton M, Graves DT, Amar S (2005):

Cytokine profiling of macrophages exposed to Porphyromonas gingivalis, its lipopolysaccharide, or its FimA protein.

Infect Immun $\underline{73}(2)$, 935-943

Zhou Q, Ye ZJ, Su Y, Zhang JC, Shi HZ (2010):

Diagnostic value of $\mathrm{N}$-terminal pro-brain natriuretic peptide for pleural effusion due to heart failure: a meta-analysis.

Heart $\underline{\text { 96}}$ (15), 1207-1211 


\section{Danksagung}

Zunächst möchte ich mich bei Herrn Prof. Dr. med. dent. Rainer F. Mausberg für die Überlassung des Dissertationsthemas und die konstruktive Kritik und Beratung an meiner Arbeit bedanken.

Ein weiteres Dankeschön geht an Herrn Priv.-Doz. Dr. med. dent. Dirk Ziebolz für die engagierte Betreuung und Unterstützung in allen Phasen dieser Dissertation.

Vielen Dank auch an Frau Monika Hoch und Frau Regina Waldmann-Beushausen für die überaus freundliche und kompetente Betreuung während der experimentellen Untersuchungen.

Des Weiteren danke ich Herrn Prof. Dr. med. Dipl. Phys. Friedrich A. Schöndube und den Mitarbeitern der Abteilung Thorax-, Herz- und Gefäßchirurgie der Universitätsmedizin Göttingen für die Ermöglichung der klinischen Untersuchungen und die Überlassung der Herzgewebeproben.

Schließlich möchte ich mich noch bei den Patienten bedanken, die sich bereit erklärt haben, an dieser Studie teilzunehmen. 